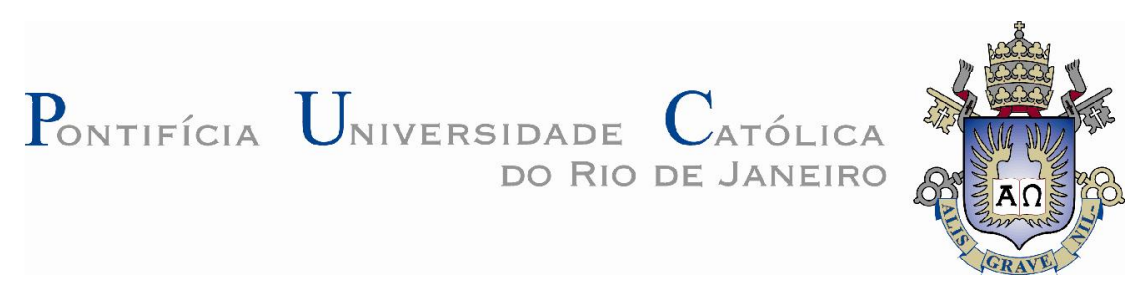

Paulo Henrique de Lima Silva

Caracterização de emulsões de água em óleo visando ao estudo da formação de hidratos

\begin{abstract}
Dissertação de Mestrado
Dissertação apresentada como requisito parcial para obtenção do grau de Mestre pelo Programa de PósGraduação em Engenharia Mecânica do Departamento de Engenharia Mecânica da PUC-Rio.
\end{abstract}

Orientadora: Profa. Mônica Feijó Naccache Co-orientador: Prof.Paulo Roberto de Souza Mendes

Rio de Janeiro

Setembro de 2014 


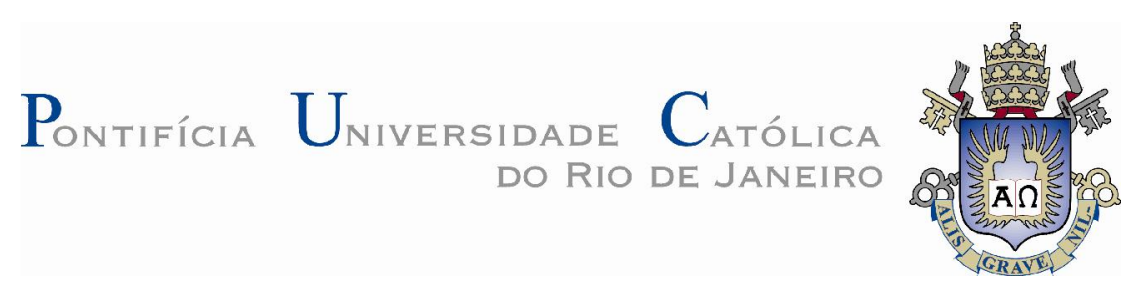

Paulo Henrique de Lima Silva

\section{Caracterização de emulsões de água em óleo visando ao estudo da formação de hidratos}

Dissertação apresentada como requisito parcial para obtenção do grau de Mestre pelo Programa de Pós-graduação em Engenharia Mecânica do Departamento de Engenharia Mecânica do Centro Técnico Científico da PUC-Rio. Aprovada pela Comissão Examinadora abaixo assinada.

Profa. Mônica Feijó Naccache Orientadora

Departamento de Engenharia Mecânica - PUC - Rio

Prof. Paulo Roberto de Souza Mendes Co-Orientador Departamento de Engenharia Mecânica - PUC - Rio

Prof. Márcio da Silveira Carvalho Departamento de Engenharia Mecânica - PUC - Rio

Profa. Aurora Pérez Gramatges Departamento de Química - PUC - Rio

Prof. José Eugenio Leal Coordenador Setorial do Centro

Técnico Científico - PUC-Rio

Rio de Janeiro, 17 de setembro de 2014. 
Todos os direitos reservados. É proibida a reprodução total ou parcial do trabalho sem autorização da universidade, do autor e do orientador.

\section{Paulo Henrique de Lima Silva}

Graduou-se em Engenharia de Produção na UCAM (Universidade Cândido Mendes), em 2012. Atualmente tem continuado com a linha de pesquisa na área de Engenharia de Petróleo, com o estudo de reologia de hidratos.

\section{Ficha Catalográfica}

Silva, Paulo Henrique de Lima

Caracterização de emulsões de água em óleo visando ao estudo da formação de hidratos / Paulo Henrique de Lima Silva; orientador: Mônica Feijó Naccache; co-orientador: Paulo Roberto de Souza Mendes. -2014.

94 f. : il. (color.) ; $29,7 \mathrm{~cm}$

Dissertação (mestrado)-Pontifícia Universidade

Católica do Rio de Janeiro, Departamento de Engenharia Mecânica, 2014.

Inclui bibliografia

1. Engenharia mecânica - Teses. 2. Emulsões.

3. Reologia. 4. Hidratos. 5. Reometria. I. Naccache, Mônica Feijó. II. Mendes, Paulo Roberto de Souza. III. Pontifícia Universidade Católica do Rio de Janeiro. Departamento de Engenharia Mecânica. IV. Título. 


\section{Agradecimentos}

Agradeço inicialmente a Deus e a minha família, pais, esposa, filhos e irmãos por mais essa conquista.

Faço um agradecimento em particular ao órgão de fomento à pesquisa CAPES e a PUC - Rio por ter me dado suporte financeiro, sem o qual este trabalho simplesmente não teria sido possível.

A todos os Professores e aos colegas Luiz, Alberto, Maurício, Hugo e Dario que me incentivaram em todos os momentos, não me deixando desistir e nem desanimar.

Agradeço principalmente aos Professores Mônica e Paulo pela paciência e dedicação, pela ajuda e pelo ânimo durante todo o processo da montagem deste trabalho.

Também gostaria de agradecer aos membros do Grupo de Reologia da PUC-Rio pela assistência prestada, em muitos aspectos, especialmente à Priscila, Alexandra, Caroline, Aline, Patrícia, Carina, Bruno e Alexandre, por me ensinar e apoiar quando eu precisava. A professora Aurora do Departamento de Química e ao professor Marcos do Departamento de Engenharia de Materiais, ambos da PUC-Rio. Muito obrigado a todos. 


\section{Resumo}

Silva, Paulo Henrique de Lima; Naccache, Mônica Feijó. Caracterização de emulsões de água em óleo visando ao estudo da formação de hidratos. Rio de Janeiro, 2014. 94p. Dissertação de Mestrado Departamento de Engenharia Mecânica, Pontifícia Universidade Católica do Rio de Janeiro.

Os hidratos de gás natural são sólidos cristalinos, semelhantes ao gelo, formados pela associação de moléculas de água e de gás numa determinada estrutura organizada. Sua ocorrência é uma preocupação inegável para a Indústria de Petróleo e Gás, dado o risco potencial de garantia de escoamento, podendo ocasionar paradas não programadas em operações como a perfuração e produção. Portanto, grandes investimentos são feitos a fim de prevenir a formação de hidratos. No entanto, os cenários cada vez mais desafiadores de produção de petróleo estão incentivando a busca de metodologias de avaliação de risco, procurando identificar as condições para a formação de hidratos, mas com pouca possibilidade de entupimento. Neste contexto, o entendimento de reologia de hidratos é um elemento chave, pois permite detectar a formação do hidrato a partir de variações das propriedades reológicas. Entretanto, uma dificuldade desta abordagem ocorre devido à condição necessária para a formação de hidrato, a combinação de alta pressão e baixa temperatura. Este trabalho se insere neste contexto: para avaliar o processo de formação de hidrato em condições mais favoráveis utiliza-se em geral um fluido modelo que forma hidratos à pressão atmosférica. Este trabalho visa analisar os efeitos dos cortes de água e de tensoativos na viscosidade, nos módulos de armazenagem e dissipação de um fluido modelo, uma emulsão de água-em-óleo. A formação de hidrato ocorre com a adição de ciclopentano a este modelo de emulsão.

\section{Palavras chaves}

Emulsões; reologia; hidratos; reometria. 


\section{Abstract}

Silva, Paulo Henrique de Lima; Naccache, Mônica Feijó (Advisor). Characterization of water-in-oil emulsions for the study of hydrates formation. Rio de Janeiro, 2014. 94p. MSc. Dissertation - Departamento de Engenharia Mecânica, Pontifícia Universidade Católica do Rio de Janeiro.

Natural gas hydrates are solid crystalline, similar to the ice, formed by the association of water molecules and gas of a given organized structure. Its occurrence is an undeniable concern for Oil and Gas, given the potential risk of flow assurance and may cause unscheduled downtime in operations, such as drilling and production. Therefore, large investments are made in order to prevent the formation of hydrates. However, the increasingly challenging scenarios of oil production are encouraging the pursuit of new methodologies for risk assessment, seeking to identify the conditions hydrates will form, but with little chance of clogging. In this context, the understanding of rheology of hydrate is a key element, it allows detecting the formation of hydrate as of changes in rheological properties. However, a difficulty of this approach occurs due to need for hydrate formation conditions, the combination of high pressure and low temperature. This work fits in this context: to evaluate the process of hydrate formation on conditions more favorable is used usually a fluid model that form hydrates at atmospheric pressure. This work aims to analyze the effects of the water cuts and surfactants on viscosity, in storage and dissipation modules of model fluid water emulsion in oil. The hydrate formation occurs adding on this model fluid cyclopentane.

\section{Keywords}

Emulsions; rheology; hydrates; rheometry. 


\section{Sumário}

1. Introdução 14

1.1 Motivação 14

1.2 Objetivo 16

$\begin{array}{ll}1.3 \text { Justificativa } & 16\end{array}$

$\begin{array}{ll}1.4 \text { Estrutura da Dissertação } & 17\end{array}$

2. Estado da Arte 18

2.1 Principais Conceitos 21

$\begin{array}{ll}2.1 .1 \text { Hidratos } & 21\end{array}$

2.1.2 Emulsões 21

2.1.3 Fluido Não - Newtoniano 24

2.1.4 Reologia 26

2.1.5 Tensão Interfacial / Superficial 27

2.1.6 Balanço Hidrofílico - Lipofílico (HLB) 29

3. Materiais e Métodos 31

3.1 Materiais 31

3.1.1 Fase Oleosa 31

3.1.1.1 Shell Morlina S2 BL $10 \quad 31$

3.1.1.2 Shell Morlina S2 B 150

3.1.1.3 Óleo Mineral (Vaselina branca) 33

3.1.2 Fase Aquosa 33

3.1.3 Tensoativos 33

3.2 Equipamentos e Acessórios 34

3.3 Métodos 35

3.3.1 Preparo das Emulsões 35

3.3.2 Caraterização Reológica das Emulsões 37

3.3.3 Medidas da Tensão Superficial/Interfacial 38

$\begin{array}{ll}\text { 3.3.4 Correção de placas paralelas } & 39\end{array}$ 
4. Resultados 42

4.1 Avaliação da Tensão Interfacial 42

4.2 Resultados dos Testes Reológicos 46

4.2.1 Resultados - Shell Morlina S2 BL 10 com 5\% de tensoativos 47

4.2.2 Resultados - Shell Morlina S2 BL 10 com 1\% de tensoativos 57

4.2.3 Resultados - Shell Morlina S2 B 150 com 5\% de tensoativos 62

4.2.4 Resultados - Shell Morlina S2 B 150 com 1\% de tensoativos 68

4.2.5 Resultados - Óleo Mineral com 5\% de tensoativos 73

4.2.6 Resultados - Óleo Mineral com 1\% de tensoativos 78

4.3 Discussão 83

4.3.1 Efeito da concentração de tensoativos 83

5. Conclusões e sugestões para trabalhos futuros 87

5.1 Conclusões 87

$\begin{array}{ll}5.2 \text { Sugestões para trabalhos futuros } & 90\end{array}$

6. Referências Bibliográficas 91 


\section{Lista de Tabelas}

Tabela 1: Faixa de valores de HLB. 29

Tabela 2: Propriedades do Óleo Mineral a $25^{\circ} \mathrm{C}$.

Tabela 3: Percentuais em massa da composição das emulsões com $1 \%$ de tensoativos. 36

Tabela 4: Percentuais em massa da composição das emulsões com $5 \%$ de tensoativos. 36

Tabela 5: Massa específica medida para as fases oleosas. 43

Tabela 6: Valores medidos de tensão para cada uma das fases oleosas. 44

Tabela 7: Valores calculados de tensão interfacial. 45

Tabela 8: Índices das emulsões com Morlina S2 BL10 e 5\% de tensoativos. $\quad 50$

Tabela 9: Índices das emulsões com Morlina S2 BL10 a $0^{\circ} \mathrm{C}$ e $5 \%$ de tensoativos. $\quad 55$

Tabela 10: Índices das emulsões com Morlina S2 BL10 e 1\% de tensoativos. 59

Tabela 11: Índices das emulsões com Morlina S2 B150 e 5\% de tensoativos.

Tabela 12: Índices das emulsões com Morlina S2 B150 e 1\% de tensoativos.

Tabela 13: Índices das emulsões com Óleo Mineral e 5\% de tensoativos.

Tabela 14: Índices das emulsões com Óleo Mineral e 1\% de tensoativos.

Tabela 15: Análise qualitativa entre os óleos. 


\section{Lista de Figuras}

Figura 1: Produção de petróleo por localização - Terra e Mar, 2002 até 2013.

Figura 2: Número de publicações sobre hidratos.

Figura 3: Tipos de emulsões segundo a fase contínua. .

Figura 4: Classificação do comportamento reológico de diferentes tipos de fluidos.

Figura 5: Classificação esquemática dos comportamentos reológicos.

Figura 6: Distribuição de forças nas moléculas de água.

Figura 7: Características do Shell Morlina S2 BL10.

Figura 8: Características do Shell Morlina S2 B 150.

Figura 9: Estrutura molecular do Monooleato de Sorbitano - Span $80^{\circledR}$.

Figura 10: Estrutura molecular do Dioctil sulfosuccinato de sódio (AOT).

Figura 11: Princípio de funcionamento do tensiômetro.

Figura 12: Geometria de placas paralelas.

Figura 13: Gráfico da correção aplicada à placa paralela.

Figura 14: Picnometro. Fonte: www.pro-analise.com.br

Figura 15: Tensão Interfacial entre as fases oleosas e a água.

Figura 16: Viscosidade dos óleos a $20^{\circ} \mathrm{C}$.

Figura 17: Viscosidade vs. tempo, taxa de deformação constante de 2 1/s para o corte de água de $20 \%$ e 0,01 1/s para os cortes de água, $30 \%$ e $40 \%$, Morlina S2 BL 10 a $20^{\circ} \mathrm{C}$ e $5 \%$ de tensoativos.

Figura 18: Curvas de escoamento: (a) viscosidade vs. taxa de deformação e (b) tensão de cisalhamento vs. taxa de deformação, Morlina S2 BL 10 a $20{ }^{\circ} \mathrm{C}$ e $5 \%$ de tensoativos.

Figura 19: Prova de gota com Morlina S2 BL10 e 5\% de tensoativos, (a) $20 \%$, (b) $30 \%$ e (c) $40 \%$ de corte de água.

Figura 20: Mircoscopia das emulsões com Morlina S2 BL10 e 5\% de tensoativos: (a) $20 \%$, (b) $30 \%$ e (c) $40 \%$ de corte de água. 
Figura 21: Varredura de tensão Morlina S2 BL10 a $20{ }^{\circ} \mathrm{C}$ e $5 \%$ de tensoativos.

Figura 22: Varredura no tempo Morlina S2 BL10 a $20{ }^{\circ} \mathrm{C}$ e $5 \%$ de tensoativos.

Figura 23: Viscosidade vs. tempo, taxa de deformação constante $0,011 / \mathrm{s}$, Morlina S2 BL 10 a $0^{\circ} \mathrm{C}$ e $5 \%$ de tensoativos.

Figura 24: Curvas de escoamento: (a) viscosidade vs. taxa de deformação e (b) tensão de cisalhamento vs. taxa de deformação, Morlina S2 BL10 a $0^{\circ} \mathrm{C}$ e $5 \%$ de tensoativos.

Figura 25: Varredura de tensão Morlina S2 BL10 a $0{ }^{\circ} \mathrm{C}$ e $5 \%$ de tensoativos . 55

Figura 26: Varredura no tempo Morlina S2 BL10 a $0{ }^{\circ} \mathrm{C}$ e $5 \%$ de tensoativos .

Figura 27: Viscosidade vs. tempo, taxa de deformação constante $0,011 / \mathrm{s}$, Morlina S2 BL 10 a $20^{\circ} \mathrm{C}$ e $1 \%$ de tensoativos.

Figura 28: Curvas de escoamento: (a) viscosidade vs. taxa de deformação e (b) tensão de cisalhamento vs. taxa de deformação, Morlina S2 BL 10 a $20^{\circ} \mathrm{C}$ e $1 \%$ de tensoativos.

Figura 29: Prova de gota com Morlina S2 BL10 e 1\% de tensoativos, (a) $20 \%$, (b) $30 \%$ e (c) $40 \%$ de corte de água.

Figura 30: Mircoscopia das emulsões com Morlina S2 BL10 e 1\% de tensoativos: (a) 20\%, (b) 30\% e (c) 40\% de corte de água.

Figura 31: Varredura de tensão Morlina S2 BL10 a $20{ }^{\circ} \mathrm{C}$ e $1 \%$ de tensoativos.

Figura 32: Varredura no tempo Morlina S2 BL10 a $20{ }^{\circ} \mathrm{C}$ e $1 \%$ de tensoativos.

Figura 33: Viscosidade vs. tempo, taxa de deformação constante $0,011 / \mathrm{s}$, Morlina S2 B 150 a $20^{\circ} \mathrm{C}$ e $5 \%$ de tensoativos.

Figura 34: Curvas de escoamento: (a) viscosidade vs. taxa de deformação e (b) tensão de cisalhamento vs. taxa de deformação, Morlina S2 B150 a $20^{\circ} \mathrm{C}$ e $5 \%$ de tensoativos.

Figura 35: Prova de gota com Morlina S2 B150 e 5\% de tensoativos, (a) $20 \%$, (b) $30 \%$ e (c) $40 \%$ de corte de água. 
Figura 36: Mircoscopia das emulsões com Morlina S2 B150 e 5\% de tensoativos: (a) 20\%, (b) 30\% e (c) 40\% de corte de água.

Figura 37: Varredura de tensão Morlina S2 B150 a $20{ }^{\circ} \mathrm{C}$ e $5 \%$ de tensoativos.

Figura 38: Varredura no tempo Morlina S2 B150 a $20{ }^{\circ} \mathrm{C}$ e $5 \%$ de tensoativos.

Figura 39: Viscosidade vs. tempo, taxa de deformação constante $0,011 / \mathrm{s}$, Morlina S2 B 150 a $20^{\circ} \mathrm{C}$ e $1 \%$ de tensoativos.

Figura 40: Curvas de escoamento: (a) viscosidade vs. taxa de deformação e (b) tensão de cisalhamento vs. taxa de deformação, Morlina S2 B150 a $20^{\circ} \mathrm{C}$ e $1 \%$ de tensoativos.

Figura 41: Prova de gota com Morlina S2 B150 e 1\% de tensoativos, (a) $20 \%$, (b) $30 \%$ e (c) $40 \%$ de corte de água.

Figura 42: Mircoscopia das emulsões com Morlina S2 B150 e 1\% de tensoativos: (a) 20\%, (b) 30\% e (c) 40\% de corte de água.

Figura 43: Varredura de tensão Morlina S2 B150 a $20^{\circ} \mathrm{C}$ e $1 \%$ de tensoativos.

Figura 44: Varredura no tempo Morlina S2 B150 a $20^{\circ} \mathrm{C}$ e $1 \%$ de tensoativos.

Figura 45: Viscosidade vs. tempo, taxa de deformação constante $0,011 / \mathrm{s}$, Óleo Mineral a $20^{\circ} \mathrm{C}$ e $5 \%$ de tensoativos.

Figura 46: Curvas de escoamento: (a) viscosidade vs. taxa de deformação e (b) tensão de cisalhamento vs. taxa de deformação, Óleo Mineral a $20^{\circ} \mathrm{C}$ e $5 \%$ de tensoativos.

Figura 47: Prova de gota com Óleo Mineral e 5\% de tensoativos, (a) $20 \%$, (b) $30 \%$ e (c) $40 \%$ de corte de água.

Figura 48: Mircoscopia das emulsões com Óleo Mineral e 5\% de tensoativos: (a) 20\%, (b) 30\% e (c) 40\% de corte de água.

Figura 49: Varredura de tensão Óleo Mineral a $20^{\circ} \mathrm{C}$ e $5 \%$ de tensoativos.

Figura 50: Varredura no tempo Óleo Mineral a $20^{\circ} \mathrm{C}$ e $5 \%$ de tensoativos.

Figura 51: Viscosidade vs. tempo, taxa de deformação constante $0,011 / \mathrm{s}$, Óleo Mineral a $20^{\circ} \mathrm{C}$ e $1 \%$ de tensoativos. 
Figura 52: Curvas de escoamento: (a) viscosidade vs. taxa de deformação e (b) tensão de cisalhamento vs. taxa de deformação, Óleo Mineral a $20^{\circ} \mathrm{C}$ e $1 \%$ de tensoativos.

Figura 53: Prova de gota com Óleo Mineral e 5\% de tensoativos, (a) $20 \%$, (b) $30 \%$ e (c) $40 \%$ de corte de água.

Figura 54: Mircoscopia das emulsões com Óleo Mineral e 1\% de tensoativos: (a) 20\%, (b) 30\% e (c) 40\% de corte de água.

Figura 55: Varredura de tensão Óleo Mineral a $20{ }^{\circ} \mathrm{C}$.

Figura 56: Varredura no tempo Óleo Mineral a $20{ }^{\circ} \mathrm{C}$.

Figura 57: Morlina S2 BL 10 com 5\% e 1\% de tensoativos.

Figura 58: Morlina S2 B 150 com 5\% e 1\% de tensoativos.

Figura 59: Óleo Mineral com 5\% e 1\% de tensoativos. 
1.

\section{Introdução}

\section{1.}

Motivação

O Brasil é um grande produtor de petróleo, tendo a maior parte de sua produção, cerca de 92\% (noventa e dois por cento), proveniente do mar (ANP 2014). Diante desta fronteira, grandes desafios são lançados a cada dia, inúmeros problemas surgem durante a explotação desse petróleo, principalmente em lâminas d'água profundas e ultras profundas (define-se lâminas d'água rasa, profunda e ultra profunda aquelas situadas, respectivamente, até $300 \mathrm{~m}$, entre $300 \mathrm{~m}$ e $1000 \mathrm{~m}$, e acima de $1000 \mathrm{~m}$ ). Esta produção é escoada através de longas tubulações denominadas de linhas de produção.

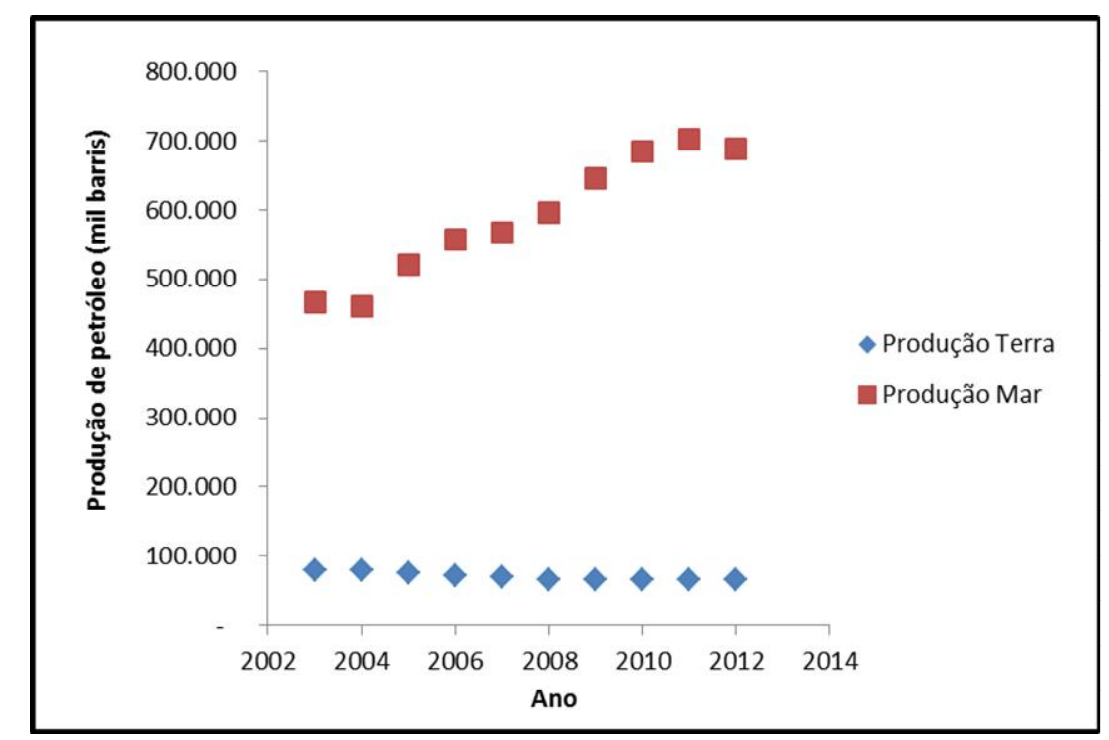

Figura 1: Produção de petróleo por localização - Terra e Mar, 2002 até 2013

(ANP, 2014).

Um problema comum que pode ocorrer, devido às condições particulares, nestas linhas de produção é o surgimento de hidratos, devido às condições de 
baixa temperatura, por volta de $4^{\circ} \mathrm{C}$ (temperatura média da água no leito marinho), e altas pressões. Hidratos de gás natural são sólidos cristalinos compostos de água e gás. As moléculas de gás ficam aprisionadas pelas moléculas de água. Moléculas de gás natural típico incluem metano, etano, propano e dióxido de carbono (Sloan e Koh, 2008).

A formação de hidratos pode causar entupimento das linhas de produção, podem provocar paradas não programadas em operações como a perfuração e a completação de poços (Santos, 2006). Além do entupimento das linhas de produção, a formação de hidratos pode causar danos em equipamentos e comprometer a segurança da instalação. Do mesmo modo, em muitos casos, é preciso interromper totalmente as operações de perfuração ou de produção para remoção desses hidratos, constituindo grandes prejuízos financeiros (Baptista, 2007).

A forma mais comum de se prevenir a formação de hidratos em águas profundas é a utilização de inibidores, dentre os quais, os sais são os mais empregados. Além disso, quando um poço vai ficar fechado por um longo período de tempo, um tampão de glicol ou glicerol é recomendado para o deslocamento do fluido na região próxima à cabeça do poço, pois também trazem um bom resultado na inibição da formação de hidratos. A escolha do inibidor adequado para cada situação e a quantidade ótima a ser utilizada implica na necessidade de se avaliar previamente em que condições podem ocorrer à formação de hidratos na presença de inibidores (Baptista, 2007).

A utilização de inibidores gera um custo adicional que pode comprometer a viabilidade econômica do projeto. Portanto, o projeto em que e este estudo está inserido irá propor um método para a análise do processo de formação de hidratos, utilizando uma análise reológica para prever a sua formação ou detectar a formação em sua fase inicial (pasta de hidrato). Isto será feito a partir da definição de um fluido modelo que permitirá criar as condições necessárias em laboratório para a formação de hidratos, baixas temperaturas (aproximadamente $0^{\circ} \mathrm{C}$ ) e baixas pressões (1atm.). 


\section{2. \\ Objetivo}

O presente estudo tem como objetivo geral desenvolver um fluido modelo, ou melhor, emulsões de água em óleo capazes de originar hidrato a pressão ambiente. Nos experimentos serão utilizados reômetros rotacionais para a realização dos testes de caracterização reológica das emulsões.

Serão analisadas emulsões com três cortes de água (20\%, 30\% e 40\%), porém a fase contínua, teoricamente, será sempre o óleo. Dois tensoativos serão utilizados em duas concentrações ( $1 \%$ e $5 \%$ em peso da emulsão) para cada tipo de óleo. Todas essas variações terão como objetivo encontrar o fluido modelo nas faixas apropriadas de valores de torque dos reômetros (mínimo de $20 \mu \mathrm{Nm}$ ) para a medição das propriedades reológicas, e que essas emulsões sejam estáveis por um tempo mínimo de 3 dias, tempo necessário para a realização dos testes nos mesmos. Assim pretende-se:

- Verificar a influência dos cortes de água na estabilidade da emulsão, na viscosidade e nos módulos de armazenamento e de dissipação da emulsão;

- Verificar a influência da viscosidade do óleo na estabilidade da emulsão, na viscosidade e nos módulos de armazenamento e de dissipação da emulsão;

- Verificar a influência da quantidade de tensoativos utilizada na estabilidade da emulsão, na viscosidade e nos módulos de armazenamento e de dissipação da emulsão.

\section{3.}

Justificativa

Nas últimas décadas, pesquisas relacionadas ao desenvolvimento tecnológico na área de perfuração e produção em águas profundas e ultra profundas tem sido realizadas sob forte investimento. A formação de hidratos é um tema inserido nesse contexto. Este estudo foi proposto com a intenção de aprofundar o conhecimento sobre esse fenômeno e de desenvolver um processo 
de experimentação que venha a ter aplicação prática para a indústria de petróleo. O estudo da formação de hidratos sugere um projeto multidisciplinar, pois demanda conhecimentos vinculados à Engenharia Mecânica, Química, Física e Reologia, dentre outros. Além desses conhecimentos, conceitos e metodologias de projeto e de pesquisa são de suma importância para se alcançar os objetivos desejados.

Academicamente o desenvolvimento do projeto é interessante, pois engloba disciplinas e áreas da Engenharia que são consideradas complexas, transformando o projeto em um grande desafio científico, podendo o estudo ser estendido a uma tese de doutorado.

\section{4 Estrutura da Dissertação}

Este estudo exporá a seguinte composição: No Capítulo 1, apresenta-se a Introdução, descrevendo os pontos fundamentais como motivação, justificativa, objetivos do estudo. No Capítulo 2, estado da arte, descrevendo os principais conceitos abordados na dissertação, hidratos, emulsões, fluidos não Newtonianos, reologia, tensão superficial / interfacial, equilíbrio hidrofílico lipofílico; no Capítulo 3, serão mostrados os materiais utilizados, equipamentos e aparelhagem auxiliar, ainda será descrita a metodologia de preparo das emulsões e os principais parâmetros envolvidos nessa preparação; no Capítulo 4 , serão apresentados e analisados os resultados obtidos nos testes de tensão superficial / interfacial e reológicos, também será feita uma comparação entre os óleos utilizados nas emulsões; no Capítulo 5, a conclusão do estudo. 


\section{2. \\ Estado da Arte}

De acordo com Sloan e Koh (2008), podem-se dividir historicamente os esforços de investigação sobre os hidratos de gás em três momentos que cobrem os seguintes limites:

- O primeiro momento desde o seu descobrimento em 1810 até o presente, inclui hidratos de gás como uma curiosidade científica em que o gás e a água são transformados em um sólido.

- O segundo momento, a partir de 1934 até o presente, predominantemente ligado às preocupações de hidratos de gás como um empecilho para a indústria do gás natural devido às atividades de natureza humana.

- O terceiro momento teve início na metade da década de 60, quando se constatou que a formação de hidratos pode ocorrer de maneira natural, em particular nas profundezas do oceano e até mesmo em ambientes extraterrestres. Tais estudos não visam evitar a formação de hidratos, mas os aproveitar para diversos fins, tais como: fonte energética, transporte e estocagem de gás, dentre outros.

Em 1810 Sir Humphrey Davy ministrou uma palestra sob o título: "On Some of the Principles to Inflammable Bodies and on the Chemical Relations of These Combinations of Oxymuriatic Gas and Oxygene", que traduzindo para o português temos "Alguns princípios sobre os corpos inflamáveis e sobre as Relações químicas destas combinações de Gás Oxymuriatic - ácido clorídrico e Oxigênio" (Davy, 1811) na Royal Society em Londres, onde hidratos de gás natural foram documentados pela primeira vez. Uma estrutura sólida composta por gás cloro e água poderia ser formada com a uma temperatura acima do ponto de fusão da água. Desde essa data o interesse por esse tema cresceu exponencialmente, conforme a Fig. 2. 


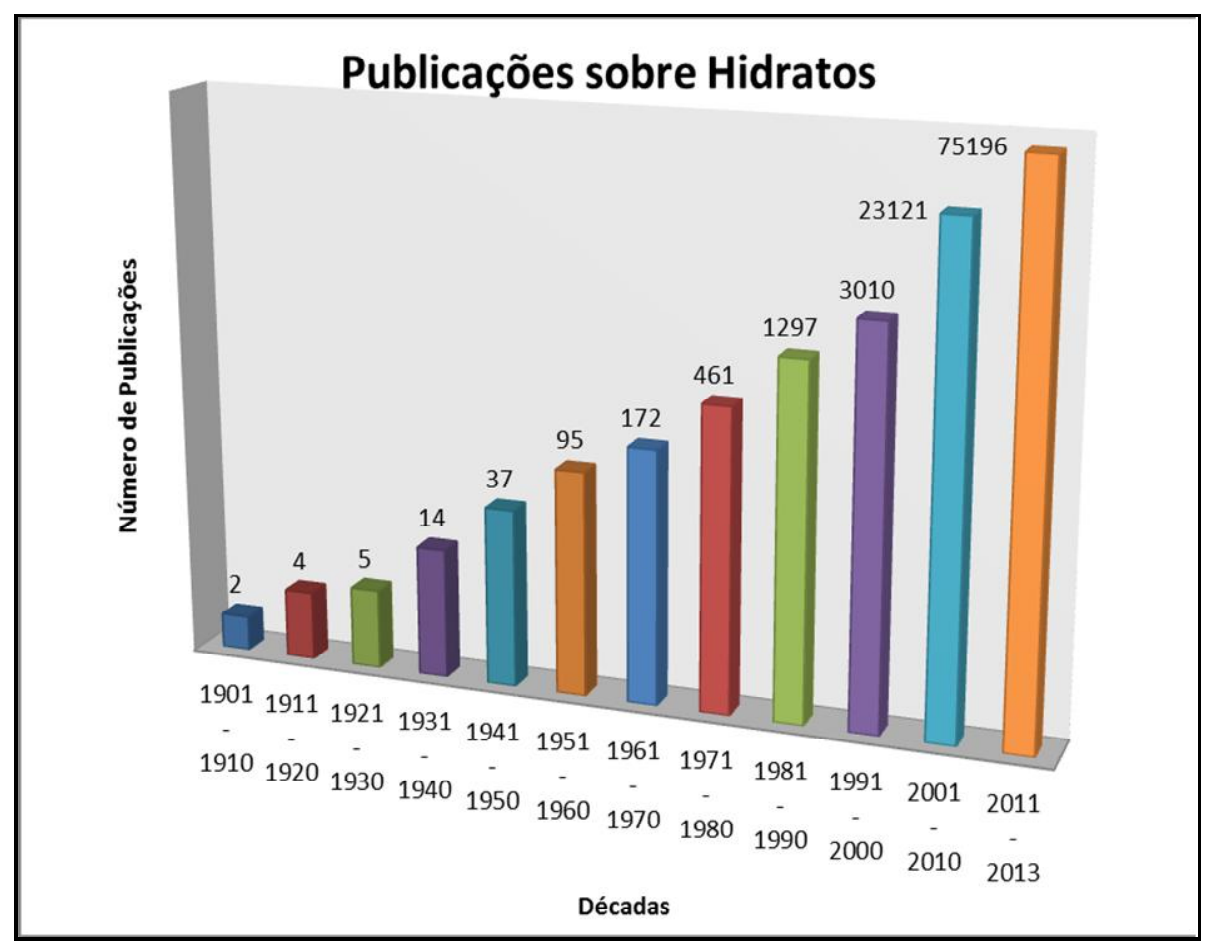

Figura 2: Número de publicações sobre hidratos (adaptado de Sloan e Koh - 2008 e http://www.sciencedirect.com).

Nos anos seguintes a essa descoberta, os pesquisadores que se dedicaram a estudar a formação de hidratos abraçaram dois objetivos: o primeiro seria determinar todos os compostos formadores de hidratos e o segundo seria descrever os compostos quantitativamente por suas composições e propriedades físicas (Baptista, 2007).

Diante dessa nova fronteira, os primeiros cientistas começaram a desenvolver seus trabalhos, porém os mesmos tinham interesse simplesmente acadêmico. Apenas nos anos de 1930, com o desenvolvimento da indústria do gás natural, o primeiro trabalho visando uma aplicação industrial do estudo sobre hidratos foi realizado. Hammershmidt (1934) apresentou um estudo sobre o entupimento de tubulações de gás durante os meses de inverno, onde baixas temperaturas afetavam as condições de escoamento. Hammershmidt demonstrou que esse problema era causado pela formação de hidratos, e não pela formação de gelo, como se desconfiava. Além disso, seu estudo mostrou uma relação entre a temperatura, a pressão e a composição da mistura vapor d'água e gás na formação desses sólidos. 
Diante da possibilidade de se aplicar industrialmente estudos pertinentes a hidratos, vários outros pesquisadores principiaram estudos em técnicas de prognóstico e prevenção da formação de hidratos. Esta fase de detecção de hidratos em tubulações de gás representou um divisor para a indústria de gás natural, dando ênfase a uma nova frente de pesquisa: a prevenção da formação de hidratos em sistemas de gás natural (Baptista, 2007).

$\mathrm{Na}$ natureza existe uma grandeza de composições de gás natural, tornando inviável o mapeamento experimental de todas as composições em que haverá formação de hidratos. Deste modo, a termodinâmica foi ferramenta fundamental no desenvolvimento de técnicas e métodos que permitam predizer as condições de formação de hidratos em função de uma dada composição de gás. Inicialmente os esforços de pesquisa se concentram nas propriedades de equilíbrio termodinâmico independentes do tempo, devido à relativa facilidade de medida. Conforme o amadurecimento das pesquisas aumentou, o equilíbrio de fases tornou-se melhor definido e a pesquisa se voltou para medidas dependentes do tempo, tais como cinética e propriedades de transporte.

Uma grande mudança no pensamento veio da área de garantia de escoamento, grande parte impulsionada pela tecnologia utilizada, alterando o foco que era prevenir a formação hidratos para a gestão de riscos da formação de hidratos.

A prevenção envolve a formação de hidratos, evitando que o hidrato entre na zona de estabilidade termodinâmica. Já na de gestão de riscos estão envolvidos outros conceitos, tais como: utilização de métodos transientes para atrasar a formação de hidratos ou impedir que as partículas de hidrato se aglomerem, impedindo, assim, os bloqueios de gasodutos, linhas de produção, equipamentos, etc.

Este estudo segue a linha de gestão de riscos na formação de hidratos, e utilizará análises reológicas para avaliar emulsões de água em óleo que, potencialmente, poderão a vir ser usadas para gerar hidratos a pressão ambiente. 


\section{1 \\ Principais Conceitos}

\subsection{1}

Hidratos

Como definido anteriormente, hidrato de gás ou clatrato, que em latim significa "gaiola", é um composto cristalino no qual as moléculas de água encapsulam moléculas de gás, como por exemplo, o metano e dióxido de carbono (Sloan e Koh, 2008). O tipo de ligação intermolecular é parecido com a estrutura do gelo comum, mas o arranjo geométrico produz cavidades que circundam os gases originalmente em solução na água. Apesar da ausência de ligações químicas entre hospedeiro (água) e hóspede (gás), a estrutura estável do clatrato permite que o mesmo não se funda até temperaturas bem acima de 0 ${ }^{\circ} \mathrm{C}$, desde que a pressão predominante e a concentração de gases sejam suficientemente altas.

\subsection{2 Emulsões}

Existem vários tipos de sistemas e cada um recebe uma designação. Sistemas com uma fase sólida dispersa em uma fase líquida são denominados suspensões, sistemas com uma fase gás dispersa em uma fase líquida são chamados de espumas e sistemas com dois líquidos imiscíveis são denominados emulsões. Emulsões podem ser definidas como dispersões instáveis de dois líquidos, do ponto de vista termodinâmico, de uma fase dispersa em uma fase contínua (Myers, 1999).

São necessárias três condições para a formação de uma emulsão:

- Imiscibilidade entre os líquidos da emulsão;

- Agitação para dispersar um líquido em outro; e,

- Presença de agentes tensoativos. 
Agente tensoativo (ou emulsificante, ou surfactante) é um composto caracterizado pela capacidade de alterar as propriedades superficiais e interfaciais de um líquido. A estrutura química espacial é caracterizada por uma extremidade polar (solúvel em água) da molécula e uma parte apolar (não solúvel em água) da molécula (Mulligan, 2005).

Uma emulsão tende a se estabilizar devido à migração dos agentes tensoativos para a interface, os quais possuem caráter anfifílico, ou seja, possuem afinidade por ambas as fases, formando um filme elástico e mecanicamente resistente (Sjöblom et al., 2003).

As características de uma emulsão mudam constantemente, desde o início da sua formação até que a sua separação seja completa, e ainda variam com a temperatura, pressão, grau de agitação, tempo de formação, dentre outros. No entanto, a maior parte da emulsão é estável durante um período de tempo, a estabilidade cinética é proporcionada pelos menores tamanhos de gotas e a presença de uma película interfacial ao redor das gotas (Chrisman et al., 2012).

Segundo Cunha (2007, apud, Kokal, 2005) na indústria do petróleo as emulsões podem ser encontradas em diversas etapas da produção: nos reservatórios, nos poços de produção, nas linhas de produção, nos dutos de transporte, processamento primário e armazenamento, dentre outras.

As emulsões podem ser classificadas de duas formas: a primeira em relação ao componente da fase dispersa e da fase contínua e a segunda em relação à sua estabilidade. O principal fator envolvido na estabilização das emulsões são os emulsificantes naturais, que reduzem a probabilidade da coalescência das gotas.

A classificação das emulsões segundo a sua fase contínua é a seguinte: água em óleo (A/O); óleo em água (O/A); múltiplas ou complexas (A/O/A e O/A/O). A Fig. 3 permite uma melhor compreensão desses tipos de emulsões. 


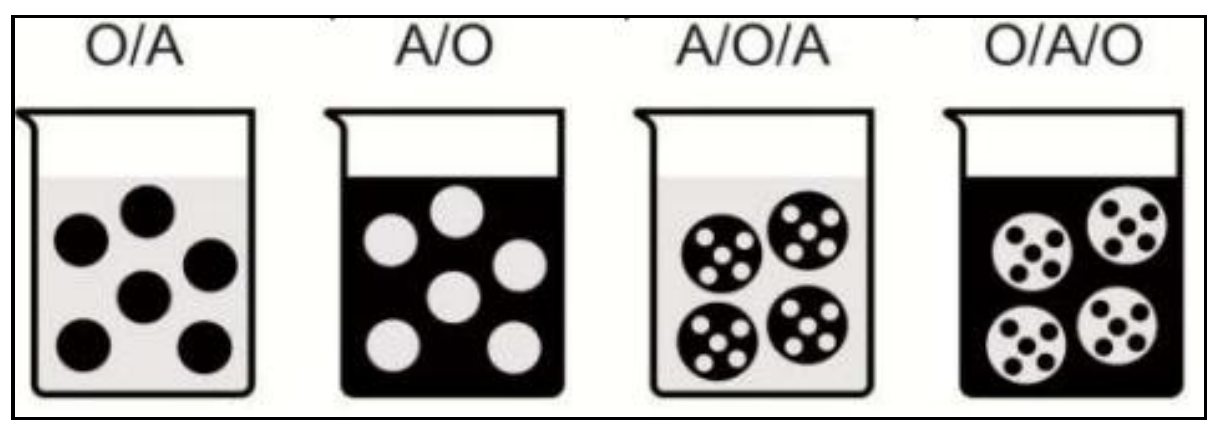

Figura 3: Tipos de emulsões segundo a fase contínua. (Adaptado de Melo, 2008).

As emulsões denominadas múltiplas ou complexas são aquelas que possuem gotas de óleo dispersas em água com tamanho suficientemente grande para congregar pequenas gotas de água no seu interior (A/O/A). Portanto, emulsões com gotas de água dispersas em óleo contendo em seu interior gotículas de óleo (O/A/O) (Myers, 1999; Kokal, 2005).

A estabilidade das emulsões pode ser determinada por alguns mecanismos clássicos descritos na literatura, são eles: Repulsão Eletrostática, Repulsão Estérica e Efeito Gibbs-Marangoni.

A aproximação das gotas pode gerar uma repulsão eletrostática mantendo a emulsão estável, em função da presença de emulsificantes iônicos na interface. De acordo com Sullivan e Kilpatrick (2002), as forças eletrostáticas não são muito expressivas na estabilização de emulsões $A / O$ devido à baixa constante dielétrica do óleo.

A resistência à adsorção de espécies nas interfaces das gotas e as interações com espécies adsorvidas em outras gotas é denominada repulsão estérica. A repulsão estérica ocorre quando o material adsorvido se encontra energeticamente mais favorável em interagir com a fase contínua do que com o material adsorvido em outras gotas (Sullivan e Kilpatrick, 2002).

Por fim, o Efeito Gibbs-Marangoni ocorre durante a aproximação de duas gotas que possuem moléculas adsorvidas com atividade interfacial, essa aproximação gera um gradiente de tensão, provocando um alongamento nessas gotas. Este gradiente de tensão possui força e sentido contrários à tensão de 
deformação e tenta restaurar o estado com tensão interfacial invariável, de forma que a interface se comporta elasticamente (Coutinho, 2005).

\subsection{3}

Fluido Não - Newtoniano

Fluidos cujo comportamento mecânico não pode ser descrito pela Lei de Viscosidade de Newton, isto é, não apresentam uma relação linear entre a tensão de cisalhamento e a taxa de cisalhamento, ou taxa de deformação, são denominados não Newtonianos. Há várias categorias destes, e tais categorias são baseadas nas relações entre a tensão e a taxa de deformação no fluido. Os fluidos não Newtonianos mais simples são chamados de puramente viscosos, e têm como única diferença em relação ao fluido Newtoniano o fato da viscosidade depender da taxa de deformação (Fig. 4).

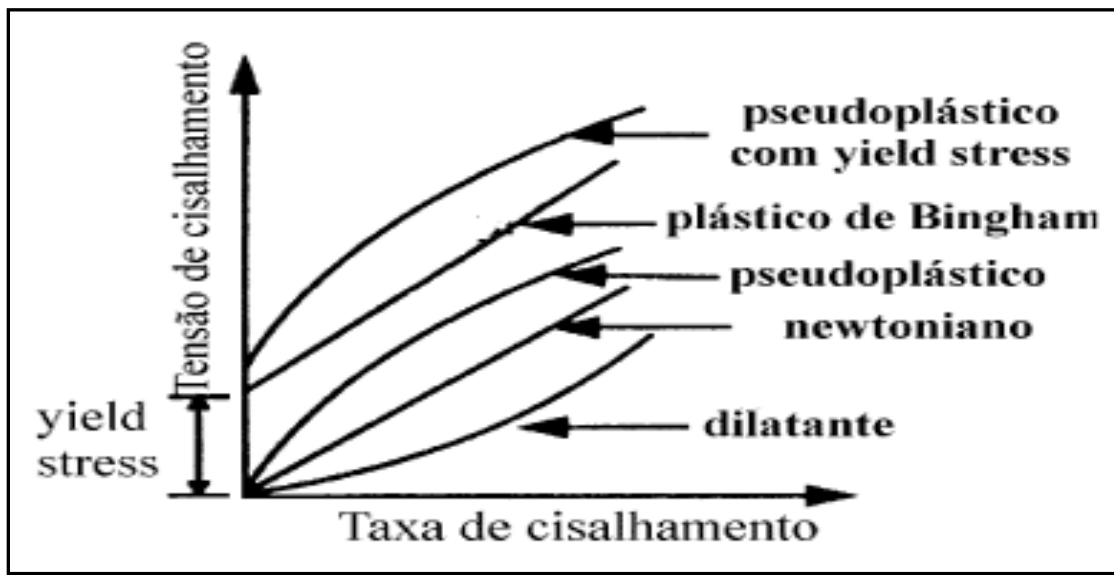

Figura 4: Classificação do comportamento reológico de diferentes tipos de fluidos (Kawatra e Bakshi 1996).

Para alguns fluidos não Newtonianos, os valores de viscosidade diminuem com o aumento da taxa de deformação, para outros o contrário acontece, ou seja, a viscosidade aumenta com aumento da taxa de deformação. No primeiro caso diz-se que o material possui comportamento pseudo-plástico, enquanto no segundo, diz-se que o fluido possui comportamento dilatante (Ferreira et al, 2005). 
Outros tipos de fluidos não Newtonianos necessitam de um valor inicial, uma tensão finita, conhecida como tensão limite de escoamento ou "yield stress", para que ocorra deformação, como por exemplo, os materiais denominados fluido de Bingham.

Ainda existe fluidos onde a viscosidade muda com o tempo, tais fluidos são classificados em dois grupos, os tixotrópicos e os reopéticos. Para os fluidos tixotrópicos a viscosidade diminui com o tempo, quando submetidos a uma taxa de deformação constante. Já os fluidos conhecidos como reopéticos, a viscosidade aumenta com o tempo, quando uma mesma taxa de deformação é aplicada.

Muitos fluidos podem apresentar também uma resposta elástica em determinadas condições. Estes fluidos são denominados fluidos viscoelásticos.

Conforme o comportamento do fluido num escoamento de cisalhamento, diferentes expressões para a função viscosidade foram determinadas empiricamente. Por exemplo, pode-se citar o Modelo Power-Law ou modelo de Ostwald de Waele (Barnes et. al., 2000):

$$
\eta=\mathrm{k} \cdot \dot{\gamma}^{\mathrm{n}-1} \quad \text { ou } \quad \tau=\mathrm{k} \cdot \dot{\gamma}^{\mathrm{n}}
$$

No modelo apresentado acima temos que $\eta$ é a função viscosidade, $\tau$ é a tensão de cisalhamento, $\mathrm{k}$ é o índice de consistência, $\mathrm{n}$ é o índice de potência e $\dot{\gamma}$ é a taxa de deformação.

Outro modelo muito utilizado é o de Herschel-Bulkley. Este tipo de fluido precisa de uma tensão inicial para começar a escoar. A relação entre a tensão de cisalhamento e a taxa de deformação não é linear, e depende do expoente adimensional $\mathrm{n}$, característico para cada fluido. A equação que modela este fluido é (Barnes et. al., 2000):

$$
\eta=\frac{\tau_{0}}{\dot{\gamma}}+k \dot{\gamma}^{n-1} \quad \text { ou } \quad \tau=\tau_{0}+k \cdot \dot{\gamma}^{n} \text { se } \tau>\tau_{0} \quad \text { eq. (2) }
$$

No modelo apresentado acima temos que $\eta$ é a função viscosidade, $\tau$ é 
a tensão de cisalhamento, $\tau_{0}$ é a tensão limite de escoamento, $\mathrm{k}$ é o índice de consistência, $n$ é o índice power law e $\dot{\gamma}$ é a taxa de deformação.

\subsection{4 Reologia}

A reologia surgiu como ciência no início do século $X X$ e se dedica ao estudo das deformações e do escoamento dos materiais. A origem do nome vem dos radicais gregos rheos (fluir) e logos (estudo) (Macosco, 1994). A reologia estuda o modo como os materiais respondem à aplicação de uma tensão, ou deformação, com o intuito de predizer a força necessária para causar uma deformação ou escoamento em um corpo, ou ainda predizer a deformação ou o escoamento resultante da aplicação de um dado sistema de forças em um corpo.

Na reologia tanto são estudados os materiais sólidos quanto os fluidos, e cada um desperta uma característica de interesse. Nos sólidos a característica de maior interesse é a elasticidade, enquanto nos fluidos é a viscosidade. A viscosidade é a propriedade física de um fluido de opor-se ao fluxo induzido por uma tensão de cisalhamento aplicada sobre ele e dependente: da natureza físico-química da substância, da temperatura, da pressão, da taxa de cisalhamento e do tempo, dentre outras variáveis (Castro, et al., 2001).

O comportamento reológico dos corpos reais é muito diverso e complexo. Um mesmo material pode ter diferentes comportamentos de acordo com as condições a que ele esteja submetido. Inúmeros modelos de comportamento mecânico foram propostos até hoje, cada um dentro de um limite e validade restritos.

O modelo mais simples de um corpo sólido é o sólido indeformável ou sólido de Euclides, onde a deformação é nula para qualquer estado de tensões. Todavia, na realidade todos os corpos são deformáveis, tendo Robert Hooke proposto o primeiro modelo desse sólido. Nesse modelo, denominado sólido de Hooke, as deformações são proporcionais às tensões e independentes do tempo. Nos ensaios de tração uniaxial ou de cisalhamento puro, as curvas de carregamento e descarregamento não são coincidentes, exibindo deformações 
residuais, tais corpos são nomeados como sólidos plásticos (Castro, et al., 2001).

A representação mais elementar de um fluido é o fluido perfeito ou fluido de Pascal. Esse fluido é incompressível e não existe ação de tensões tangenciais em qualquer elemento do fluido. Os fluidos reais não podem seguir tal modelo, sendo o modelo proposto por Newton o mais simples para ser adaptado em várias circunstâncias. Nesse modelo as tensões tangenciais são proporcionais à taxa de deformação. $\mathrm{Na}$ prática existem fluidos com um comportamento mais complexo, que não podem ser descritos pela lei de Newton, os chamados fluidos não newtonianos ou fluidos de Stokes (Castro, et al., 2001).

Na Fig. 5 é apresentado de forma resumida um esquema de classificação do comportamento reológico dos corpos.

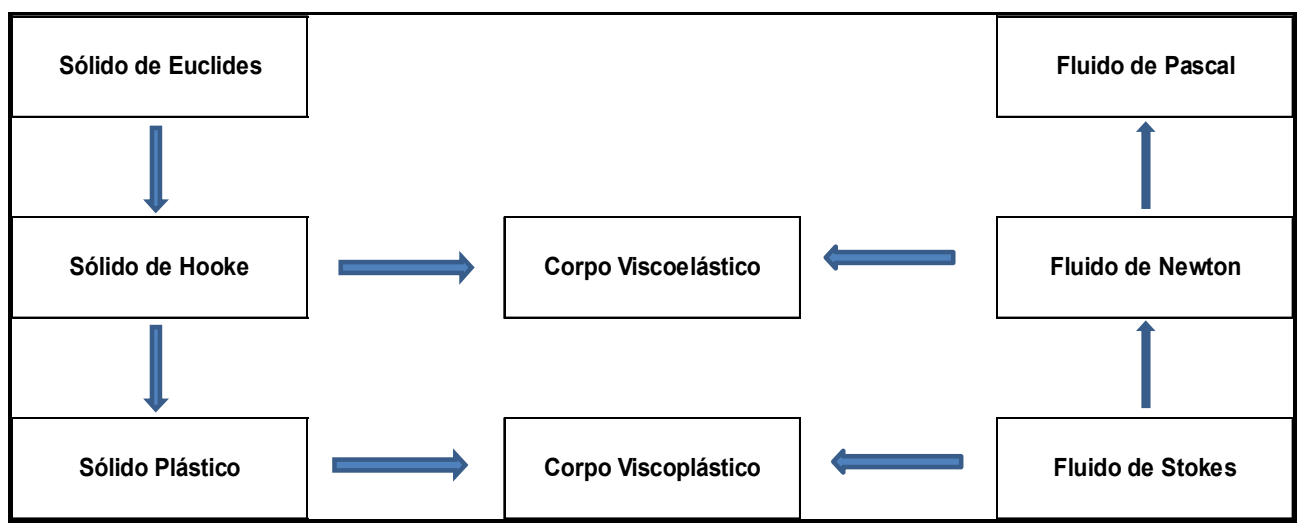

Figura 5: Classificação esquemática dos comportamentos reológicos (Castro, et al., 2001, pag. 17).

\subsection{5}

\section{Tensão Interfacial / Superficial}

No interior do líquido, cada molécula é atraída por outras moléculas em todas as direções, enquanto que as moléculas da superfície estão submetidas à tensão apenas das moléculas que têm por baixo (Fig. 6), resultando em uma 
força em direção ao interior do líquido. Esta propriedade é consequência das forças intermoleculares de coesão assimétrica (Shaw, 1975).

Ainda segundo Shaw (1975), a tensão superficial pode ser definida como a força que atua sobre a superfície aplicada paralelamente, por unidade de comprimento, com o intuito de contrabalancear a força imposta em direção ao interior do líquido, sua unidade é Newton/m (no Sistema Internacional de medidas).

A tensão superficial da água é muito intensa, devido às pontes de hidrogénio intermoleculares, sendo responsável pela formação de gotas, bolhas e meniscos. A tensão pode também existir entre dois líquidos imiscíveis, como água e óleo, sendo então chamada de tensão interfacial.

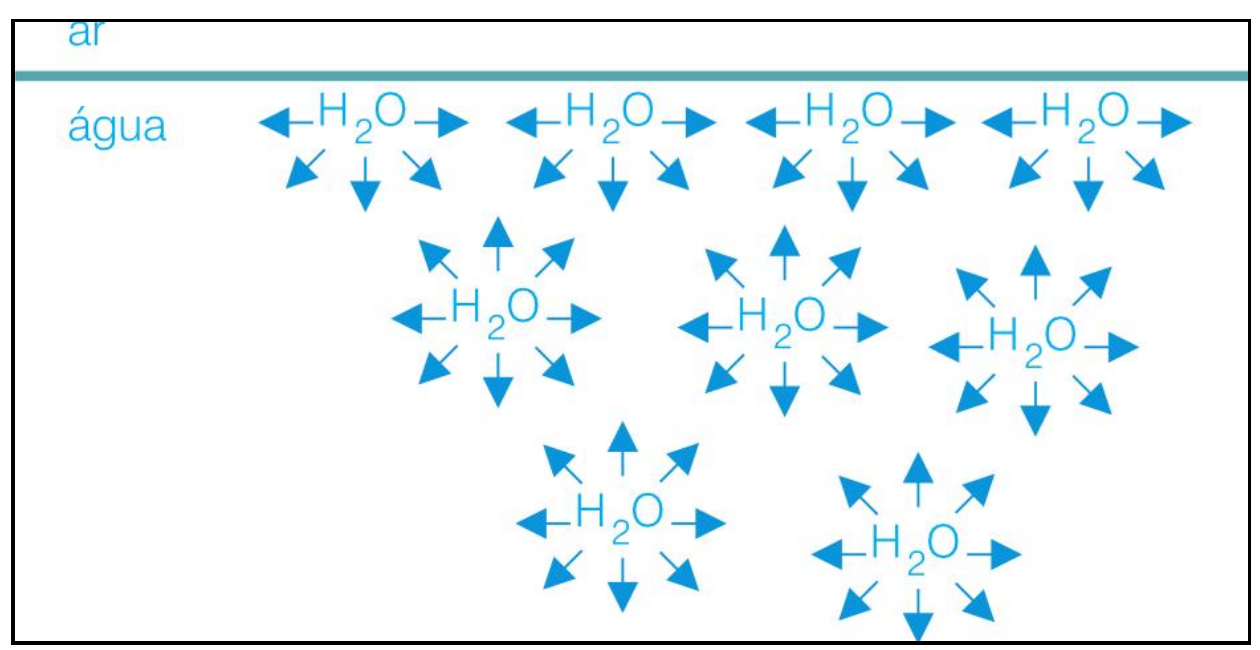

Figura 6: Distribuição de forças nas moléculas de água. Fonte: http://qnint.sbq.org.br/qni/visualizarConceito.php?idConceito=42.

Os tensoativos são utilizados para diminuir a tensão superficial/interfacial, mesmo em baixas concentrações. Esta diminuição é crescente com o aumento da concentração de tensoativos até a chamada concentração micelar crítica (CMC). Quando a CMC é alcançada, a adição de tensoativos não promove alterações relevantes sobre os valores de tensão superficial (Shaw, 1975). 


\subsection{6 \\ Balanço Hidrofílico - Lipofílico (HLB)}

Tensoativos são classificados, empiricamente, por meio de seus valores de HLB, que descreve uma relação entre as partes hidrofílica e lipofílica de sua molécula. Uma ampla faixa de valores de HLB pode ser obtida por meio do controle do grau de esterificação e da natureza do ácido graxo e do açúcar empregado nas reações de sintetização dos tensoativos, logo, é possível ter uma ampla faixa de aplicação desses (Plou et. al., 2002).

Em 1949 Griffin criou uma escala numérica adimensional de valores entre 1 e 20 , usada para descrever a natureza do agente tensoativo, quanto maiores os valores de HLB maior é a hidrofilia da molécula. O equilíbrio hidrófilo-lipófilo de um tensoativo é uma propriedade importante no processo de emulsificação, visto que determina o tipo de emulsão que tende a produzir. Agentes emulsivos de HLB baixo tendem a formar emulsões $A / O$, ao passo que aqueles com HLB alto formam emulsões O/A (Griffin, 1949).

A Tabela 1 apresenta essas faixas típicas de valores de HLB e suas aplicações mais sugeridas.

Tabela 1: Faixa de valores de HLB. (Griffin, 1949).

\begin{tabular}{|c|c|}
\hline HLB & Aplicações \\
\hline $1-3$ & Agentes antiespumantes \\
\hline $4-6$ & Emulsão A/O \\
\hline $7-9$ & Agentes de molhabilidade \\
\hline $8-18$ & Emulsão O/A \\
\hline $13-15$ & Detergentes \\
\hline $15-18$ & Agentes solubilizantes \\
\hline
\end{tabular}

O HLB é um indicador das características emulsionantes de um tensoativo, mas não a sua eficiência, a escolha do mais indicado deve ser feita por meio de experimentos. Muitas vezes, por exemplo, misturas de agentes tensoativos são mais eficazes do que os componentes individuais, mesmo se a finalidade for o mesmo HLB (Schramm, et. al, 2003). 
Assim como a solubilidade dos agentes tensoativos variaram com a temperatura, o mesmo acontece com o HLB, especialmente para os tensoativos não iônicos. Assim um surfactante pode estabilizar emulsões O/A, a baixa temperatura, mas estabilizar emulsões $\mathrm{A} / \mathrm{O}$ em alguma temperatura mais elevada. A temperatura de transição, cuja estabilização do tensoativo muda as emulsões de O/A para $\mathrm{A} / \mathrm{O}$, é conhecida como a temperatura de inversão de fase - PIT (Schramm, et. al, 2003). 


\section{3. \\ Materiais e Métodos}

Neste capítulo descrevem-se os materiais, os aparelhamentos e a metodologia utilizados para a produção das emulsões, bem como os equipamentos que proporcionaram as medições reológicas dessas últimas.

\section{1 \\ Materiais}

Para a realização do estudo foram feitas, na conjectura, distintas emulsões de água em óleo $(\mathrm{A} / \mathrm{O})$ e estas foram avaliadas quanto à reologia e a tensão superficial/interfacial. Também foram adicionados dois tensoativos ao óleo para testar seu comportamento com relação à estabilidade das emulsões $\mathrm{A} / \mathrm{O}$.

\subsection{1}

Fase Oleosa

Óleos minerais utilizados: Shell Morlina S2 BL 10, Shell Morlina S2 B 150 e Óleo Mineral (União Química).

\subsubsection{1}

Shell Morlina S2 BL 10

Shell Morlina BL S2 são óleos especiais de baixa viscosidade, de base mineral refinada misturada com aditivos livres de zinco, especialmente desenvolvidos para aplicações de altas rotações (Folha de Dados Técnica - Shell Morlina S2 BL 10, v1). 


\begin{tabular}{|c|c|c|c|c|}
\hline Properties & & & Method & Shell Morlina S2 BL. \\
\hline ISO VG & & & ISO 3448 & 10 \\
\hline Viscosidade Cinemática & $@ 20^{\circ} \mathrm{C}$ & $\mathrm{mm}^{2} / \mathrm{s}$ & ASTM D 445 & - \\
\hline Viscosidade Cinemática & @40 $0^{\circ} \mathrm{C}$ & $\mathrm{mm}^{2} / \mathrm{s}$ & ASTM D 445 & 10 \\
\hline Viscosidade Cinemática & $@ 100^{\circ} \mathrm{C}$ & $\mathrm{mm}^{2} / \mathrm{s}$ & ASTM D 445 & 2.3 \\
\hline Densidade & $@ 15^{\circ} \mathrm{C}$ & $\mathrm{kg} / \mathrm{m}^{3}$ & ISO 12185 & 881 \\
\hline Ponto de Fulgor ( $\mathrm{COC}$ ) & & ${ }^{\circ} \mathrm{C}$ & ASTM D 93 & 150 \\
\hline Ponto de Fluidez & & ${ }^{\circ} \mathrm{C}$ & ISO 3016 & -30 \\
\hline Ferugem, Água salgada & & & ASTM D 665B & Passa \\
\hline Teste de Controle de Oxidaçāo : TOST & & Hrs & ASTM D 943 & $2000+$ \\
\hline Teste de Controle de Oxidação : RPVOT & & Mins & ASTM 2272 & 300 \\
\hline
\end{tabular}

Figura 7: Características do Shell Morlina S2 BL10. Fonte: Folha de Dados Técnica - Shell Morlina S2 BL 10, v1.

\subsubsection{2 \\ Shell Morlina S2 B 150}

Shell Morlina S2 B 150 é um óleo de alto desempenho designado para promover máxima proteção contra a corrosão, empregado em sistemas de circulação de óleo, mancais industriais e outras aplicações. É composto por uma blenda de alta qualidade, com solventes refinados que promovem boa separação da água e liberação de ar (Folha de Dados Técnica - Shell Morlina S2 B 150, v2).

\begin{tabular}{|c|c|c|c|c|}
\hline Propertles & & & Method & Shell Morlina S2 B 150 \\
\hline Categorla de Viscosidade ISO & & & ISO 3448 & 150 \\
\hline Viscosidade Cinemática & (1) $40^{\circ} \mathrm{C}$ & $\mathrm{mm}^{2} / \mathrm{s}$ & ASTM D445 & 150 \\
\hline Viscosidade Cinemática & (100 $100^{\circ} \mathrm{C}$ & $\mathrm{mm}^{2} / \mathrm{s}$ & ASTM D445 & 15 \\
\hline Densidade & @ $15^{\circ} \mathrm{C}$ & $\mathrm{kg} / \mathrm{m}^{3}$ & ISO 12185 & 887 \\
\hline Indice de Viscosidade & & & ISO 2909 & 95 \\
\hline Ponto de Fulgor (COC) & & ${ }^{\circ} \mathrm{C}$ & ISO 2592 & 262 \\
\hline Ponto de Fluldez & & ${ }^{\circ} \mathrm{C}$ & ISO 3016 & -15 \\
\hline Ferrugem, Água Destllada & & & ASTM D665A & Pass \\
\hline Teste de Emulsăo - @82 ${ }^{\circ} \mathrm{C}$ (Exceto especificado por ") & & Mins & ASTM D1401 & 20 \\
\hline Teste de Controle de Oxidaçăo : TOST & & Hrs & ASTM D943 & $1300+$ \\
\hline Teste de Controle de Oxidaçăo: RBOT & & Mins & ASTM D2272 & $400+$ \\
\hline Teste de Espuma, Seq II & & $\begin{array}{l}\text { ml de espuma @ } \\
0 / 10 \text { mins }\end{array}$ & ASTM D892 & $10 / 0$ \\
\hline
\end{tabular}

Figura 8: Características do Shell Morlina S2 B 150. Fonte: Folha de Dados Técnica - Shell Morlina S2 B 150, v2. 


\subsubsection{3}

Óleo Mineral (Vaselina branca)

Líquido oleoso, transparente, incolor, inodoro ou quase inodoro, produzido por UNIÃO QUÍMICA FARMACÊUTICA NACIONAL S/A.

Tabela 2: Propriedades do Óleo Mineral a $25^{\circ} \mathrm{C}$.

\begin{tabular}{|l|c|c|}
\hline \multicolumn{2}{|c|}{ Óleo Mineral $-\mathbf{2 5}^{\circ} \mathbf{C}$} \\
\hline \multicolumn{2}{|c|}{ Propriedade } & \multicolumn{2}{|c|}{ Resultado } \\
Tensão Superficial & $\sigma[\mathrm{mN} / \mathbf{m}]$ & 28.4 \\
Densidade & $\rho\left[\mathrm{kg} / \mathbf{m}^{3}\right]$ & $\mathbf{8 6 7 . 6}$ \\
Viscosidade & $\mu[$ Pa.s $]$ & $\mathbf{0 . 1 3 3 9}$ \\
\hline
\end{tabular}

\subsection{2}

Fase Aquosa

Água deionizada recém-obtida.

\subsection{3}

Tensoativos

Monooleato de Sorbitano: surfactante não iônico, mono-éster do ácido oleico e hexitol anidrido derivado de sorbitol, fórmula empírica $\mathrm{C}_{24} \mathrm{H}_{44} \mathrm{O}_{6}$, massa molar $(\mathrm{g} / \mathrm{mol})$ de 428,60, com valor de HLB de 4,3, viscosidade 1200-2000 mPa.s $\left(20^{\circ} \mathrm{C}\right)$, Span $80^{\circledR}$. Adquirido na Sigma Aldrich. Por ser um tensoativo lipofílico, possui baixo valor de HLB, sendo solúvel em óleo, o que favorece o seu emprego em emulsões do tipo A/O. 


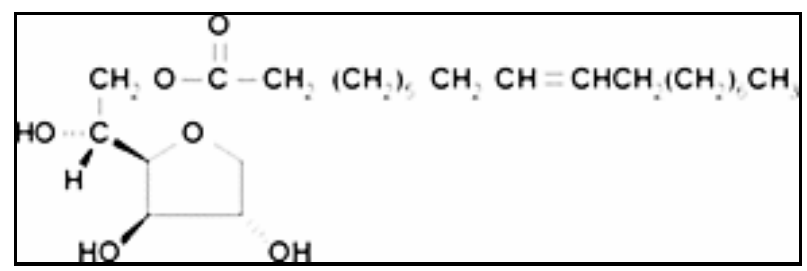

Figura 9: Estrutura molecular do Monooleato de Sorbitano - Span $80^{\circledR}$.

(http://www.sigmaaldrich.com/catalog/product/fluka/85548).

Dioctil sulfosuccinato de sódio: surfactante aniônico, é produzido a partir da reação do octano com o anidrido de ácido málico, seguido por reação com bissulfito de sódio. Sólido branco, fórmula empírica $\mathrm{C}_{20} \mathrm{H}_{38} \mathrm{O}_{7} \mathrm{~S} \cdot \mathrm{Na}$, massa molar ( $\mathrm{g} / \mathrm{mol})$ de 445,31, também conhecido como Aerosol OT (AOT). Adquirido na Fisher Scientific.

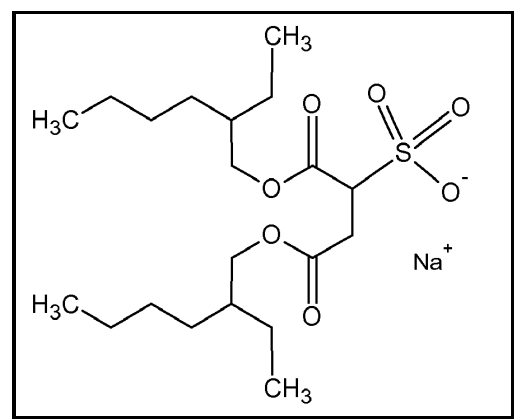

Figura 10: Estrutura molecular do Dioctil sulfosuccinato de sódio (AOT) (http://www. discovery.kcpc.usyd.edu.au).

\section{2}

\section{Equipamentos e Acessórios}

- Agitador magnético com placa de aquecimento - FISATOM, modelo 754A.

- Ultra - Turrax ${ }^{\circledR}$ - IKA Modelo T25.

- Termômetro graduado.

- Tensiômetro - Lauda, modelo: Anel de Platina.

- Microscópio ótico Zeiss, modelo Imager M2m, totalmente motorizado, operando em luz transmitida, com captura de imagens por uma câmera CCD AxioCam MRc5. 
- Reômetros Physica MCR301 e Physica MCR501, ambos da Anton Paar.

- Balanças FA2104N - Bioprecisa - GEHAKA (balança analítica, com 4 casas decimais de precisão).

- BG4400 - GEHAKA (balança semi-analítica, com duas casas decimais de precisão).

- Béquer de 25, 50, 100, 250 e $500 \mathrm{ml}$.

- Pipetas Pasteur.

- Bastão de vidro.

- Vidro de Relógio.

- Picnometros.

\section{3 \\ Métodos}

\subsection{1 \\ Preparo das Emulsões}

As emulsões foram preparadas da seguinte maneira:

i. Todos os ingredientes foram pesados utilizando-se as balanças FA2104N e BG4400, conforme a Tabela 3 para uma concentração de $1 \%$ (um por cento) em peso dos tensoativos, e conforme a Tabela 4 para uma concentração de $5 \%$ (cinco por cento) em peso dos tensoativos. A fase aquosa foi pesada em um Becker de $100 \mathrm{ml}$, a fase oleosa em um Becker de $250 \mathrm{ml}$, o Span 80 pesado em um Becker de $25 \mathrm{ml}$ e o AOT pesado no vidro de relógio na balança FA2104N.

ii. Depois de pesados os ingredientes, colocou-se a fase oleosa para aquecer, a aproximadamente $50^{\circ} \mathrm{C}$, utilizando o agitador magnético com placa de aquecimento (FISATOM, modelo 754A), enquanto o AOT estava sendo misturado ao Span 80 com o auxílio do bastão de vidro, para que a solubilidade dos 
tensoativos no óleo fosse acelerada.

iii. Depois essa mistura foi adicionada a fase oleosa. Uma barra magnética (peixinho) foi utilizada para homogeneizar os tensoativos no óleo por 30 minutos.

iv. Durante o processo de homogeneização dos tensoativos na fase oleosa, a temperatura foi sendo verificada com um termômetro graduado, a fim de que essa temperatura não excedesse os $50^{\circ} \mathrm{C}$.

v. A seguir foi utilizado um dispersor de alto desempenho - Turrax - IKA modelo T25 para preparação final da emulsão A/O. Durante 10 minutos o fluido foi misturado, sendo que a água foi adicionada lentamente no primeiro minuto, numa velocidade de 8000 rpm.

Tabela 3: Percentuais em massa da composição das emulsões com 1\% de

\begin{tabular}{l|c|ccccc}
\hline Ingredientes: & $\begin{array}{c}\text { Peso } \\
(\mathbf{g})\end{array}$ & $\%$ & $\begin{array}{c}\text { Peso } \\
\mathbf{( g )}\end{array}$ & $\%$ & $\begin{array}{c}\text { Peso } \\
\mathbf{( g )}\end{array}$ & $\%$ \\
\hline Fase Aquosa & 44,80 & $20,00 \%$ & 77,00 & $30,00 \%$ & 120,00 & $40,00 \%$ \\
Fase Oleosa & 177,00 & $79,00 \%$ & 177,00 & $69,00 \%$ & 177,00 & $59,00 \%$ \\
Tensoativos & 2,24 & $1,00 \%$ & 2,57 & $1,00 \%$ & 3,00 & $1,00 \%$ \\
AOT & 0,22 & $0,1 \%$ & 0,27 & $0,1 \%$ & 0,30 & $0,1 \%$ \\
Span 80 & 2,02 & $0,9 \%$ & 2,30 & $0,9 \%$ & 2,70 & $0,9 \%$ \\
TOTAL & 224,04 & $100,00 \%$ & 256,57 & $100,00 \%$ & 300,00 & $100,00 \%$ \\
\hline
\end{tabular}

Tabela 4: Percentuais em massa da composição das emulsões com $5 \%$ de tensoativos.

\begin{tabular}{|c|c|c|c|c|c|c|}
\hline Ingredientes: & $\begin{array}{c}\text { Peso } \\
\text { (g) } \\
\end{array}$ & $\%$ & $\begin{array}{l}\text { Peso } \\
\text { (g) } \\
\end{array}$ & $\%$ & $\begin{array}{l}\text { Peso } \\
\text { (g) } \\
\end{array}$ & $\%$ \\
\hline Fase Aquosa & 47,20 & $20,00 \%$ & 81,70 & $30,00 \%$ & 128,71 & $40,00 \%$ \\
\hline Fase Oleosa & 177,00 & $75,00 \%$ & 177,00 & $65,00 \%$ & 177,00 & $55,00 \%$ \\
\hline Tensoativos & & $5,00 \%$ & & $5,00 \%$ & & $5,00 \%$ \\
\hline АOT & 1,18 & $0,50 \%$ & 1,36 & $0,50 \%$ & 1,60 & $0,50 \%$ \\
\hline Span 80 & 10,62 & $4,50 \%$ & 12,26 & $4,50 \%$ & 14,50 & $4,51 \%$ \\
\hline TOTAL & 236,00 & $100,00 \%$ & 272,32 & $100,00 \%$ & 321,81 & $100,00 \%$ \\
\hline
\end{tabular}




\subsection{2}

\section{Caraterização Reológica das Emulsões}

Para a análise das propriedades reológicas das emulsões preparadas, os reômetros utilizados foram: Physica MCR301 e Physica MCR501, ambos da Anton Paar. Essas análises seguiram as etapas descritas abaixo:

i. Seleção da geometria - de acordo com as características da fase oleosa. As geometrias selecionadas foram a de cilindro concêntrico de fenda dupla (Double Gap - DG) para o Shell Morlina S2 BL 10, e a de placas ranhuradas (Cross Hatched) para o Shell Morlina S2 B 150 e o Óleo Mineral.

ii. As emulsões preparadas, a princípio, são de água em óleo, apresentando baixa ou nenhuma evaporação. No entanto, apresentaram deslizamento quando os testes foram feitos com placas paralelas lisas. Motivo pelo qual se optou pela geometria de placas ranhuradas (Cross Hatched).

iii. Os parâmetros dos testes foram mantidos constantes para todas as emulsões no estudo, pois a intensão é fazer um estudo comparativo entre diferentes óleos, mantendo as mesmas concentrações de tensoativos, para obter a emulsão "mais estável", um fluido modelo, que será utilizado no estudo de formação de hidratos.

iv. Para os testes rotacionais foram mantidos os parâmetros de 100 a 0,01 1/s para a taxa de deformação para as curvas de escoamento (Flow Curve). O tempo de marcação de cada ponto foi obtido por meio do teste de taxa de cisalhamento constante (Cte Shear Rate), esse teste foi programado para durar 10 minutos e foi aplicada a taxa de cisalhamento mais baixa, a partir de 0,01 1/s, para determinar em quanto tempo as emulsões entrariam em regime permanente. 
v. Para os testes oscilatórios foram mantidos os parâmetros de 0,01 a 10 ou 100 Pa para a varredura de tensão (Stress Sweep), e para os testes de varredura do tempo (Time Sweep) foram utilizados até $60.000 \mathrm{~s}$ de duração para cada teste, tendo como dado de entrada para a tensão um valor na região viscoelástica linear, quando existia, obtido no teste de varredura de tensão e uma frequência padrão de $1 \mathrm{~Hz}$.

\subsection{3}

\section{Medidas da Tensão Superficial/Interfacial}

O instrumento utilizado para fazer a medição da tensão superficial ou interfacial de um material é designado tensiômetro. As medidas foram baseadas no método do anel de Du Nouy (Fig. 11). Uma das vantagens deste tipo de tensiômetro é a rapidez da medida. No entanto, tem a desvantagem de requerer um volume grande de amostra, da ordem de $20 \mathrm{ml}$.

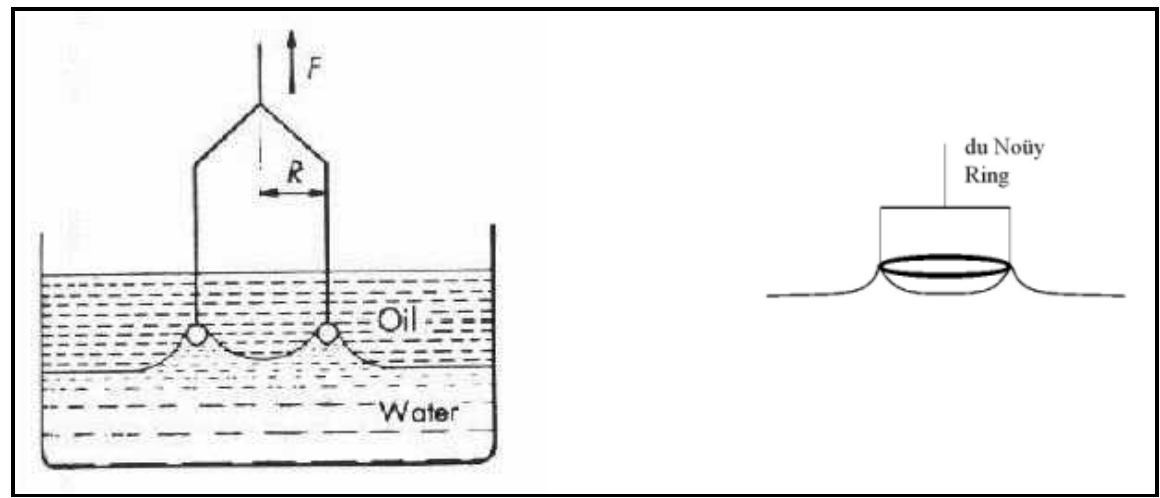

Figura 11: Princípio de funcionamento do tensiômetro. Fonte: http://www.mastrad.com/tsd2.bmp.

O tensiômetro para realizar este tipo de medição é constituído de um recipiente que contém os líquidos a serem analisados e um anel que está ligado a um dispositivo sensível de medição de força. O recipiente pode ser movido para cima e para baixo controladamente, enquanto a posição do anel é mantida constante. 
O que o tensiômetro irá medir é a força requerida para o anel ultrapassar entre as superfícies dos fluidos, esta força é dividida pela circunferência do anel e corrigida por um fator geométrico. Para medições mais precisas, a borda inferior do anel deve ser mantida paralela à superfície do fluido, e o ângulo de contato entre o líquido e o anel precisa ser o mais próximo de zero (Mcclements, 1999).

Os anéis são comumente fabricados a partir de platina ou de platina-irídio, porque promovem ângulos de contato aproximadamente iguais à zero. O método do anel Du Nouy pode ser usado para determinar as tensões superficiais com uma precisão de cerca de $0,1 \mathrm{mN} / \mathrm{m}$. O método do anel é confiável para aferir valores de tensão superficial e tensão interfacial, comumente encontrados em água, óleos, bem como em misturas de água/óleos com ou sem tensoativos (Mcclements, 1999).

Neste estudo utilizou-se o Tensiômetro - Lauda, modelo: Anel de Platina, para a medição das tensões interfaciais dos óleos utilizados nas emulsões e a água. Todas as medições foram feitas através do método do anel de Du Nouy. A água $(20 \mathrm{~mL})$ é colocada em um béquer de $50 \mathrm{~mL}$, a seguir o anel foi mergulhado cerca de $1 \mathrm{~cm}$ na água. Os óleos (20 mL) com os tensoativos são colocados cuidadosamente sobre a água e então as medidas são realizadas.

\subsection{4}

\section{Correção de placas paralelas}

A geometria de placas paralelas é largamente usada em reometria para uma grande variedade de materiais, tais como: soluções poliméricas, suspensões, dispersões e emulsões. Uma das suas vantagens sobre o cone e placa ou as geometrias de cilindros concêntricos é a facilidade de variar a folga, que é decisiva no caso de sistemas com partículas ou gotículas.

No entanto, ao contrário do cone e placa ou as geometrias de cilindros concêntricos, a taxa de deformação não é constante ao longo do raio. Assim, tanto a tensão medida quanto a viscosidade precisam ser corrigidas. A equação 
de Weissenberg-Rabinowitsch representa a dependência da taxa de cisalhamento de fluidos não Newtonianos corrigindo a tensão (Macosco, 1994). Os reômetros (Phyica 301 e Phyica 501) utilizados neste estudo medem a viscosidade e a tensão de cisalhamento aparentes, sendo necessário fazer a correção demonstrada a seguir.

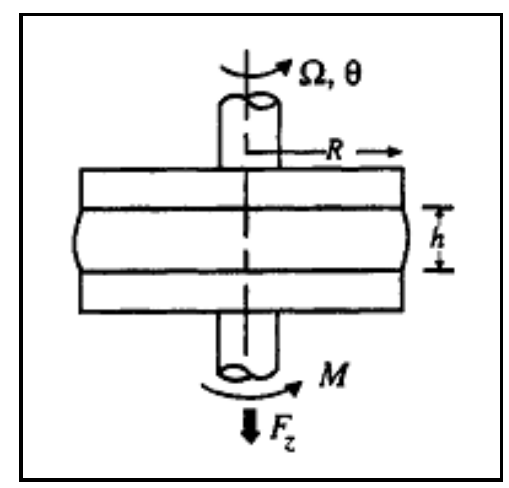

Figura 12: Geometria de placas paralelas (Macosco, 1994, p. 217).

A velocidade angular medida $\Omega$ define a taxa de deformação $\dot{\gamma}$ :

$$
\dot{\gamma}(r)=\Omega \frac{r}{h} \therefore \dot{\gamma}(R)=\Omega \frac{R}{h} \equiv \dot{\gamma}(r)=\dot{\gamma}(R) \frac{r}{R}
$$

Portanto, a taxa de deformação é função da coordenada radial. Assim, devemos usar uma derivada para relacionar tensão de deformação ao torque total. As equações resultantes são dadas abaixo:

$$
M=\int_{0}^{R} r d F_{\text {cis }}=\int_{0}^{R} r \tau_{12}(r) 2 \pi r d r=2 \pi \int_{0}^{R} r^{2} \tau_{12}(r) d r
$$

Rearmando a equação 3:

$$
r=\frac{h}{\Omega} \dot{\gamma}=\frac{R \cdot \dot{\gamma}}{\dot{\gamma}_{R}} \therefore \dot{\gamma}_{R}=\frac{\Omega R}{h}
$$


Então:

$$
d r=\frac{R}{\dot{\gamma}} d \dot{\gamma}
$$

Substituindo na equação 4:

$M=2 \pi \int_{0}^{\dot{\gamma}}\left(\frac{R}{\gamma}\right)^{3} \dot{\gamma}^{2} \tau_{\mathrm{L} Z} d \gamma^{n}$

Reorganizando e diferenciando usando a regra de Leibnitz, tem-se:

$$
\tau_{12}(R)=\frac{M}{2 \pi R^{3}}\left[3+\frac{d \ln M}{d \ln \gamma_{R}^{2}}\right]=\frac{\tau_{a R}}{4}\left[3+\frac{d \ln M}{d \ln \gamma_{R}}\right]
$$

A viscosidade real pode ser calculada a partir da correção feita acima, portanto:

$$
\eta\left(\dot{\gamma}_{R}\right)=\frac{\tau_{R}}{\gamma^{\prime \prime}}=\frac{\eta_{a}}{4}\left[3+\frac{d \ln M}{d \ln \dot{\gamma}_{R}}\right]
$$

Para demonstração do efeito da correção, abaixo segue um resultado de um teste reológico de uma emulsão, neste caso utilizando o Óleo Mineral com corte de água de $20 \%$ (Fig. 13).

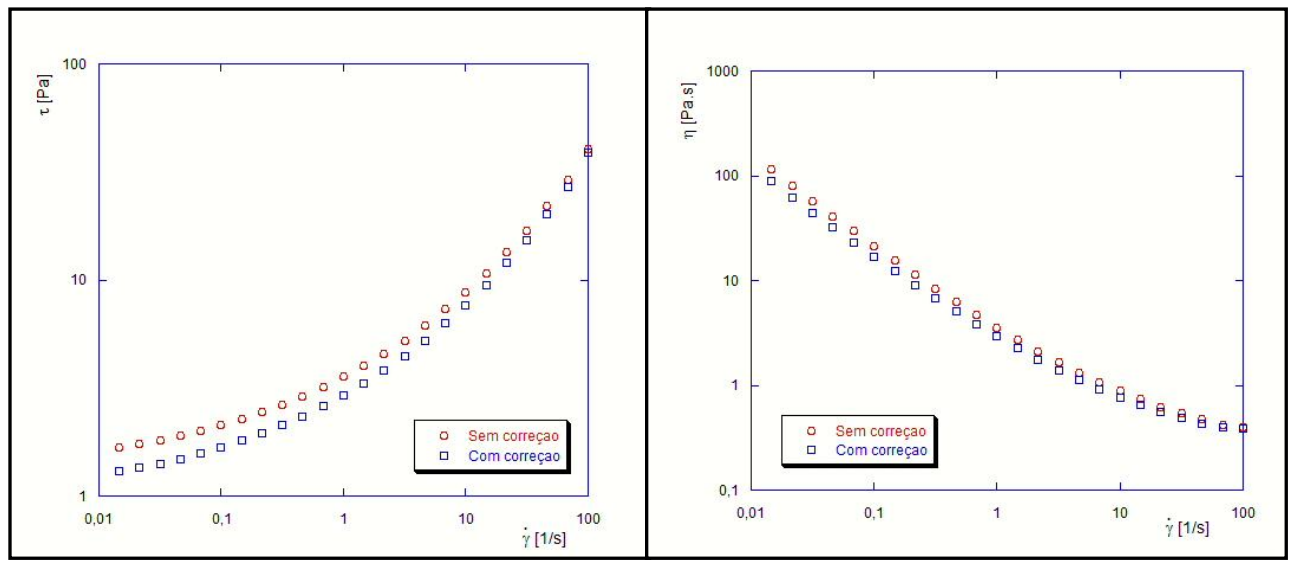

Figura 13: Gráfico da correção aplicada à placa paralela. 


\section{4. \\ Resultados}

Neste capítulo serão apresentados os resultados dos testes de tensão interfacial e da caracterização reológica das emulsões.

\section{1}

\section{Avaliação da Tensão Interfacial}

As medidas de tensão Interfacial (TIF) entre as fases oleosas deste estudo e a água foram realizadas no Laboratório de Caracterização de Fluidos da PUC - Rio. Para calcular esta TIF é preciso obter a massa específica de cada fase oleosa com a sua respectiva concentração de tensoativos.

As fases oleosas foram colocadas em um banho a $20^{\circ} \mathrm{C}$, até que as temperaturas das amostras estabilizassem. O tempo total de estabilização de temperatura empregado neste estudo foi de uma hora. A partir daí, realiza-se a medida da massa específica com picnometros (pequeno frasco de vidro construído cuidadosamente de forma que o seu volume seja invariável. Possui uma abertura suficientemente larga e tampa muito bem esmerilhada, provida de um orifício capilar longitudinal) de volumes definidos, com o auxílio de uma balança de precisão (Balança FA2104N). 


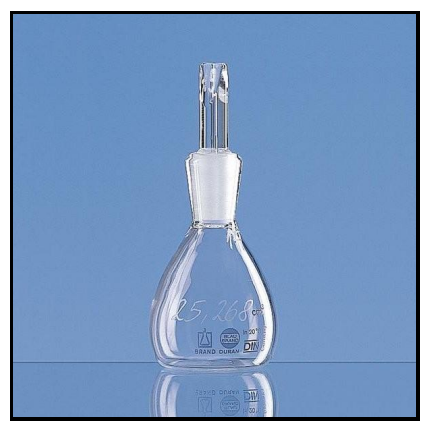

Figura 14: Picnometro. Fonte: www.pro-analise.com.br

Para este estudo seis concentrações diferentes de tensoativos, em peso das amostras, foram propostas: $5 \%, 1 \%, 0.5 \%, 0.1 \%, 0.05 \%$ e $0.001 \%$. $\mathrm{Na}$ tabela 5 estão os valores de massa específica medidos para as fases oleosas com suas referentes concentrações de tensoativos. Vale ressaltar que a proporção dos tensoativos não foi alterada, continuando a mesma proporção, $90 \%$ de Span 80 e $10 \%$ de AOT.

Tabela 5: Massa específica medida para as fases oleosas.

\begin{tabular}{|l|c|c|c|c|c|c|}
\cline { 2 - 7 } \multicolumn{1}{c|}{} & \multicolumn{6}{c|}{ Concentração de Tensoativos } \\
\cline { 2 - 7 } \multicolumn{1}{c|}{} & $5,0 \%$ & $1,0 \%$ & $0,50 \%$ & $0,10 \%$ & $0,05 \%$ & $0,001 \%$ \\
\hline Fase Oleosa & 0,8830 & 0,8768 & 0,8763 & 0,8938 & 0,8775 & 0,8674 \\
\hline Morlina S2 BL10 & $0,85 a$ Específica $(\mathrm{g} / \mathrm{mL})$ \\
\hline Morlina S2 B150 & 0,8950 & 0,8922 & 0,8885 & 0,8643 & 0,8638 & 0,8633 \\
\hline Óleo Mineral & 0,8845 & 0,8752 & 0,8727 & 0,8765 & 0,8761 & 0,8720 \\
\hline
\end{tabular}

Com essas amostras foram realizados os testes no Tensiômetro. Três medidas para cada uma das amostras, entre uma medida e outra o anel de platina foi imerso em querosene e depois flambado, para evitar a contaminação de uma amostra com outra, ou a da fase oleosa com a água. Na Tabela 6 estão os valores medidos de tensão para cada uma das fases oleosas e suas respectivas concentrações de tensoativos a $20^{\circ} \mathrm{C}$. 
Tabela 6: Valores medidos de tensão para cada uma das fases oleosas.

\begin{tabular}{|l|c|c|c|c|c|c|}
\hline Concentração de Tensoativos & $\mathbf{5 \%}$ & $\mathbf{1 \%}$ & $\mathbf{0 , 5} \%$ & $\mathbf{0 , 1} \%$ & $\mathbf{0 , 0 5 \%}$ & $\mathbf{0 , 0 0 1 \%}$ \\
\hline \multicolumn{7}{|c|}{ Morlina S2 B150 } \\
\hline Tensão medida (V) - teste 1 & 0,056 & 0,061 & 0,070 & 0,116 & 0,153 & 0,212 \\
\hline Tensão medida (V) - teste 2 & 0,052 & 0,061 & 0,070 & 0,112 & 0,159 & 0,214 \\
\hline Tensão medida (V) - teste 3 & 0,056 & 0,061 & 0,070 & 0,114 & 0,158 & 0,214 \\
\hline Tensão medida (V) - média & 0,055 & 0,061 & 0,070 & 0,114 & 0,157 & 0,213 \\
\hline \multicolumn{7}{|c|}{ Morlina S2 BL10 } \\
\hline Tensão medida (V) - teste 1 & 0,077 & 0,076 & 0,084 & 0,097 & 0,098 & 0,172 \\
\hline Tensão medida (V) - teste 2 & 0,070 & 0,080 & 0,089 & 0,108 & 0,094 & 0,186 \\
\hline Tensão medida (V) - teste 3 & 0,072 & 0,074 & 0,085 & 0,090 & 0,109 & 0,170 \\
\hline Tensão medida (V) - média & 0,073 & 0,077 & 0,086 & 0,098 & 0,100 & 0,176 \\
\hline \multicolumn{7}{|c|}{ Óleo Mineral } \\
\hline Tensão medida (V) - teste 1 & 0,067 & 0,078 & 0,076 & 0,149 & 0,195 & 0,315 \\
\hline Tensão medida (V) - teste 2 & 0,069 & 0,075 & 0,078 & 0,150 & 0,198 & 0,300 \\
\hline Tensão medida (V) - teste 3 & 0,071 & 0,076 & 0,077 & 0,153 & - & 0,298 \\
\hline Tensão medida (V) - média & 0,069 & 0,076 & 0,077 & 0,151 & 0,197 & 0,304 \\
\hline
\end{tabular}

De posse desses dados, o cálculo da TIF de cada fase oleosa, com a respectiva concentração de tensoativos, e a água utilizando a equação (10), tornar-se relativamente simples. Porquanto todos os demais parâmetros dessa fórmula são tabelados e estão descritos em seguida.

$\sigma_{L}=\left[a_{0}+\left(\frac{a_{1}+a_{2} \cdot \sigma_{i}}{\rho_{L} \cdot \rho_{a r}}+a_{3}\right)^{0.5}\right] \cdot\left(\frac{g_{0}}{g_{1}}\right) \cdot\left(a_{4}+a_{5} \cdot \sigma_{i}\right)+a_{5} \cdot \sigma_{i}+a_{7} \cdot T_{L}+a_{3}$ eq.(10)

Onde:

$\sigma_{\mathrm{L}}=$ tensão superficial/interfacial do líquido corrigida em $\mathrm{mN} / \mathrm{m}$;

$\sigma_{\mathrm{i}}=$ tensão superficial indicada no multímetro em $\mathrm{V}$;

$\mathrm{T}_{\mathrm{L}}=$ temperatura do líquido $\mathrm{em}{ }^{\circ} \mathrm{C}$;

$\rho_{\mathrm{L}}=$ massa específica do líquido em $\mathrm{g} / \mathrm{cm}^{3}$;

$\rho_{\mathrm{ar}}=$ massa específica do ar em $\mathrm{g} / \mathrm{cm}^{3}$;

$\mathrm{g}_{0}=$ aceleração da gravidade no local da calibração em $\mathrm{m} / \mathrm{s}^{2}$;

$\mathrm{g}_{1}=$ aceleração da gravidade no local de utilização do tensiômetro $\mathrm{m} / \mathrm{s}^{2}$;

$a_{0}, a_{1}, a_{2}, a_{3}, a_{4}, a_{5}, a_{6}, a_{7}$ e $a_{8}$ são constantes, e eu valores são:

$a_{0}=0,7250$

$a_{1}=0,00016853 \mathrm{~g} / \mathrm{m}^{3}$

$\mathrm{a}_{2}=0,039955 \mathrm{~g} \cdot \mathrm{m}^{3} \cdot \mathrm{V}^{-1}$

$a_{3}=0,012798$ 


$$
\begin{aligned}
& a_{4}=0,417473 \mathrm{mN} / \mathrm{m} \\
& a_{5}=98,972922 \mathrm{mN} \cdot \mathrm{m}^{-1} \cdot \mathrm{V}^{-1} \\
& a_{6}=0,763219 \mathrm{mN} \cdot \mathrm{m}^{-1} \cdot \mathrm{V}^{-1} \\
& a_{7}=-1,235590 \mathrm{mN} \cdot \mathrm{m}^{-1} \cdot{ }^{\circ} \mathrm{C}^{-1} \\
& a_{8}=24,841177 \mathrm{mN} / \mathrm{m}
\end{aligned}
$$

Todos os parâmetros acima constam no Certificado DIMCI 0488/2012 página 4, expedido pelo Inmetro para o Laboratório de Caracterização de Fluidos da PUC - Rio. Utilizou-se a tensão medida média da Tabela 6 para o cálculo da TIF.

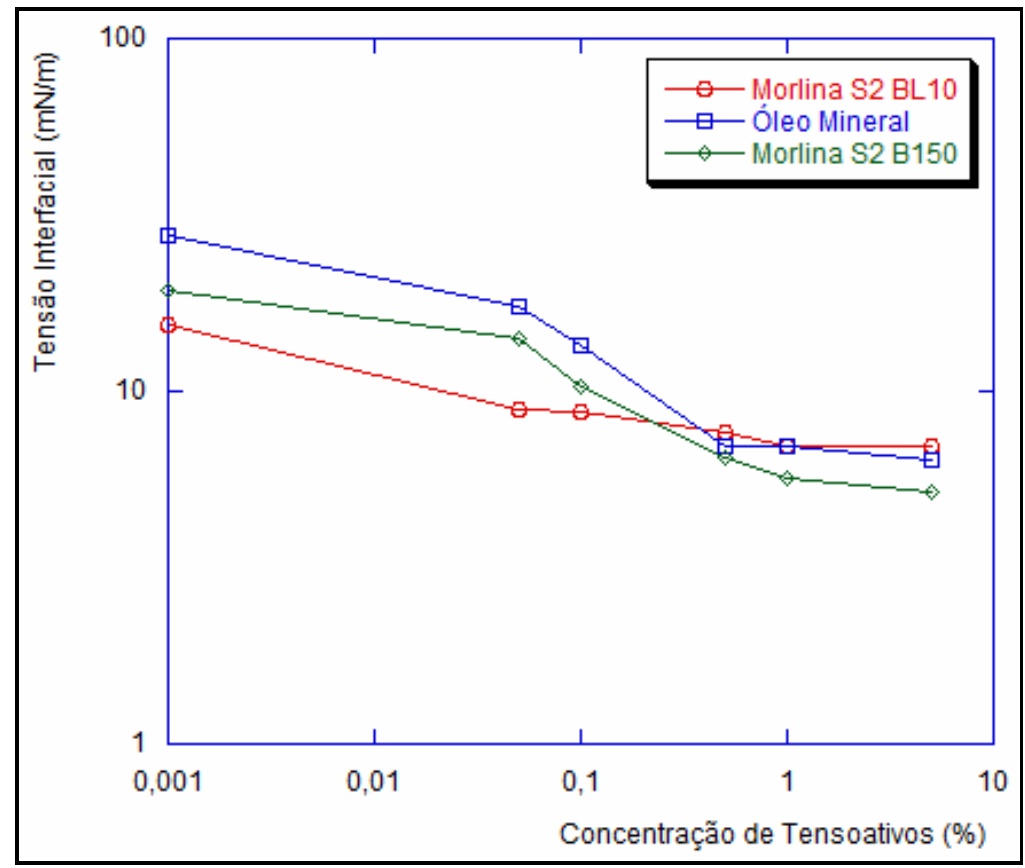

Figura 15: Tensão Interfacial entre as fases oleosas e a água.

Tabela 7: Valores calculados de tensão interfacial.

\begin{tabular}{|c|c|c|c|c|c|c|}
\hline $\begin{array}{c}\text { Concentração de } \\
\text { Tensoativos }\end{array}$ & $\mathbf{5 \%}$ & $\mathbf{1 \%}$ & $\mathbf{0 , 5} \%$ & $\mathbf{0 , 1} \%$ & $\mathbf{0 , 0 5 \%}$ & $\mathbf{0 , 0 0 1 \%}$ \\
\hline Morlina S2 BL10 & \multicolumn{5}{|l|}{} \\
\hline Tensão Interfacial (mN/m) & 7 & 7 & 7,7 & 8,8 & 8,9 & 15,4 \\
\hline Morlina S2 B150 & \multicolumn{7}{|l|}{} & & \\
\hline Tensão Interfacial (mN/m) & 5,2 & 5,7 & 6,5 & 10,3 & 14,1 & 19,2 \\
\hline Óleo Mineral & & & & & & \\
\hline Tensão Interfacial (mN/m) & 6,4 & 7,0 & 7,0 & 13,5 & 17,5 & 27,7 \\
\hline
\end{tabular}


Os valores encontrados na Tabela 7, e plotados na Fig. 15, são de extrema importância, pois a partir deles é que se pôde confirmar experimentalmente a escolha pelas concentrações de tensoativos utilizadas nos testes do item 4.2.

No início dos testes há uma queda acentuada no valor da tensão interfacial nos sistemas com baixa concentração de tensoativos. Depois esse valor tende a estabilizar, aproximando-se de um patamar.

Em todas as fases oleosas estudadas, o valor de tensão interfacial tende a estabilizar um pouco antes de 1\%, ou seja, concentrações superiores a essa, já não promovem alterações significativas no valor da tensão interfacial. Este foi o motivo que se levou a escolha de $1 \%$ e $5 \%$ em concentração de tensoativos para a realização dos testes.

\section{2 Resultados dos Testes Reológicos}

A seguir serão apresentados os resultados dos testes reológicos das emulsões preparadas com os óleos descritos no Item 3.1.1. A ordem será a mesma para cada um dos óleos. Primeiramente serão expostos os testes com $5 \%$ (cinco por cento) em peso dos tensoativos, e em seguida mostrados os resultados dos testes com $1 \%$ (um por cento) em peso dos tensoativos.

A Fig. 16 mostra os resultados das curvas de escoamento dos óleos usados neste trabalho. Observa-se que os óleos têm comportamento Newtoniano, com viscosidade constante. O óleo Morlina S2 B150 é o mais viscoso, seguido do Óleo Mineral e do Morlina S2 BL10.

Para melhor explicar alguns resultados, foram feitas imagens de microscopia das emulsões, bem como um teste de gota para verificar a natureza da emulsão, ou seja, se a emulsão é de água em óleo $(\mathrm{A} / \mathrm{O})$ ou óleo em água $(\mathrm{O} / \mathrm{A})$.

As imagens das emulsões foram obtidas por meio do microscópio ótico da marca Zeiss, modelo Imager M2m, totalmente motorizado, operando em luz 
transmitida. Na captura de imagens foi empregada uma câmera CCD AxioCam MRc5, com uma lente de cem vezes (100x) de aumento está originando imagens.

A prova de gota é uma forma rápida e simples de determinar se uma emulsão é de óleo em água $(\mathrm{O} / \mathrm{A})$ ou água em óleo $(\mathrm{A} / \mathrm{O})$. Algumas gotas da emulsão são derramadas em um tubo de ensaio, ou béquer, contendo água e outro contendo o óleo usado para fazer as emulsões. Caso as gotículas da emulsão dispersarem na amostra de água e não na amostra de óleo, a emulsão é caracterizada como O/A. Da mesma forma, é uma emulsão de $\mathrm{A} / \mathrm{O}$, quando as gotículas desta emulsão se dispersarem no óleo e permanecem intactas no tubo de ensaio, ou béquer, contendo a fase aquosa.

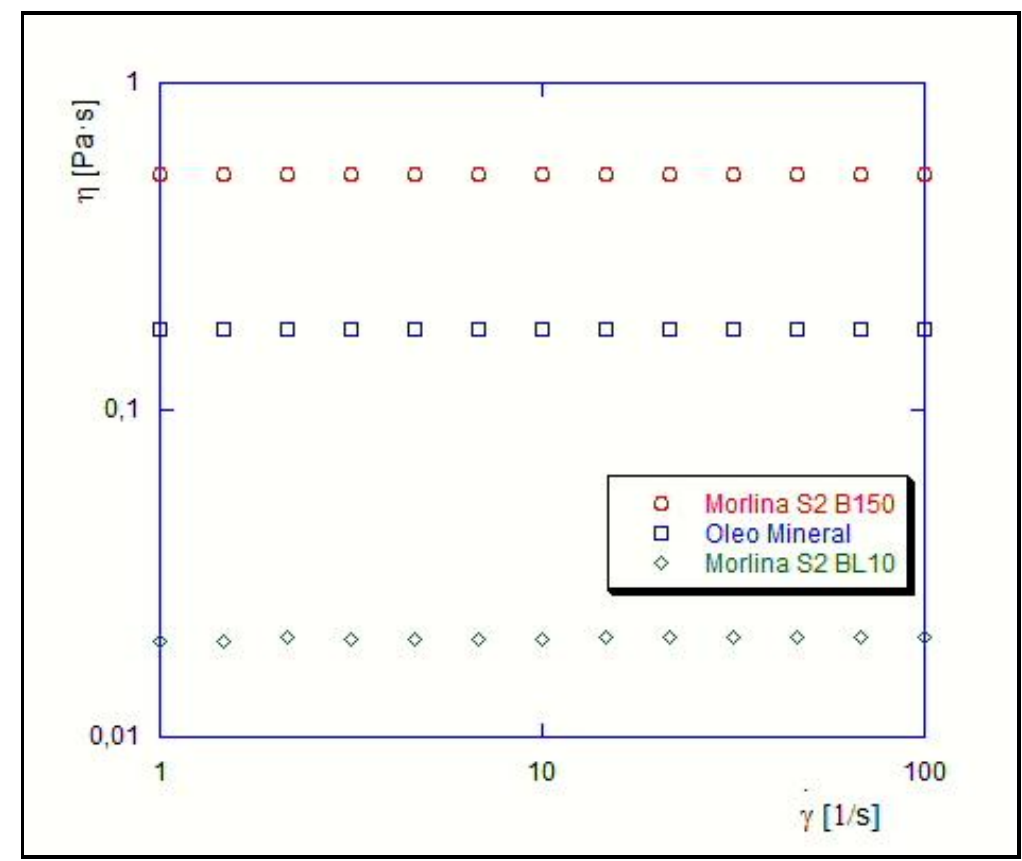

Figura 16: Viscosidade dos óleos a $20^{\circ} \mathrm{C}$.

\subsection{1}

Resultados - Shell Morlina S2 BL 10 com 5\% de tensoativos

Para o estudo das emulsões preparadas com Shell Morlina S2 BL 10 foi selecionada a geometria de cilindro concêntrico de fenda dupla (Double Gap $D G)$, como descrito no item 3.3.2 deste estudo. 


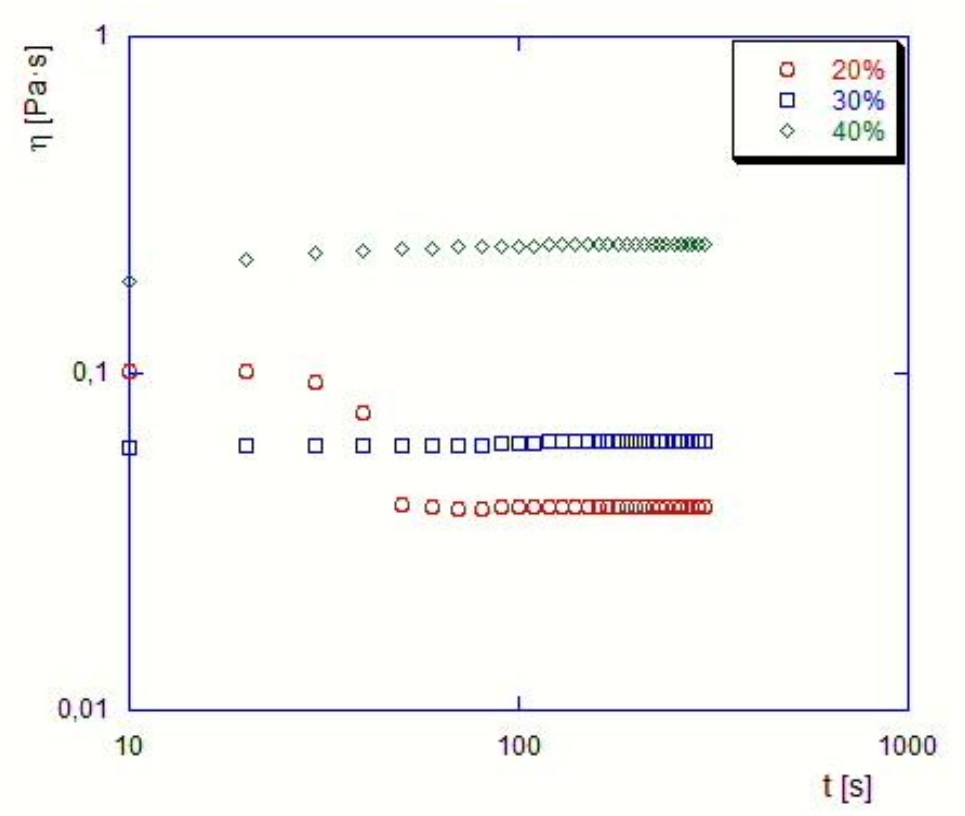

Figura 17: Viscosidade vs. tempo, taxa de deformação constante de $21 / \mathrm{s}$ para o corte de água de $20 \%$ e 0,01 1/s para os cortes de água, $30 \%$ e $40 \%$, Morlina S2 $\mathrm{BL} 10$ a $20^{\circ} \mathrm{C}$ e $5 \%$ de tensoativos.

Pelos resultados mostrados na Fig. 17 podem-se obter os tempos necessários para alcançar o regime permanente. Tempo a ser utilizado na obtenção dos dados das curvas de escoamento. Portanto, foram utilizados os seguintes tempos: 100 s para o corte de água de $20 \%, 120$ s para o corte de água de $30 \%$ e 140 s para o corte de água de $40 \%$.

A taxa de deformação apresentada na Fig. 17 foi de 2 1/s para o corte de água de $20 \%$, por dois motivos. O primeiro para obter torques confiáveis, ou seja, valores de torque acima da sensibilidade do reômetro utilizado (Phyica 301), e o segundo motivo para que as emulsões entrassem em regime permanente. Os demais cortes de água, 30\% e 40\%, a taxa de deformação utilizada foi de $0,011 / \mathrm{s}$. 

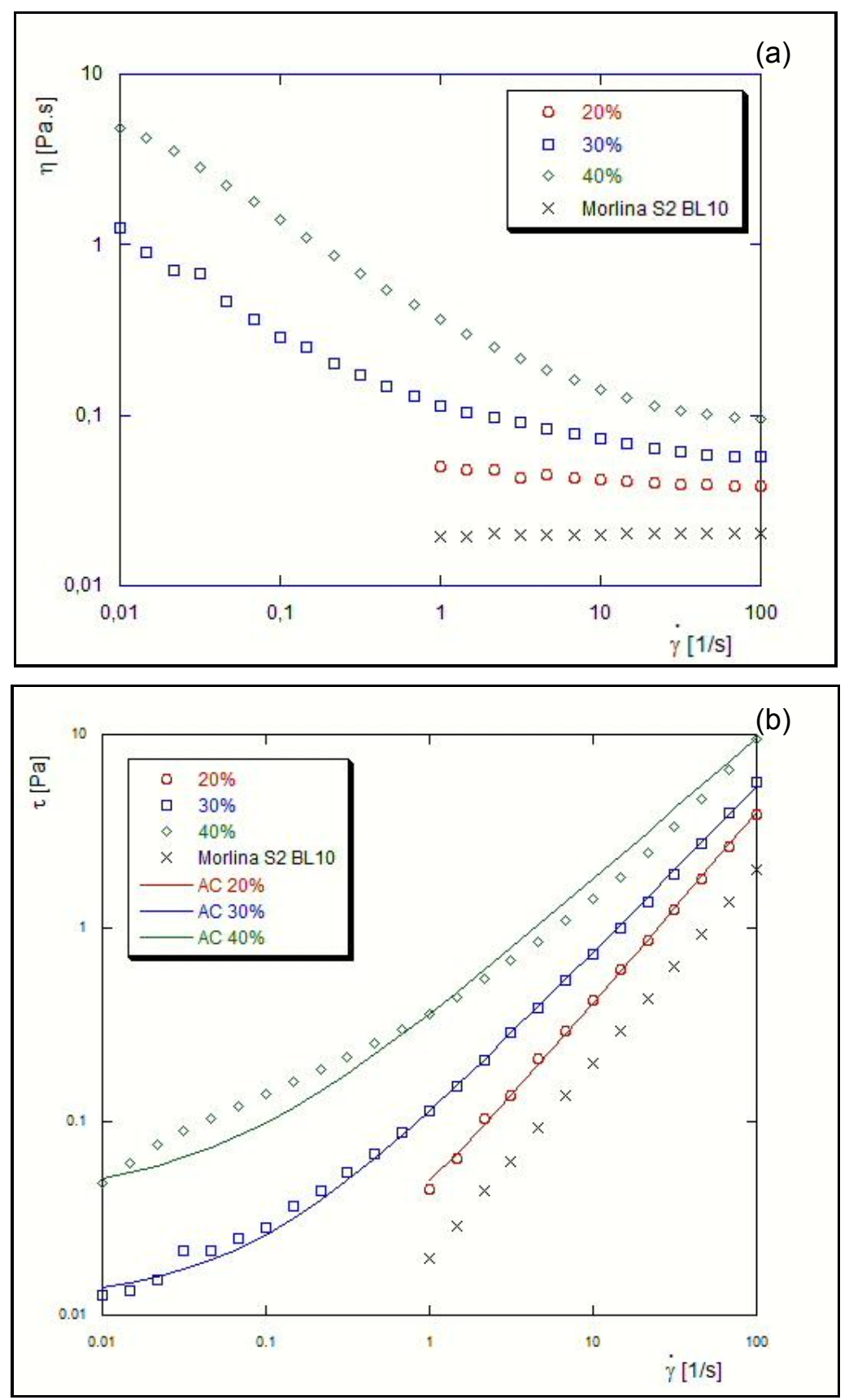

Figura 18: Curvas de escoamento: (a) viscosidade vs. taxa de deformação e (b) tensão de cisalhamento vs. taxa de deformação, Morlina S2 BL10 a $20{ }^{\circ} \mathrm{C}$ e $5 \%$ de tensoativos .

Os comportamentos das emulsões, assim como a viscosidade, variaram de acordo com o corte de água. Como era esperado para este óleo, ou seja, a viscosidade está crescendo com o aumento da concentração de água. Na Fig. 18 (a) e (b) também são mostrados os Ajustes de Curvas (AC). 
Pode se obsevar que o modelo de um fluido newtoniano se ajusta ao corte de água de $20 \%$, enquanto o modelo de Herschel-Bulkley se adapta melhor aos cortes de água de $30 \%$ e $40 \%$. Os parâmetros da equação que melhor se amoldam ao corte de água de $20 \%$ são: coeficiente angular de 0.04 e coeficiente linear de 0.01 . Na Tabela 8 estão os parâmetros utilizados para obter o ajuste de curva dos cortes de água de $30 \%$ e $40 \%$.

Tabela 8: Índices das emulsões com Morlina S2 BL10 e 5\% de tensoativos.

\begin{tabular}{|c|c|c|c|c|c|}
\hline \multicolumn{5}{|c|}{ Morlina S2 BL 10 } \\
\hline Corte de água & Tensão Limite de Escoamento (Pa) & $\mathbf{k}$ & $\mathbf{n}$ & $\mathbf{R}^{\mathbf{2}}$ & Modelo de fluido \\
\hline $20 \%$ & - & - & - & 0,999 & Newtoniano \\
\hline $30 \%$ & 0,012 & 0,102 & 0,860 & 0,998 & Herschel-Bulkley \\
\hline $40 \%$ & 0,040 & 0,322 & 0,737 & 0,992 & Herschel-Bulkley \\
\hline
\end{tabular}

Os índices são, respectivamente, $\mathrm{k}$ é o índice de consistência, n é o índice power law e $\mathrm{R}^{2}$ é coeficiente de determinação (é uma medida de adequação de um modelo estatístico linear generalizado, o valor de $R^{2}$ varia entre 0 e 1 , indicando o quanto o modelo consegue ilustrar os valores observados. Quanto maior o $\mathrm{R}^{2}$, melhor ele se ajusta ao modelo).

Algumas observações complementares podem ser retiradas da Tabela 8 para uma análise das emulsões com 30\% e 40\% de corte de água. Quanto maior o corte de água, maior a tensão limite de escoamento, pois a viscosidade aumenta neste sentido. Também maior é o índice de consistência $k$, ao passo que menor é índice power law $\mathrm{n}$, como este índice é menor que 1, indica um comportamento pseudo-plástico para todas as emulsões.

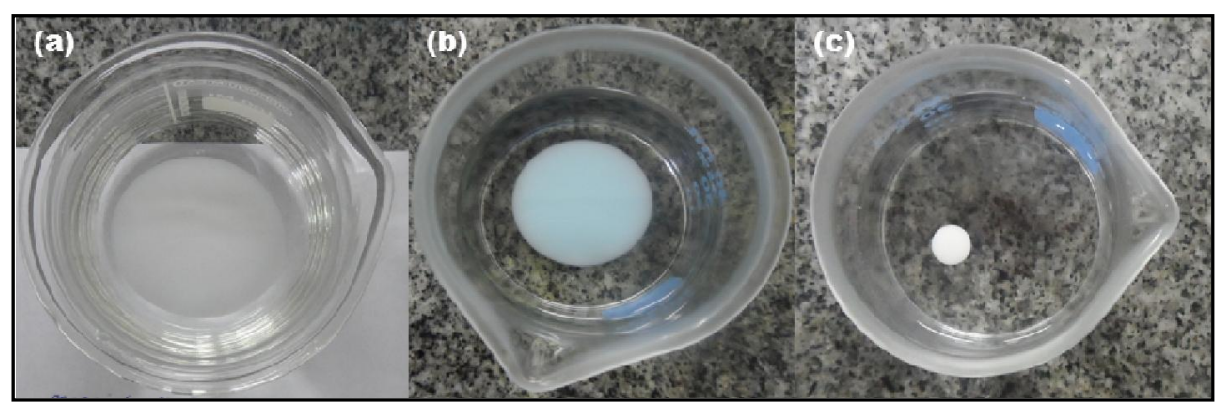

Figura 19: Prova de gota com Morlina S2 BL10 e 5\% de tensoativos, (a) $20 \%$, (b) $30 \%$ e (c) $40 \%$ de corte de água. 
De acordo com a prova de gota realizada, todas as emulsões preparadas com o Morlina S2 BL10 e 5\% de tensoativos, em todos os cortes de água (20\%, $30 \%$ e $40 \%$ ), são emulsões de água em óleo. Assim, resultados da prova de gota estão concordando com os resultados dos testes reológicos apresentados.

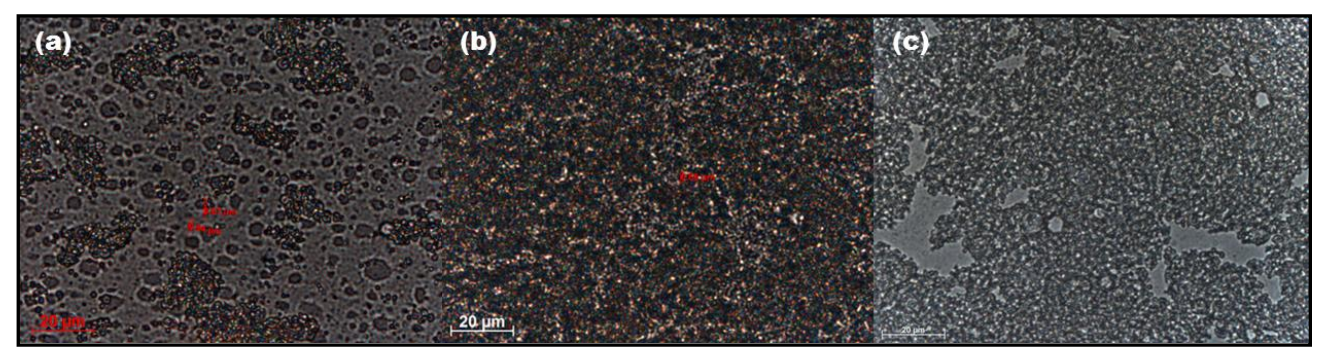

Figura 20: Mircoscopia das emulsões com Morlina S2 BL10 e 5\% de tensoativos: (a) 20\%, (b) $30 \%$ e (c) $40 \%$ de corte de água.

A partir da microscopia das emulsões produzidas com Morlina S2 BL10 e $5 \%$ de tensoativos, pode-se obter um tamanho aproximado das gotas. Em todos os cortes de água representados na Fig. 20, tem-se um tamanho entre 0,5 e 2 $\mu \mathrm{m}$ para as gotas de água que estão dispersas no óleo.

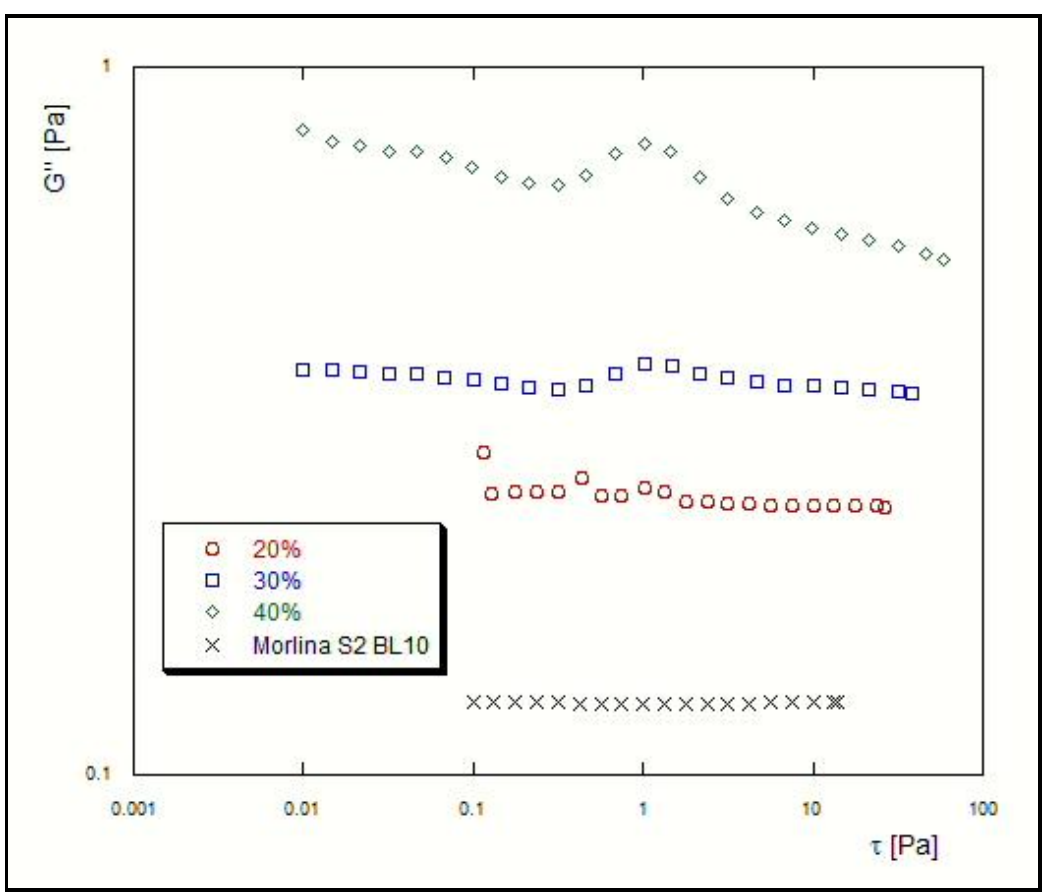

Figura 21: Varredura de tensão Morlina S2 BL10 a $20{ }^{\circ} \mathrm{C}$ e $5 \%$ de tensoativos. 
Um resultado bem diferente foi obtido nos testes de varredura de tensão (Stress Sweep), em todos os cortes de água estudados, 20\%, 30\% e 40\%. O módulo elástico ou de armazenamento G' medido ficou igual a 0 (zero) ou com valores muito pequenos, da ordem de $10^{-3}$. Por isso a Fig. 21 apresenta apenas os valores do módulo viscoso ou de perda G". Este resultado indica que as emulsões encontradas são fluidos com comportamento puramente viscoso, isto é, sem elasticidade.

Tal comportamento pode ser justificado pela baixa viscosidade do óleo, aliado ao fato das emulsões terem um tamanho de gotas muito pequeno e, ainda, cortes de água não serem tão expressivos, a ponto de fazer com que surjam os módulos elásticos nas emulsões preparadas.

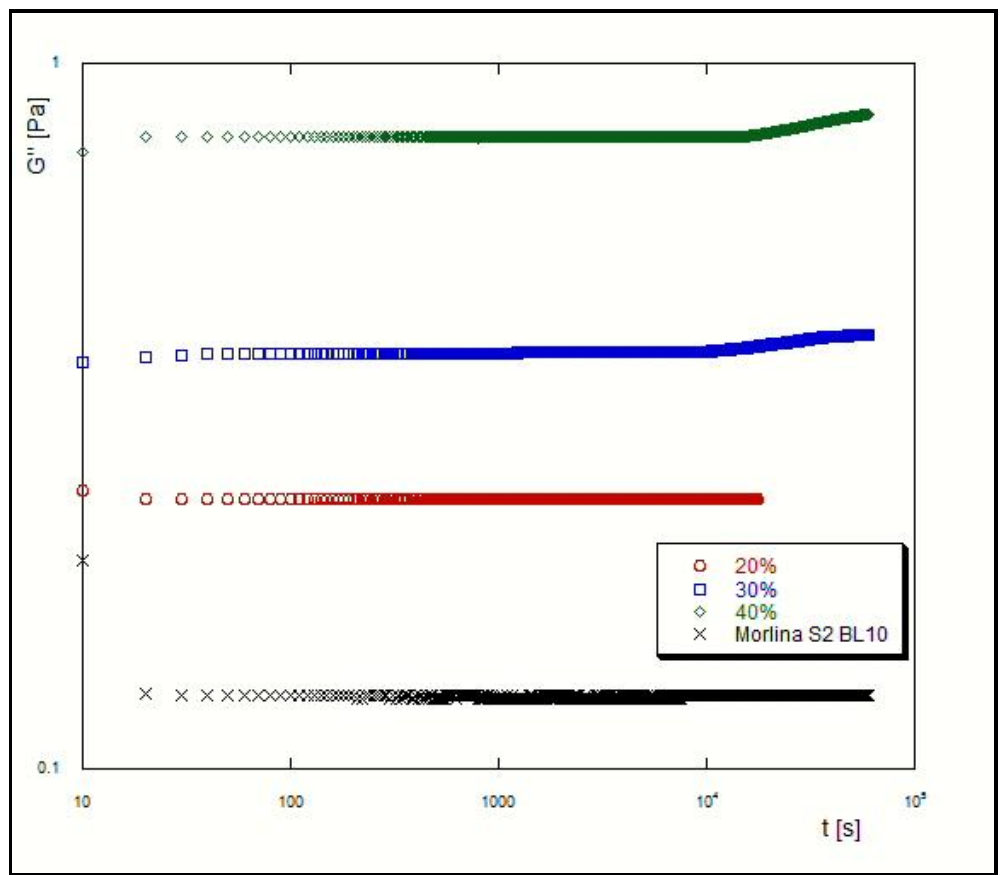

Figura 22: Varredura no tempo Morlina S2 BL10 a $20{ }^{\circ} \mathrm{C}$ e $5 \%$ de tensoativos.

O teste de varredura no tempo (Time Sweep) confirmou os resultados do teste de varredura de tensão, e também não apresentou valores representativos de módulo elástico ou de armazenamento G'. O dado de entrada deste teste foi a menor tensão que proporcionou um torque dentro do limite de sensibilidade do reômetro utilizado (Phyica 301), neste caso os testes foram realizados com $1 \mathrm{~Pa}$ de tensão e frequência de $1 \mathrm{~Hz}$. 
Vale relatar que, todas as emulsões apresentaram tempo de estabilidade, nesse teste (Time Sweep), superiores a 7000s, tempo suficiente para a realização de todos os testes anteriores.

Para esta concentração de tensoativos, $5 \%$, também foram realizados testes a $0^{\circ} \mathrm{C}$ para verificar o comportamento das emulsões a esta temperatura, pois essas emulsões apresentaram uma boa estabilidade após o seu preparo, do ponto de vista macroscópico. A investigação seguiu a mesma linha acima apresentada, dois testes oscilatórios (Stress Sweep e Time Sweep) e dois testes rotacionais (Shear Rate Constant e Flow Curve).

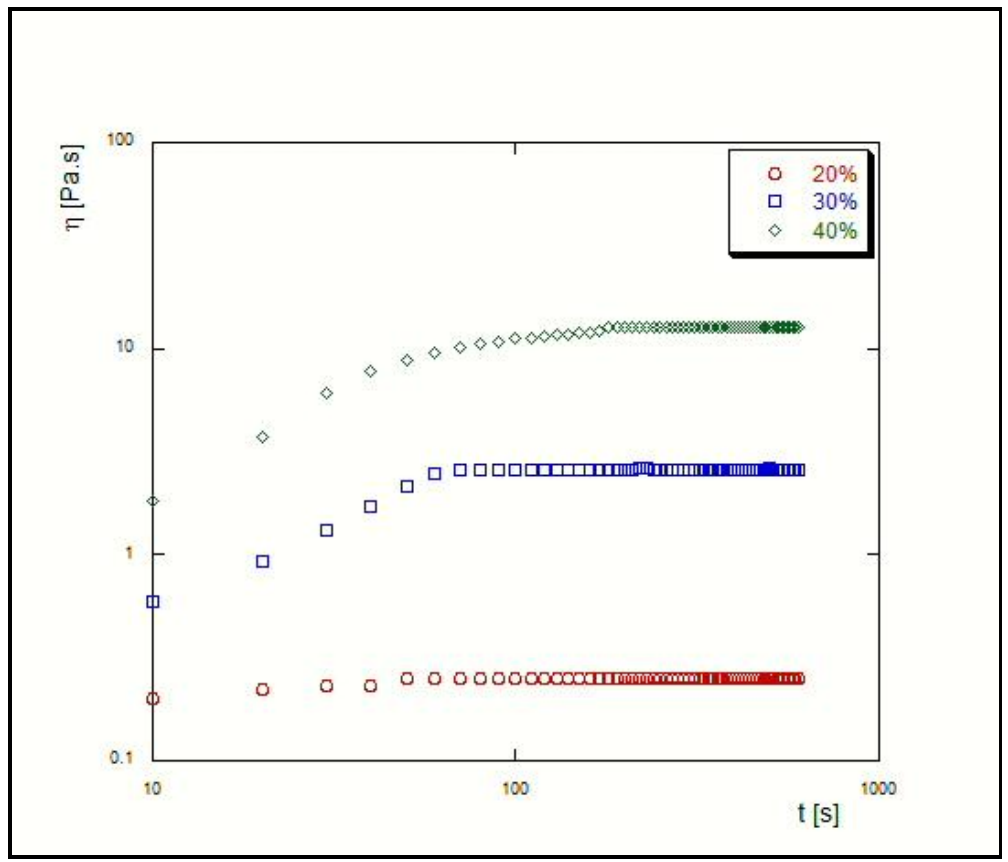

Figura 23: Viscosidade vs. tempo, taxa de deformação constante 0,01 1/s, Morlina $\mathrm{S} 2 \mathrm{BL} 10$ a $0^{\circ} \mathrm{C}$ e $5 \%$ de tensoativos.

Com a diminuição da temperatura e com consequente aumento da viscosidade, pode-se trabalhar com faixas de taxas de deformação menores. A Fig. 23 mostra que uma taxa de cisalhamento de $0,011 / \mathrm{s}$ foi utilizada com bons resultados.

Da Fig. 23 pode se obter os tempos necessários para se utilizar nas curvas de escoamento. Foram usados os seguintes tempos: 100s para o corte de água de $20 \%$ e $30 \%$ e 200 s para o corte de água de $40 \%$. 

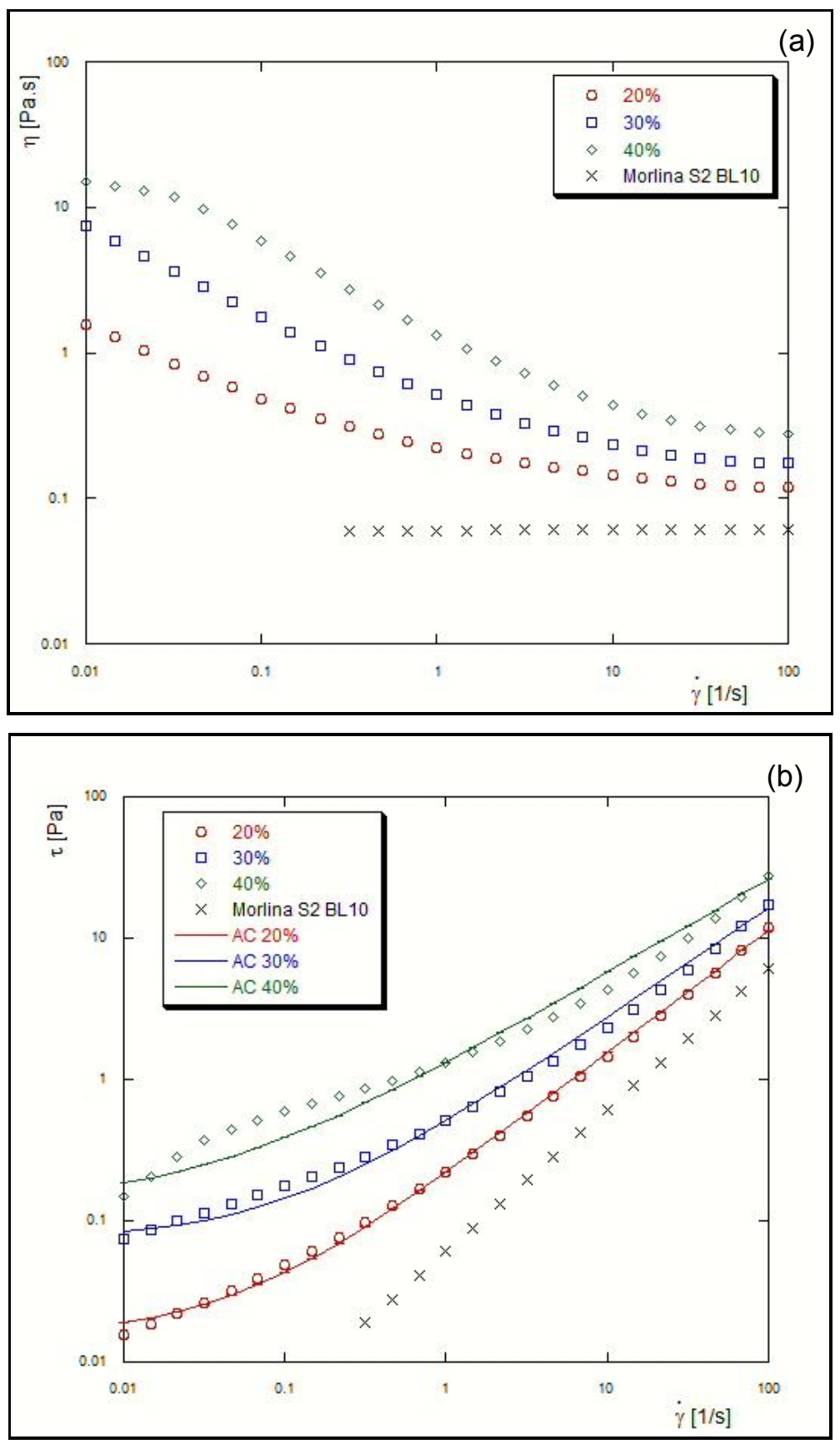

Figura 24: Curvas de escoamento: (a) viscosidade vs. taxa de deformação e (b) tensão de cisalhamento vs. taxa de deformação, Morlina S2 BL10 a $0^{\circ} \mathrm{C}$ e $5 \%$ de tensoativos.

O comportamento das curvas de escoamento para as emulsões estudadas não variaram com o decréscimo da temperatura de $20^{\circ} \mathrm{C}$ para $0^{\circ} \mathrm{C}$, apenas as viscosidades das mesmas aumentaram, como já era aguardado. A Figs. 24 (a) e (b) apresentam os resultados obtidos. As emulsões de todos os cortes de água 
apresentam comportamentos que se aproximam de um fluido de HerschelBulkley. Na Tabela 9 estão os parâmetros utilizados para obter o ajuste de curva dos cortes de água.

Tabela 9: Índices das emulsões com Morlina S2 BL10 a $0^{\circ} \mathrm{C}$ e $5 \%$ de tensoativos.

\begin{tabular}{|c|c|c|c|c|c|}
\hline \multicolumn{7}{|c|}{ Morlina S2 BL 10 } \\
\hline Corte de água & Tensão Limite de Escoamento (Pa) & $\mathbf{k}$ & $\mathbf{n}$ & $\mathbf{R}^{\mathbf{2}}$ & Modelo de fluido \\
\hline $20 \%$ & 0,0151 & 0,207 & 0,870 & 0,998 & Herschel-Bulkley \\
\hline $30 \%$ & 0,072 & 0,441 & 0,785 & 0,994 & Herschel-Bulkley \\
\hline $40 \%$ & 0,130 & 1,200 & 0,670 & 0,984 & Herschel-Bulkley \\
\hline
\end{tabular}

Do mesmo modo, certas observações podem ser retiradas da Tabela 9 a partir da variação de temperatura citada anteriormente. Quanto maior o corte de água, maior a tensão limite de escoamento, já que a viscosidade aumenta neste sentido, igualmente obtemos um maior índice de consistência $\mathrm{k}$ e um menor índice power law $\mathrm{n}$, como este índice é menor que 1 , indica um comportamento pseudo-plástico para todas as emulsões.

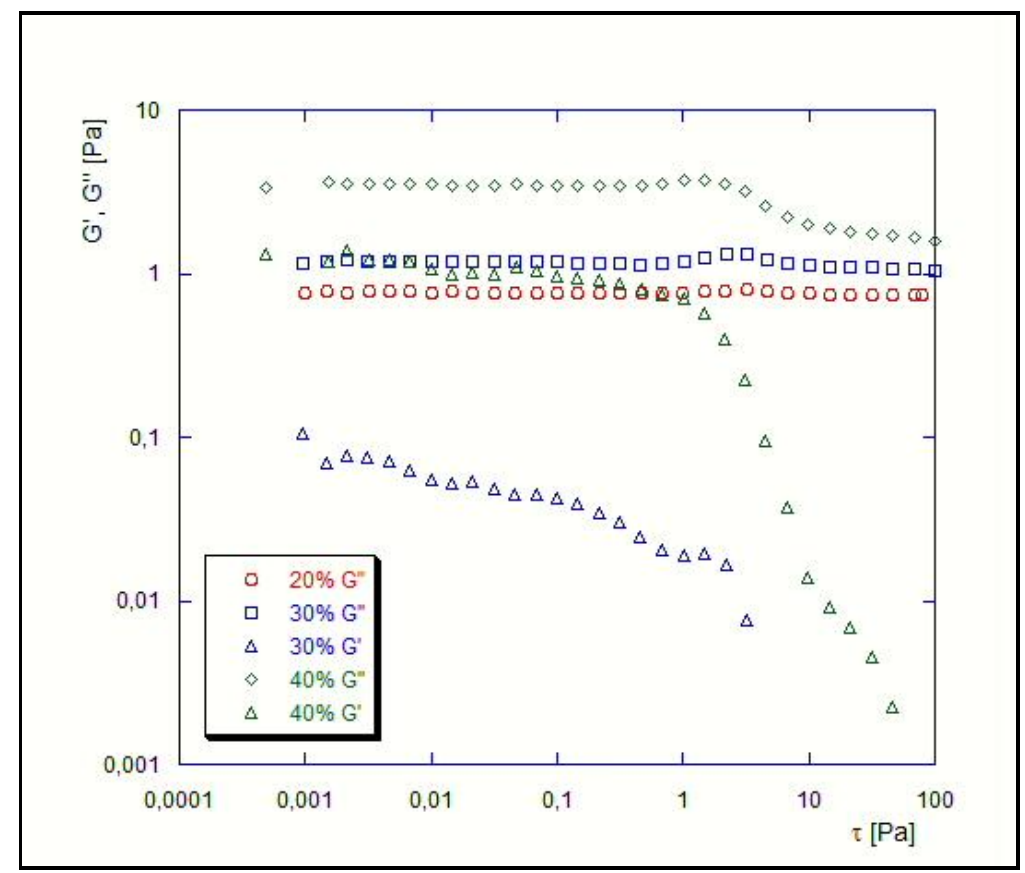

Figura 25: Varredura de tensão Morlina S2 BL10 a $0{ }^{\circ} \mathrm{C}$ e $5 \%$ de tensoativos.

Diferentemente do teste de varredura de tensão feito a $20^{\circ} \mathrm{C}$ para essas emulsões, os módulos elástico ou de armazenamento G' foram significativos nas 
medidas realizadas com as emulsões de $30 \%$ e $40 \%$ de corte de água, indicando a presença de comportamento elástico. Para o corte de água de $20 \%$ o valor medido para o módulo elástico ou de armazenamento $\mathrm{G}^{\prime}$ foi da ordem de $10^{-3}$.

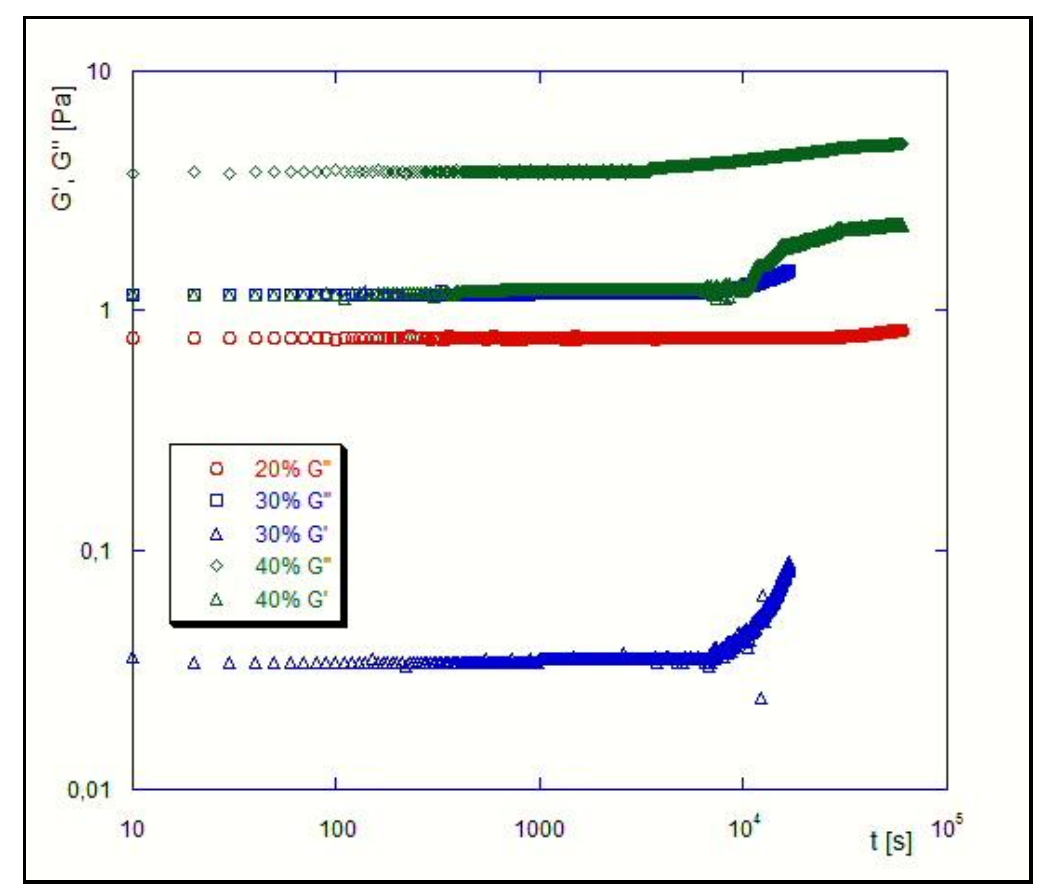

Figura 26: Varredura no tempo Morlina S2 BL10 a $0{ }^{\circ} \mathrm{C}$ e $5 \%$ de tensoativos.

Como o módulo viscoso ou de perda G" medido foi maior que o elástico ou de armazenamento $G$ ' para todas as emulsões estudadas nessa temperatura, o valor utilizado para o teste de varredura no tempo foi $0,1 \mathrm{~Pa}$, pois seria a menor tensão com um torque numa faixa de valor bem confiável para o reômetro usado (Phyica 301). Uma frequência de $1 \mathrm{~Hz}$ foi utilizada para completar os parâmetros do teste.

O teste de varredura no tempo (Time Sweep) confirmou os resultados do teste de varredura de tensão, também não apresentou valores representativos de módulo elástico ou de armazenamento G' para a emulsão com $20 \%$ de corte de água. Da Fig. 26 nota-se que as emulsões apresentaram tempo de estabilidade superior a 6000 s, tempo suficiente para a realização de todos os testes anteriores. 


\subsection{2}

\section{Resultados - Shell Morlina S2 BL 10 com 1\% de tensoativos}

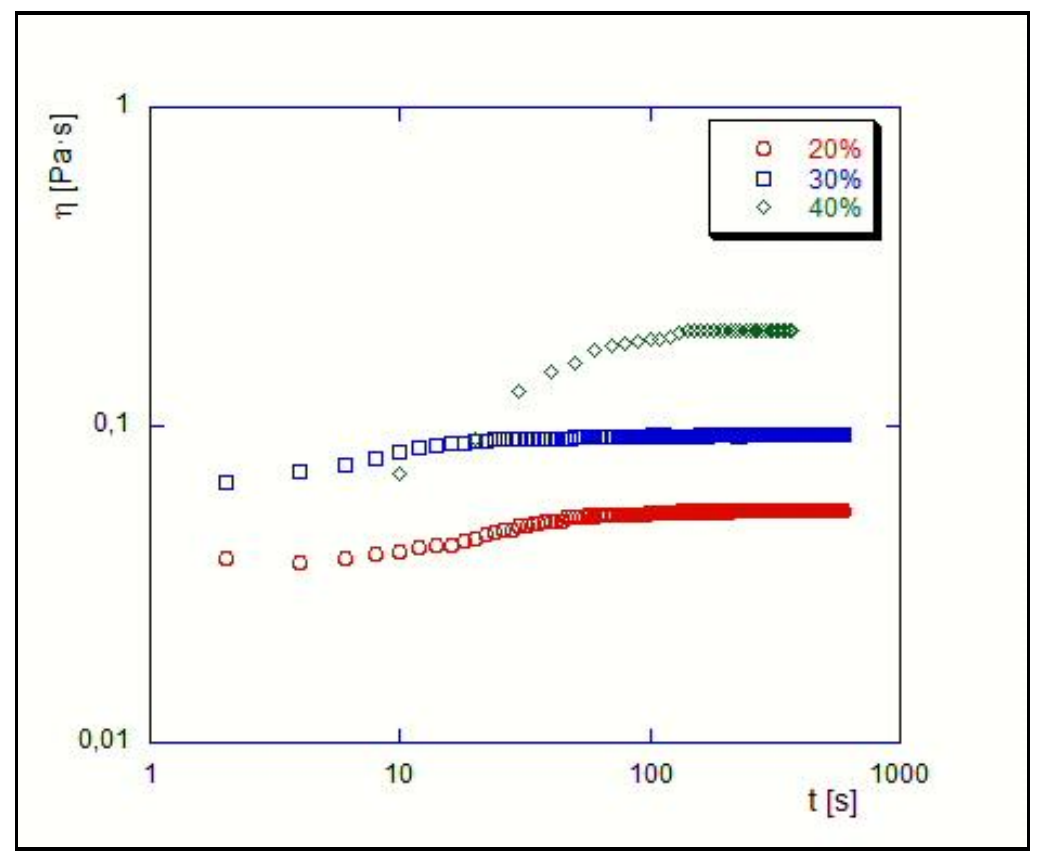

Figura 27: Viscosidade vs. tempo, taxa de deformação constante 0,01 1/s, Morlina $\mathrm{S} 2 \mathrm{BL} 10$ a $20^{\circ} \mathrm{C}$ e $1 \%$ de tensoativos.

Da Fig. 27 pode se conseguir os tempos necessários a ser utilizados nas curvas de escoamento. Portanto, foram utilizados os seguintes tempos: 140s para os cortes de água de $20 \%$ e $30 \%$ e 200 s para o corte de água de $40 \%$. A taxa de deformação apresentada na Fig. 27 foi de 0,01 1/s. 

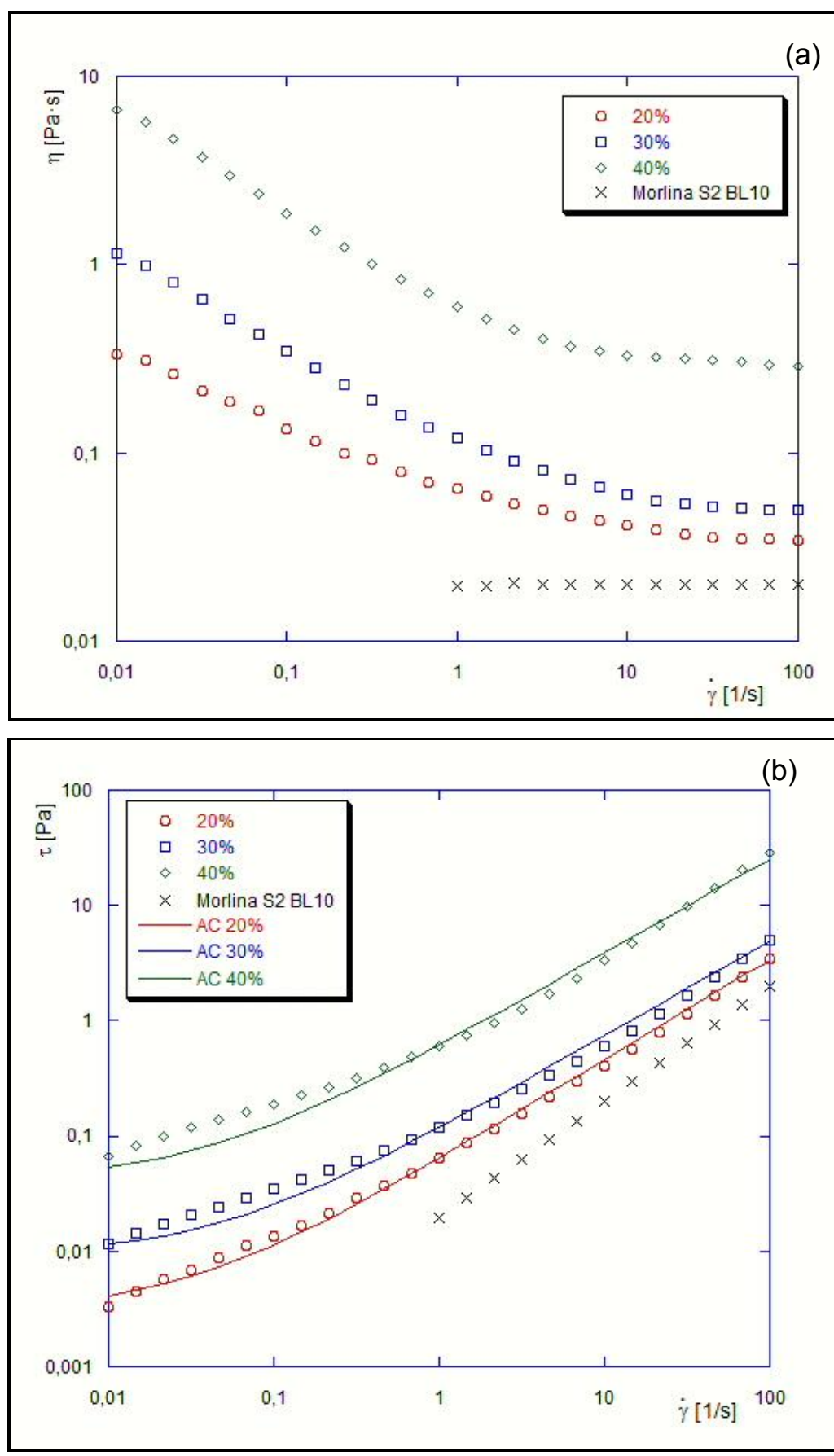

Figura 28: Curvas de escoamento: (a) viscosidade vs. taxa de deformação e (b) tensão de cisalhamento vs. taxa de deformação, Morlina S2 BL10 a $20^{\circ} \mathrm{C}$ e $1 \%$ de tensoativos.

Assim como para as emulsões com $5 \%$ de tensoativos, as viscosidades das emulsões variaram de acordo com o corte de água. Houve um aumento na viscosidade para cada incremento no corte de água. 
A partir do Figs. 28 (a) e (b) pode-se obsevar que o modelo de HerschelBulkley se adapta mais corretamente a todos os cortes de água analisados, $20 \%, 30 \%$ e $40 \%$. Quando a concentração de tensoativos diminuiu, o comportamento mecânico das emulsões também foi alterado, levando a um mesmo tipo de modelo. Na Tabela 10 estão os parâmetros utilizados para obter o ajuste de curva dos cortes de água de $20,30 \%$ e $40 \%$.

Tabela 10: Índices das emulsões com Morlina S2 BL10 e 1\% de tensoativos.

\begin{tabular}{|c|c|c|c|c|c|}
\hline \multicolumn{6}{|c|}{ Morlina S2 BL 10} \\
\hline Corte de água & Tensão Limite de Escoamento $(\mathrm{Pa})$ & $\mathbf{k}$ & $\mathbf{n}$ & $\mathbf{R}^{2}$ & $\begin{array}{l}\text { Modelo de } \\
\text { fluido }\end{array}$ \\
\hline $20 \%$ & 0,0030 & 0,067 & 0,870 & 0,998 & Herschel-Bulkley \\
\hline $30 \%$ & 0,0090 & 0,110 & 0,825 & 0,995 & Herschel-Bulkley \\
\hline $40 \%$ & 0,0400 & 0,580 & 0,820 & 0,995 & Herschel-Bulkley \\
\hline
\end{tabular}

Determinadas ressalvas podem ser retiradas da Tabela 10 para uma análise adicional das emulsões. Da mesma forma ocorrida no item anterior, item 4.2.1, quanto maior o corte de água, maior a tensão limite de escoamento, pois a viscosidade aumenta neste sentido, ainda maior é o índice de consistência k e menor é o índice power law $\mathrm{n}$, como este índice é menor que 1, indica um comportamento pseudo-plástico para todas as emulsões.

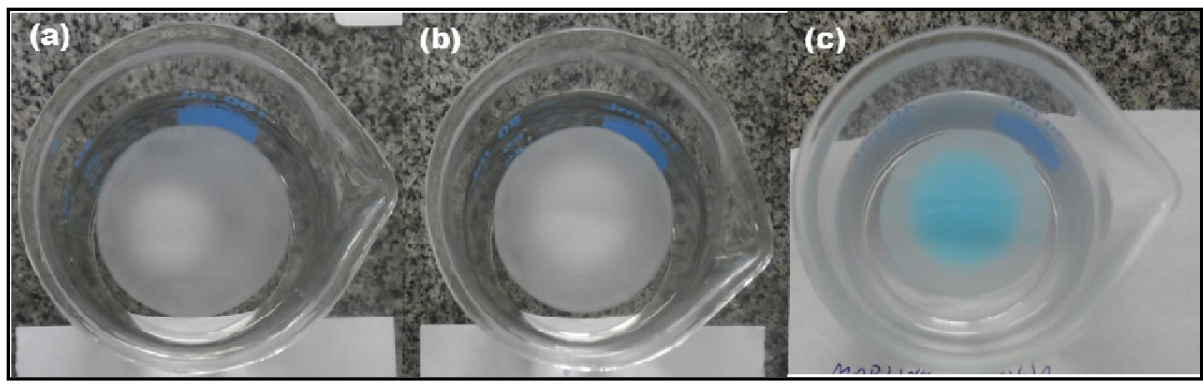

Figura 29: Prova de gota com Morlina S2 BL10 e 1\% de tensoativos, (a) $20 \%$, (b) $30 \%$ e (c) $40 \%$ de corte de água.

De acordo com a prova de gota realizada, todas as emulsões preparadas com o Morlina S2 BL10 e 1\% de tensoativos, em todos os cortes de água (20\%, $30 \%$ e 40\%), são emulsões de água em óleo. Assim, resultados da prova de gota estão aderindo aos resultados dos testes reológicos apresentados. 


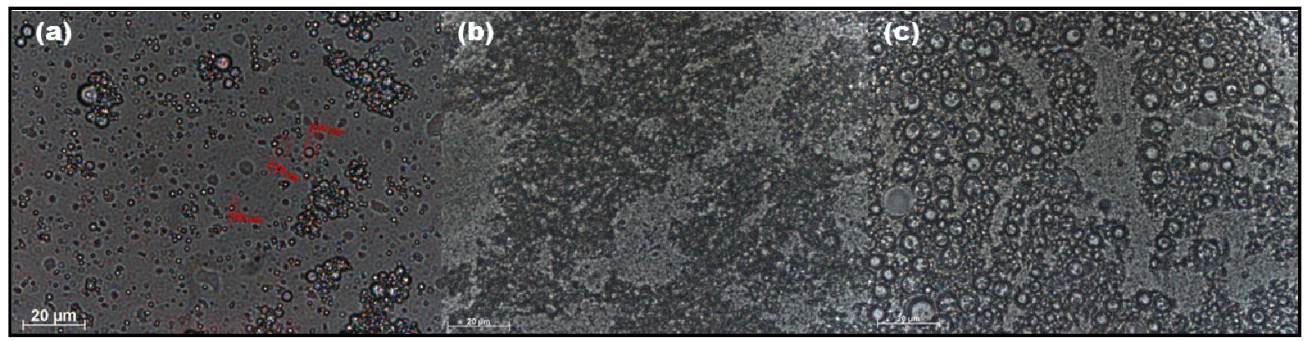

Figura 30: Mircoscopia das emulsões com Morlina S2 BL10 e 1\% de tensoativos: (a) $20 \%$, (b) $30 \%$ e (c) $40 \%$ de corte de água.

A partir da microscopia das emulsões preparadas com Morlina S2 BL10 e $1 \%$ de tensoativos, pode-se obter um tamanho aproximado das gotas. Em todos os cortes de água representados na Fig. 30, tem-se um tamanho entre 0,5 e 2 $\mu \mathrm{m}$ para as gotas de água que estão dispersas no óleo, um tamanho muito semelhante ao encontrado para as emulsões desse mesmo óleo com $5 \%$ de tensoativos.

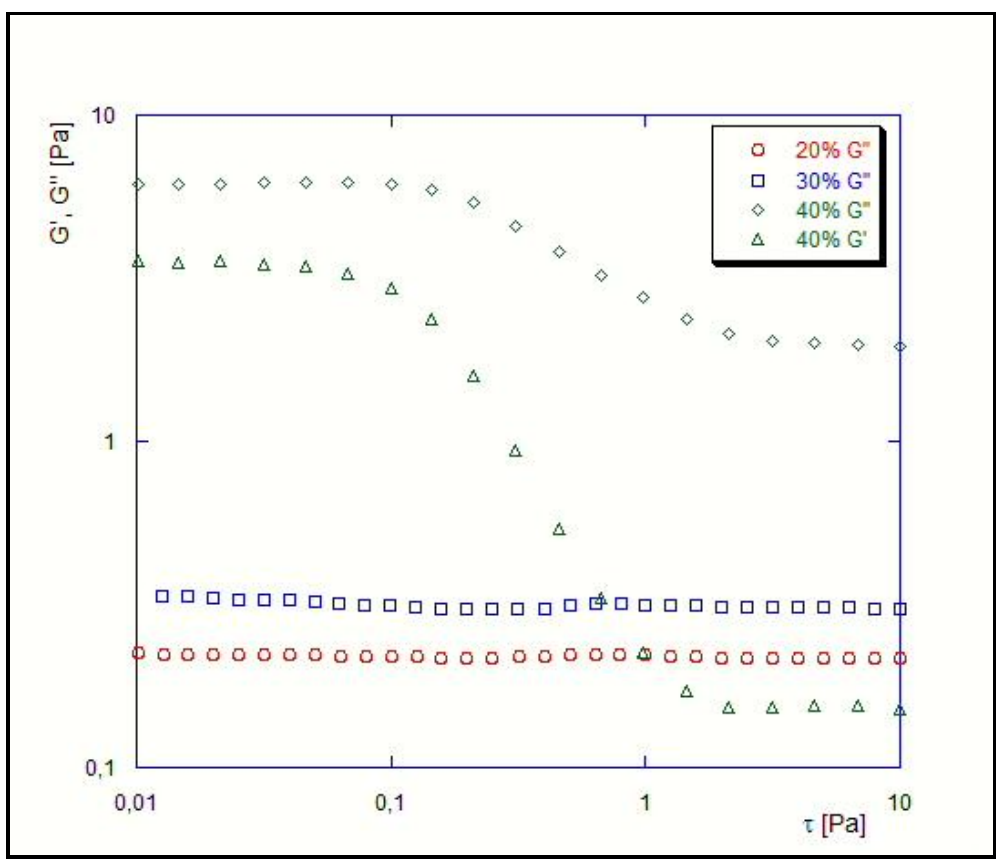

Figura 31: Varredura de tensão Morlina S2 BL10 a $20{ }^{\circ} \mathrm{C}$ e $1 \%$ de tensoativos.

Um resultado próximo das emulsões preparadas com $5 \%$ de tensoativos foi obtido nos testes de varredura de tensão (Stress Sweep). A diferença ficou com o corte de água de $40 \%$, que apresentou elasticidade, já que os valores obtidos para o módulo elástico ou de armazenamento G' foram significativos. 
Nos demais valores de corte de água o módulo elástico ou de armazenamento G' permaneceu igual a 0 (zero), ou com valores muito pequenos.

Assim como as emulsões preparadas com 5\% de tenosativos, este comportamento também pode ser justificado pela baixa viscosidade do óleo, ligado ao fato das emulsões terem um tamanho de gotas muito pequeno e, ainda, cortes de água não serem tão expressivos, a ponto de proporcionar a existência de módulos elásticos nas emulsões preparadas.

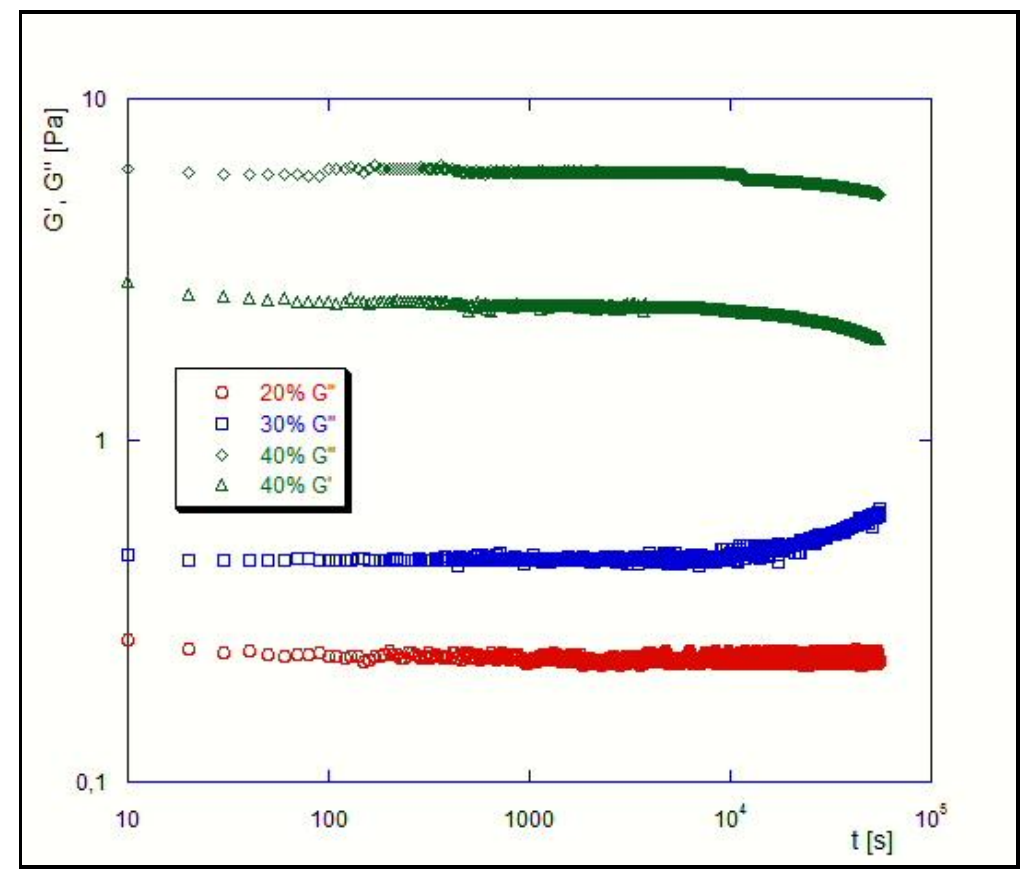

Figura 32: Varredura no tempo Morlina S2 BL10 a $20{ }^{\circ} \mathrm{C}$ e $1 \%$ de tensoativos.

O teste de varredura no tempo (Time Sweep) confirmou os resultados do teste de varredura de tensão, também não apresentou valores representativos de módulo elástico ou de armazenamento G' para os cortes de água de $20 \%$ e $30 \%$. O dado de entrada deste teste foi a menor tensão que proporcionou um torque dentro do limite de sensibilidade do reômetro utilizado (Phyica 301), neste caso os testes foram realizados com 0,1 Pa de tensão e frequência de $1 \mathrm{~Hz}$.

Além disso, como resultado da Fig. 32, pode-se destacar o tempo de estabilidade das emulsões, que para o corte de água de $20 \%$ praticamente não houve alteração durante todo o teste. Para os cortes de água de $30 \%$ e $40 \%$ este tempo ficou superior a 5000s. 


\subsection{3}

\section{Resultados - Shell Morlina S2 B 150 com 5\% de tensoativos}

A seguir serão apresentados os resultados dos testes reológicos das emulsões preparadas com o óleo Shell Morlina S2 B 150. Para o estudo das emulsões preparadas com este óleo foi selecionada a geometria de placas ranhuradas (Cross Hatched), como descrito no item 3.3.2 deste estudo, a correção, necessária para essa geometria, já está introduzida nos resultados.

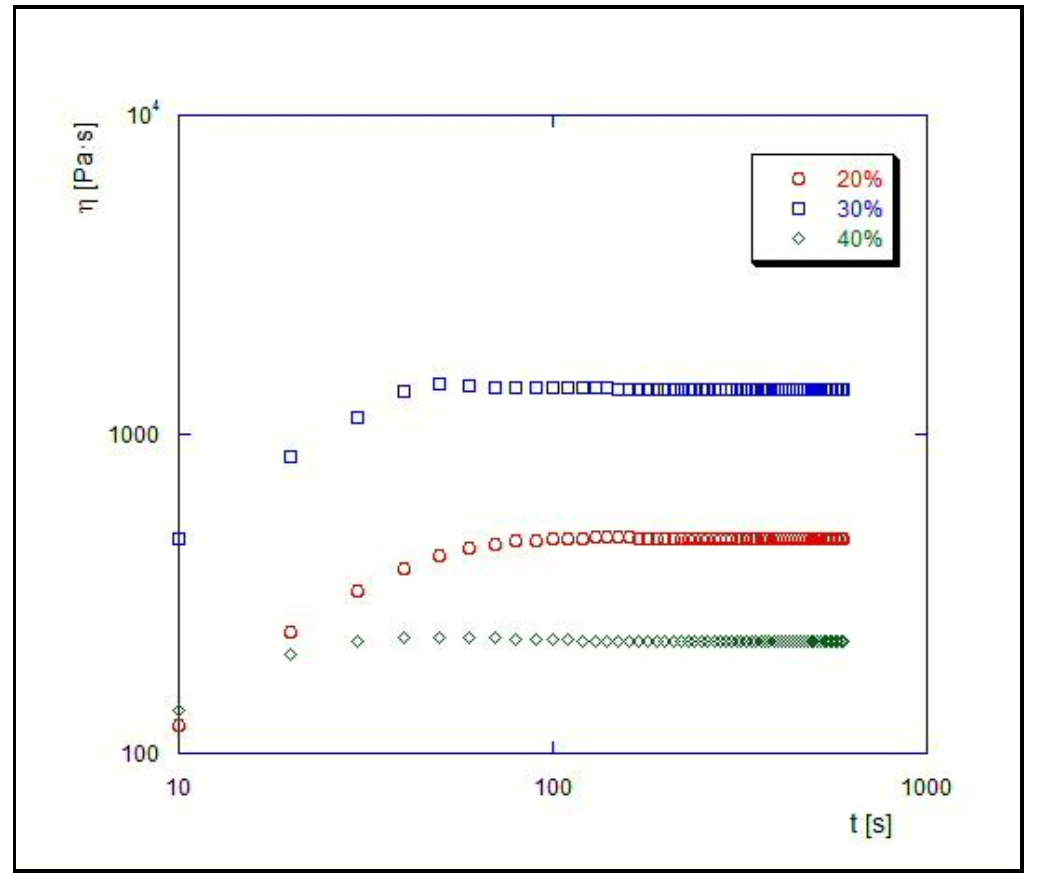

Figura 33: Viscosidade vs. tempo, taxa de deformação constante 0,01 1/s, Morlina S2 B 150 a $20^{\circ} \mathrm{C}$ e $5 \%$ de tensoativos.

Da Fig. 33 pode se obter os tempos necessários para se utilizar nas curvas de escoamento. Assim sendo, foram utilizados os seguintes tempos: 120s para os cortes de água de $20 \%$ e $30 \%$ e 100 s para o corte de água de $40 \%$. 

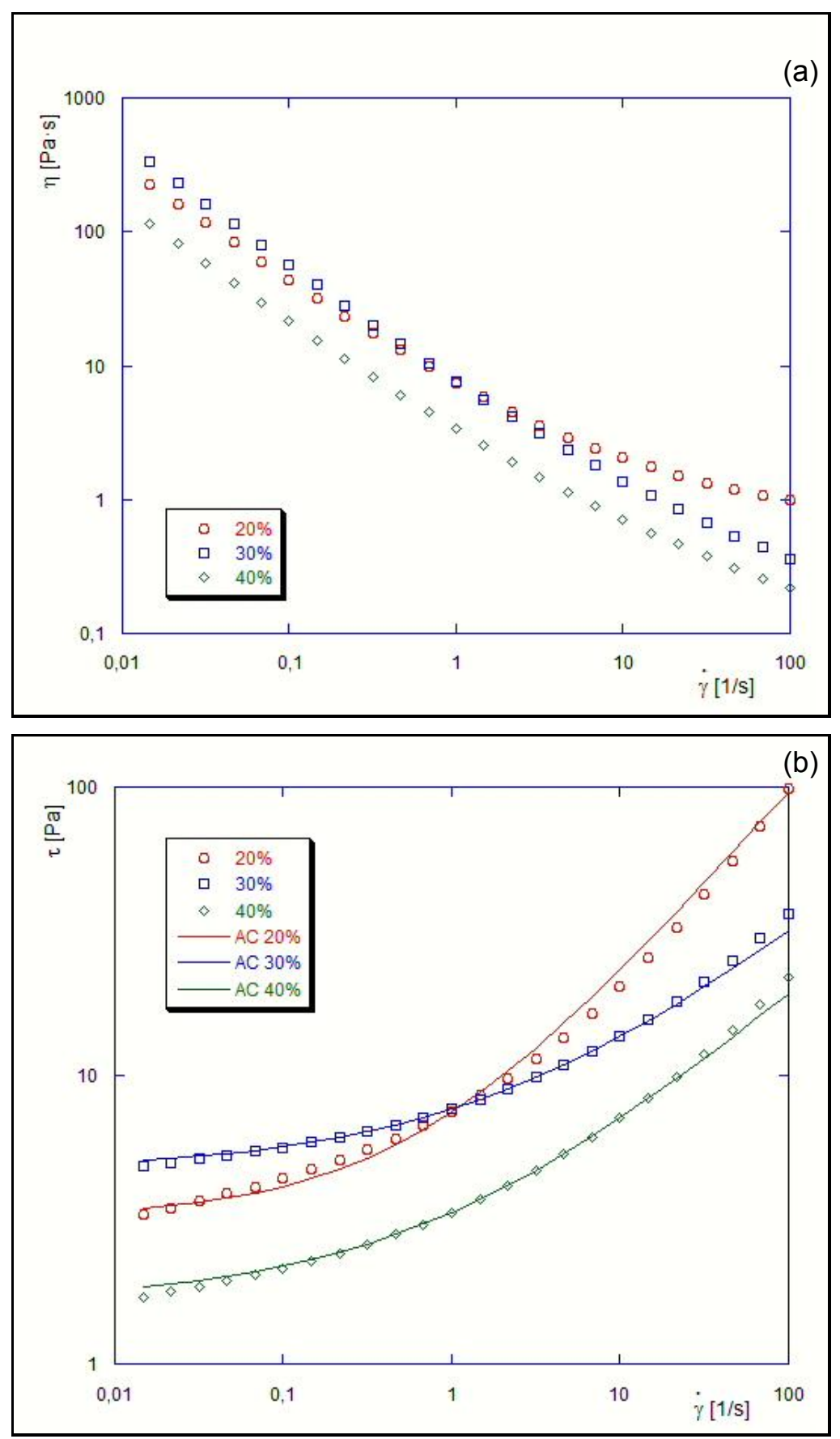

Figura 34: Curvas de escoamento: (a) viscosidade vs. taxa de deformação e (b) tensão de cisalhamento vs. taxa de deformação, Morlina S2 B150 a $20^{\circ} \mathrm{C}$ e $5 \%$ de tensoativos.

As viscosidades das emulsões variaram de acordo com o corte de água, tendo um aumento na viscosidade do corte de água de $20 \%$ para $30 \%$ em baixas taxas de deformação, e uma queda da viscosidade para altas taxas de deformação. Quando o corte de água variou de $30 \%$ para $40 \%$ houve uma 
queda no valor da viscosidade em todas as taxas de deformação estudadas, como apresentado nas Figs. 35 (a) e (b).

As emulsões preparadas com este óleo ficaram bem mais viscosas que as emulsões preparadas com o óleo dos itens anteriores (Shell Morlina S2 BL10). Para todos os cortes de água utilizados, $20 \%, 30 \%$ e 40\%, o modelo de fluido de melhor ajuste foi o modelo de Herschel-Bulkley. Na Tabela 11 estão os parâmetros utilizados para obter o ajuste de curva dos cortes de água de $20 \%$, $30 \%$ e $40 \%$.

Tabela 11: Índices das emulsões com Morlina S2 B150 e 5\% de tensoativos.

\begin{tabular}{|c|c|c|c|c|c|}
\hline \multicolumn{7}{|c|}{ Morlina S2 B 150 } \\
\hline Corte de água & Tensão Limite de Escoamento (Pa) & $\mathbf{k}$ & $\mathbf{n}$ & $\mathbf{R}^{\mathbf{2}}$ & Modelo de fluido \\
\hline $20 \%$ & 3,20 & 4,29 & 0,67 & 0,996 & Herschel-Bulkley \\
\hline $30 \%$ & 4,70 & 2,95 & 0,48 & 0,997 & Herschel-Bulkley \\
\hline $40 \%$ & 1,65 & 1,71 & 0,51 & 0,997 & Herschel-Bulkley \\
\hline
\end{tabular}

Algumas observações podem ser obtidas após uma análise da Tabela 11. O corte de água de $20 \%$ tem uma tensão limite de escoamento menor que a emulsão com 30\% de corte de água, porém apresenta índices de consistência e power law maiores. Ainda tem-se que o índice power law das emulsões preparadas com $30 \%$ e $40 \%$ de corte de água são próximos, mas a tensão limite de escoamento difere bastante, bem como o índice de consistência.

O índice power law $\mathrm{n}$, apresentou valores menores que 1 , indicando um comportamento pseudo-plástico para todas as emulsões.

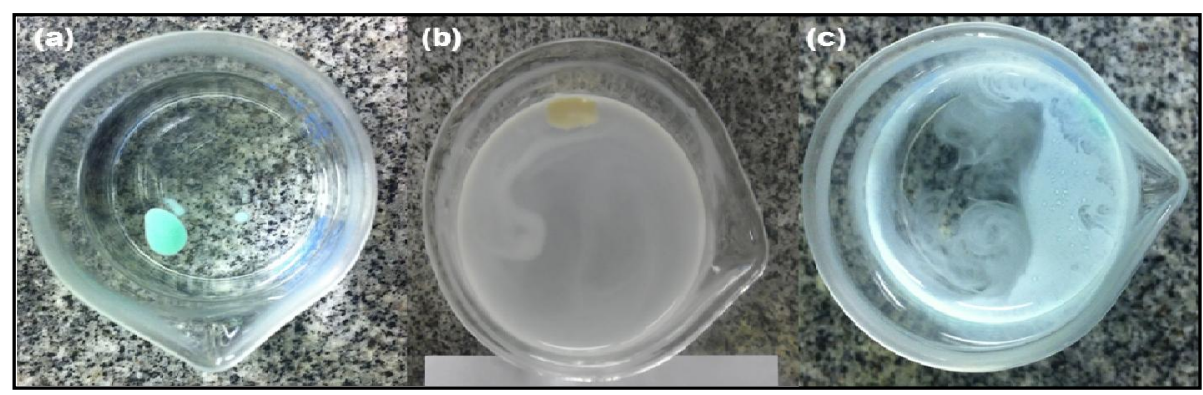

Figura 35: Prova de gota com Morlina S2 B150 e 5\% de tensoativos, (a) $20 \%$, (b) $30 \%$ e (c) $40 \%$ de corte de água. 
Um resultado bem interessante foi constatado após a realização do teste de gota nas emulsões preparadas com Morlina S2 B 150 e 5\% tensoativos. Apenas a emulsão preparada com corte de água de $20 \%$ não se dissolveu em água, levantando indícios que as demais emulsões teriam invertido de fase, isto é, podendo ser emulsões de óleo em água. Os resultados dos cortes de água de $20 \%$ e $30 \%$ são muito próximos, mas não indicam claramente uma inversão de fase. Todavia, no teste de gota a emulsão com $30 \%$ de corte de água se dissolveu, podendo, assim, ter invertido para uma emulsão do tipo óleo em água.

O Morlina S2 B 150 é um óleo bem viscoso, com uma composição química diferente do Morlina S2 BL 10. Talvez os tensoativos utilizados para preparar as emulsões não sejam os mais adequados para o Morlina S2 B 150.

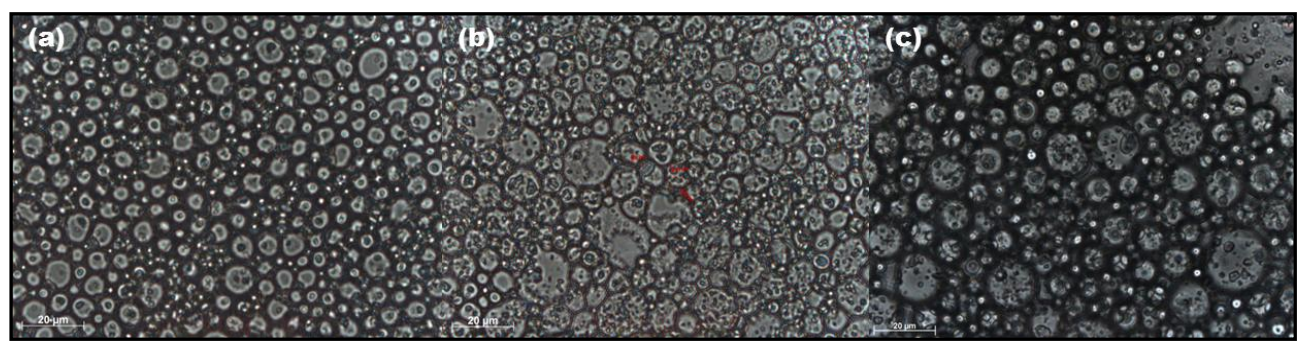

Figura 36: Mircoscopia das emulsões com Morlina S2 B150 e 5\% de tensoativos: (a) 20\%, (b) $30 \%$ e (c) $40 \%$ de corte de água.

Com as imagens da microscopia das emulsões preparadas com Morlina S2 B150 e 5\% de tensoativos, pode-se obter um tamanho aproximado das gotas. Para o corte de água de $20 \%$ as gotas de água estão dispersa no óleo com um tamanho aproximado entre 1 e $5 \mu \mathrm{m}$. Já para as emulsões com corte de água de $30 \%$ e $40 \%$ as gotas de óleo que estão dispersas na água possuem tamanho médio entre 0,5 e $4 \mu \mathrm{m}$.

Em uma análise puramente visual das emulsões, pode-se notar que as estruturas formadas são bem diferentes entre si, portanto, proporcionando comportamentos mecânicos distintos, complementando as críticas dos resultados obtidos nas curvas de escoamento. 


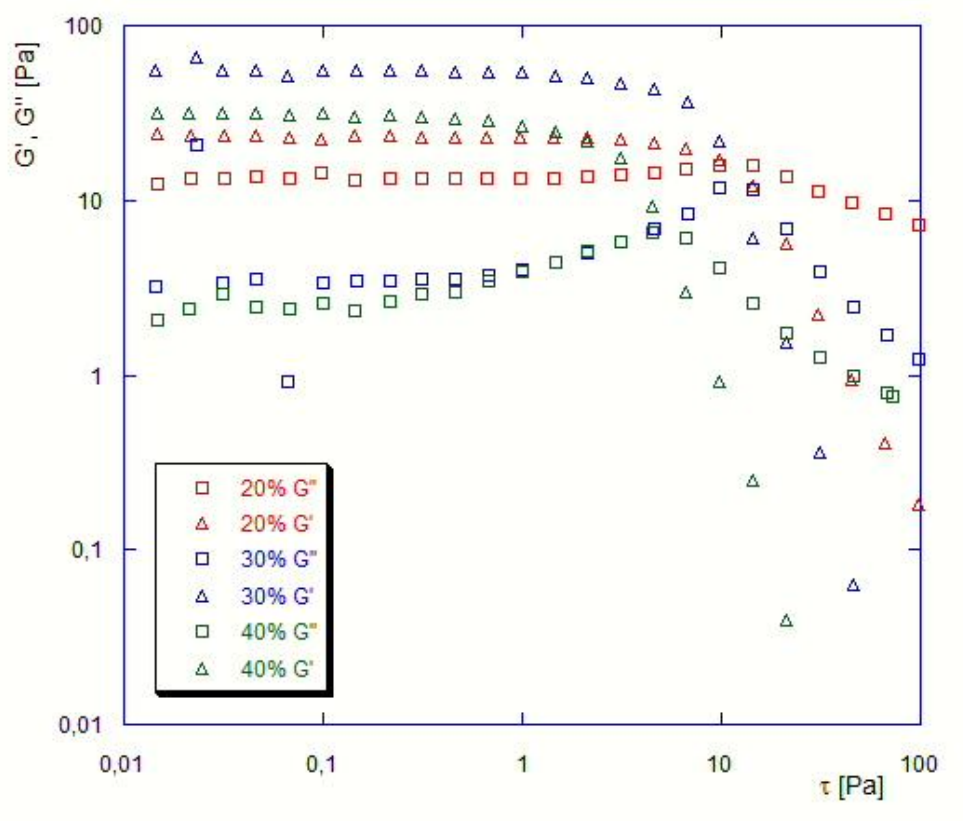

Figura 37: Varredura de tensão Morlina S2 B150 a $20{ }^{\circ} \mathrm{C}$ e $5 \%$ de tensoativos.

Um resultado dentro do aguardado foi obtido nos testes de varredura de tensão (Stress Sweep), em todos os cortes de água estudados, 20\%, 30\% e $40 \%$. O módulo elástico ou de armazenamento G' medido ficou acima do módulo viscoso ou de perda G" até certa tensão, confirmando o comportamento da curva de escoamento, onde uma tensão limite de escoamento ficou bem definida para cada corte de água.

Como dado de entrada para os testes de varredura no tempo, optou-se pela tensão de $0,2 \mathrm{~Pa}$, porque além de estar dentro da faixa confiável de torque do reômetro utilizado (Phyica 301), está dentro de uma região abaixo da tensão limite de escoamento, e uma frequência de $1 \mathrm{~Hz}$. 


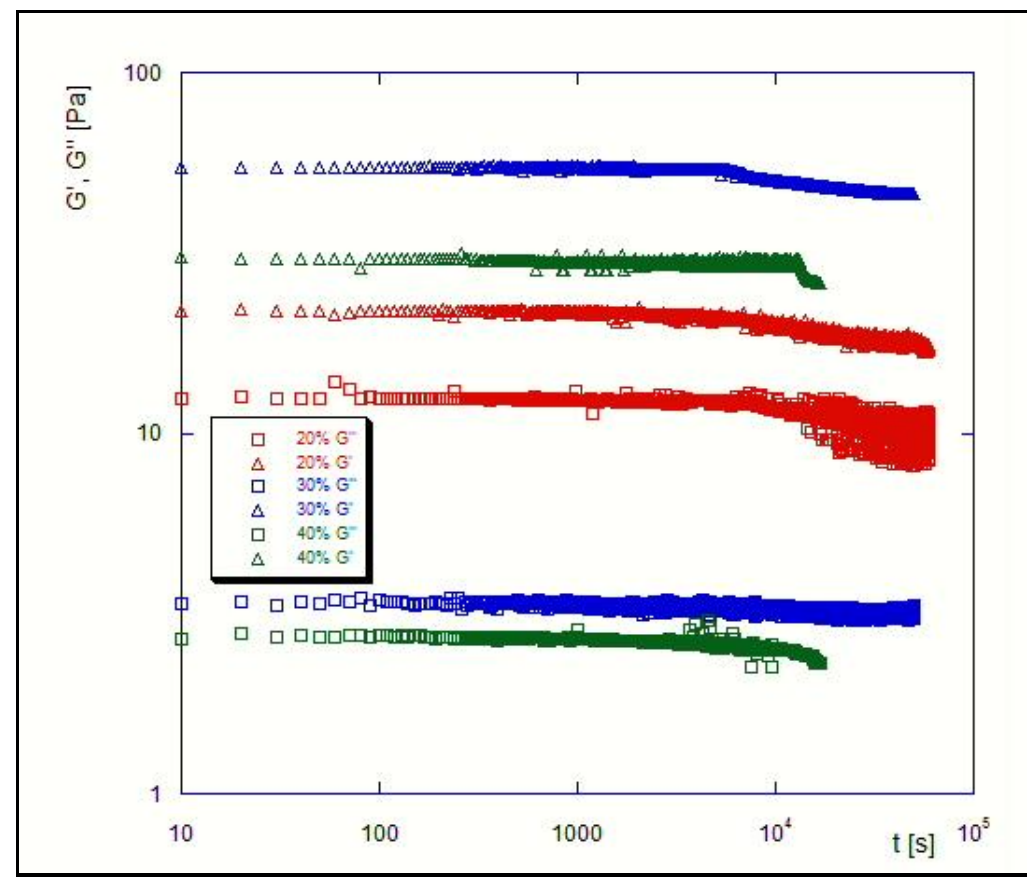

Figura 38: Varredura no tempo Morlina S2 B150 a $20{ }^{\circ} \mathrm{C}$ e $5 \%$ de tensoativos.

O teste de varredura no tempo (Time Sweep) confirmou os resultados do teste de varredura de tensão, além de mostrar que as emulsões tiveram um tempo de estabilidade superior a 5000s, tempo suficiente para executar qualquer teste deste estudo para essas emulsões. 


\subsection{4}

Resultados - Shell Morlina S2 B 150 com 1\% de tensoativos

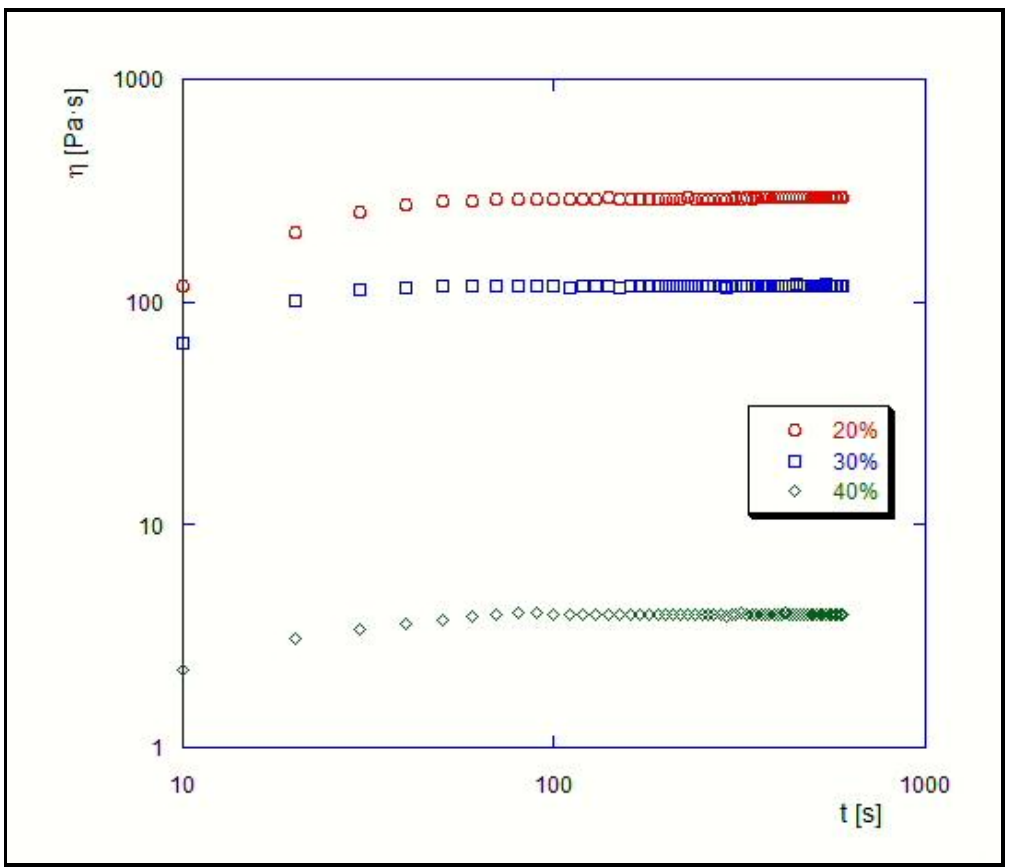

Figura 39: Viscosidade vs. tempo, taxa de deformação constante 0,01 1/s, Morlina S2 B 150 a $20^{\circ} \mathrm{C}$ e $1 \%$ de tensoativos.

Os tempos necessários para se utilizar nas curvas de escoamento são obtidos da Fig. 37. Deste modo, o mesmo tempo de 120 s foi utilizado para os cortes de água de $20 \%, 30 \%$ e $40 \%$. 

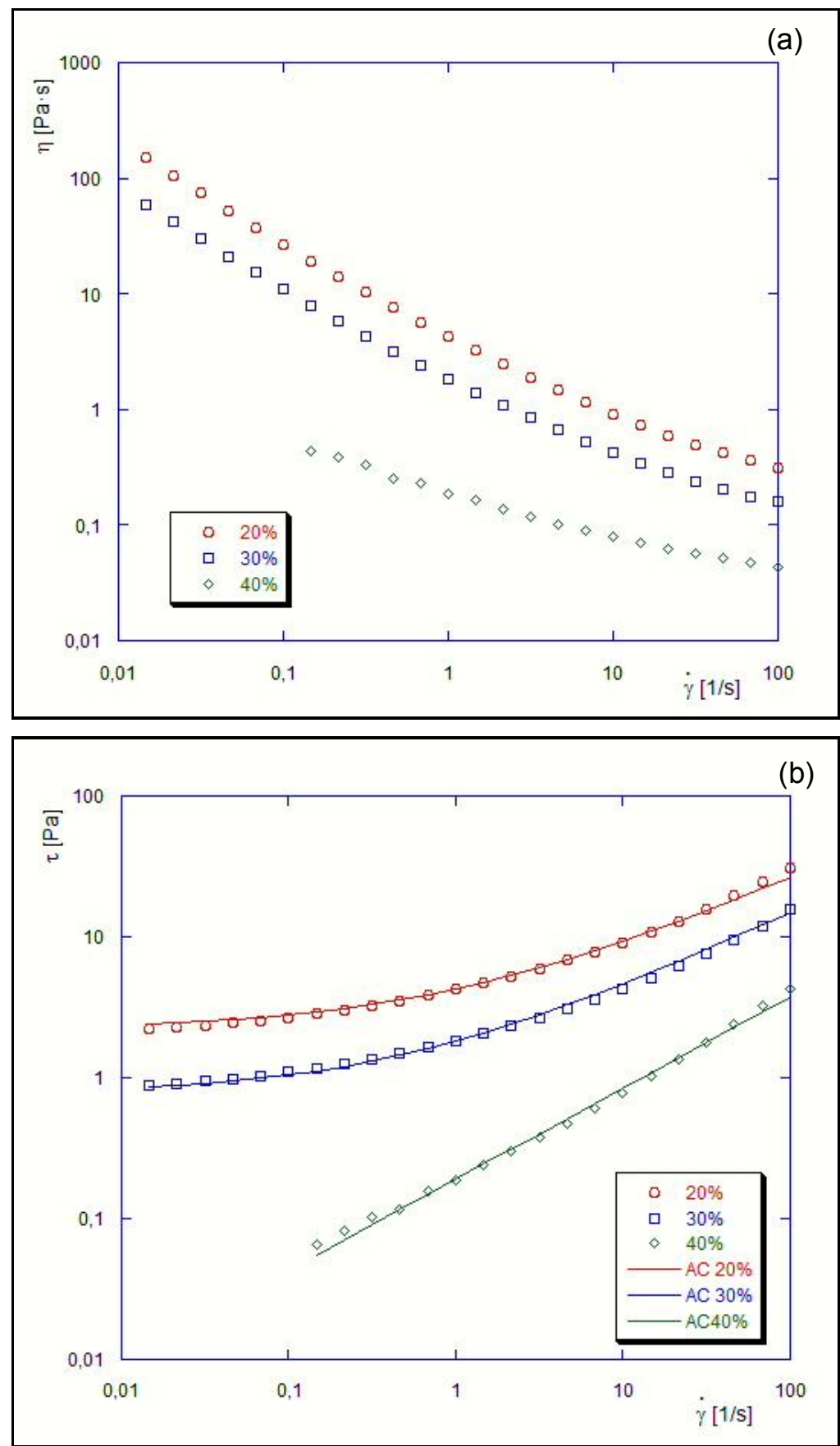

Figura 40: Curvas de escoamento: (a) viscosidade vs. taxa de deformação e (b) tensão de cisalhamento vs. taxa de deformação, Morlina S2 B150 a $20^{\circ} \mathrm{C}$ e $1 \%$ de tensoativos.

As viscosidades das emulsões variaram de acordo com o corte de água, tendo uma redução na viscosidade com o aumento do corte de água, sendo a maior variação entre os cortes de água de $30 \%$ para $40 \%$. 
De acordo com a Fig. 40 uma mudança de comportamento para a emulsão preparada com $40 \%$ de corte de água fica bem evidente. Enquanto as emulsões preparadas com $20 \%$ e $30 \%$ de corte de água tem um comportamento próximo ao modelo de Herschel-Bulkley, a emulsão preparada com $40 \%$ de corte de água melhor se ajusta ao modelo Power Law.

Tabela 12: Índices das emulsões com Morlina S2 B150 e 1\% de tensoativos.

\begin{tabular}{|c|c|c|c|c|c|}
\hline \multicolumn{5}{|c|}{ Morlina S2 B 150 } & $\begin{array}{c}\text { Modelo de } \\
\text { fluido }\end{array}$ \\
\hline Corte de água & Tensão Limite de Escoamento (Pa) & $\mathbf{k}$ & $\mathbf{n}$ & $\mathbf{R}^{\mathbf{2}}$ & \begin{tabular}{c} 
(Palkey \\
\hline $20 \%$
\end{tabular} \\
\hline $30 \%$ & 2,20 & 2,04 & 0,54 & 0,995 & Herschel-Bulkley \\
\hline $40 \%$ & 0,75 & 1,08 & 0,56 & 0,994 & Herschel-Bulkley \\
\hline
\end{tabular}

Na Tabela 12 estão os parâmetros utilizados para obter o ajuste de curva dos cortes de água. Uma informação importante obtida a partir do aumento do corte de água é a diminuição do índice de consistência e o aumento do índice power law de forma mais acentuada. $\mathrm{O}$ índice power law $\mathrm{n}$, apresentou valores menores que 1 , indicando um comportamento pseudo-plástico para todas as emulsões.

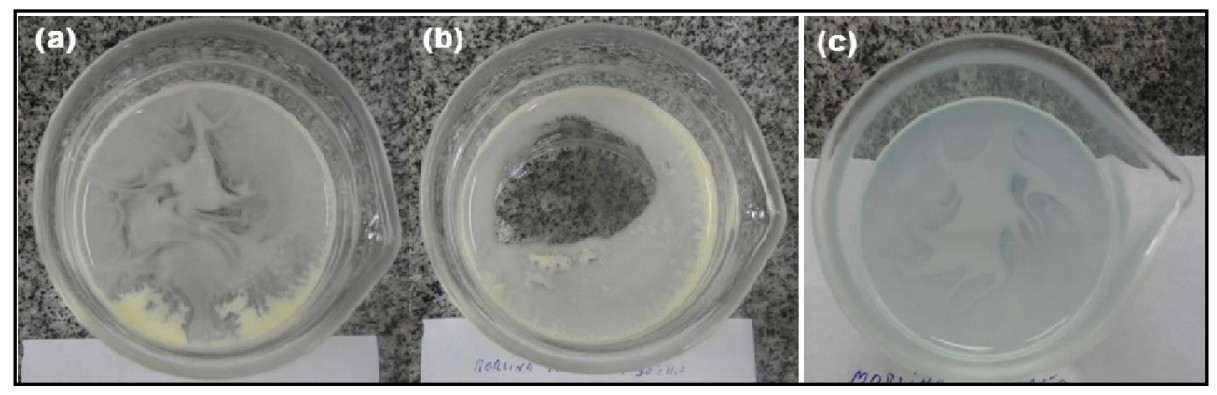

Figura 41: Prova de gota com Morlina S2 B150 e 1\% de tensoativos, (a) $20 \%$, (b) $30 \%$ e (c) $40 \%$ de corte de água.

Os testes reológicos, para o Morlina S2 B 150, apontaram para uma redução de viscosidade com aumento do corte de água para as emulsões preparadas com $1 \%$ de tensoativos, indicando uma provável inversão de fase. No teste da prova de gota este resultado foi confirmado, pois todas as emulsões, quando gotejadas em água, dissolveram. 


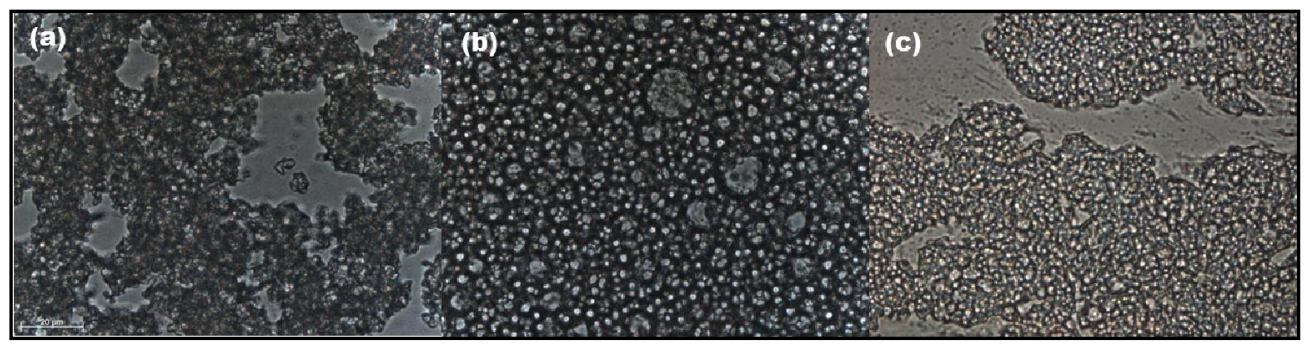

Figura 42: Mircoscopia das emulsões com Morlina S2 B150 e 1\% de tensoativos: (a) 20\%, (b) $30 \%$ e (c) $40 \%$ de corte de água.

Com as imagens da microscopia das emulsões preparadas com Morlina S2 B150 e 1\% de tensoativos, pode-se obter um tamanho aproximado das gotas. Para todos os cortes de água apresentados os tamanhos médios estão ente $1 \mathrm{e}$ $5 \mu \mathrm{m}$. Advertindo que os tamanhos são das gotas de óleo dispersas em água.

Em uma análise meramente visual das emulsões, pode-se notar que os arranjos espaciais formados são diferentes entre si, logo, proporcionando comportamentos mecânicos distintos, concluindo as críticas dos resultados obtidos nas curvas de escoamento.

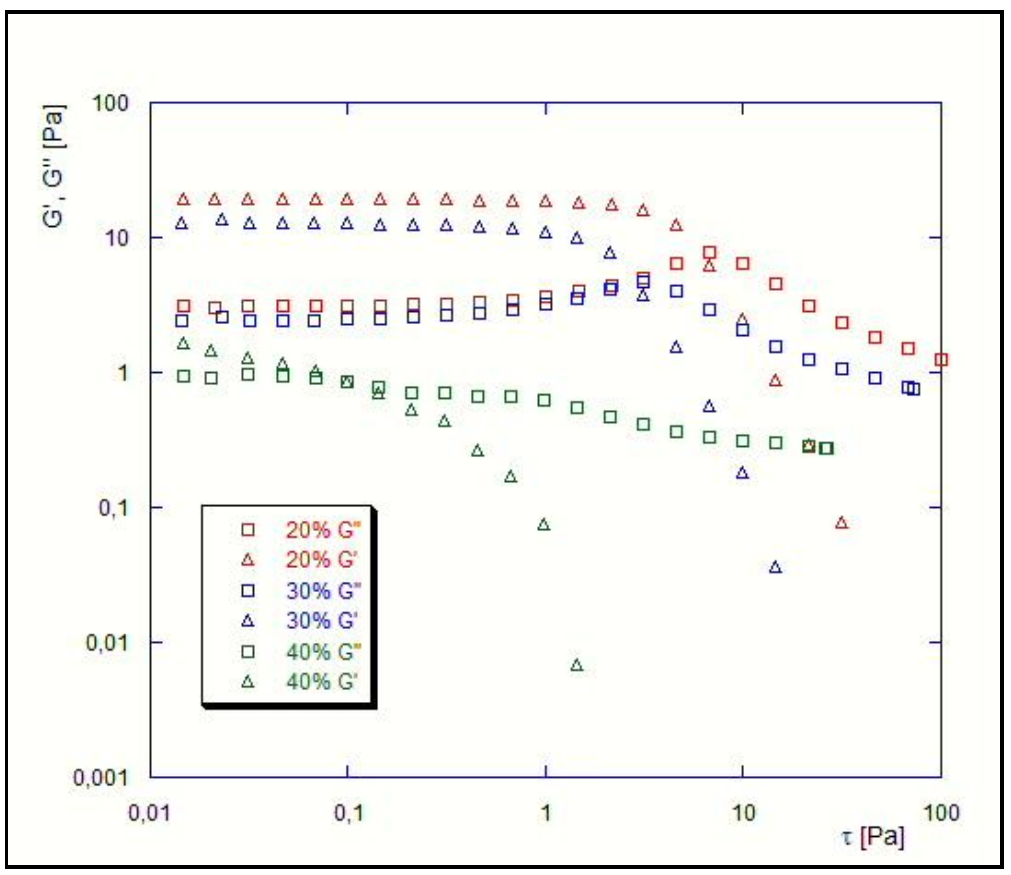

Figura 43: Varredura de tensão Morlina S2 B150 a $20^{\circ} \mathrm{C}$ e $1 \%$ de tensoativos. 
As emulsões apresentaram módulo elástico ou de armazenamento G' e módulo viscoso ou de perda G" dentro da faixa tensões avaliada. Contudo, o teste realizado para o corte de água de $40 \%$ revelou uma pequena região onde o valor do módulo elástico ou de armazenamento G' é maior que módulo viscoso ou de perda G", tanto que o dado de entrada para o teste de varredura no tempo para essa emulsão foi uma tensão de $0,02 \mathrm{~Pa}$, e para os cortes de água de $20 \%$ e $30 \%$ foi usada uma tensão de 0,25 Pa, e uma frequência de $1 \mathrm{~Hz}$.

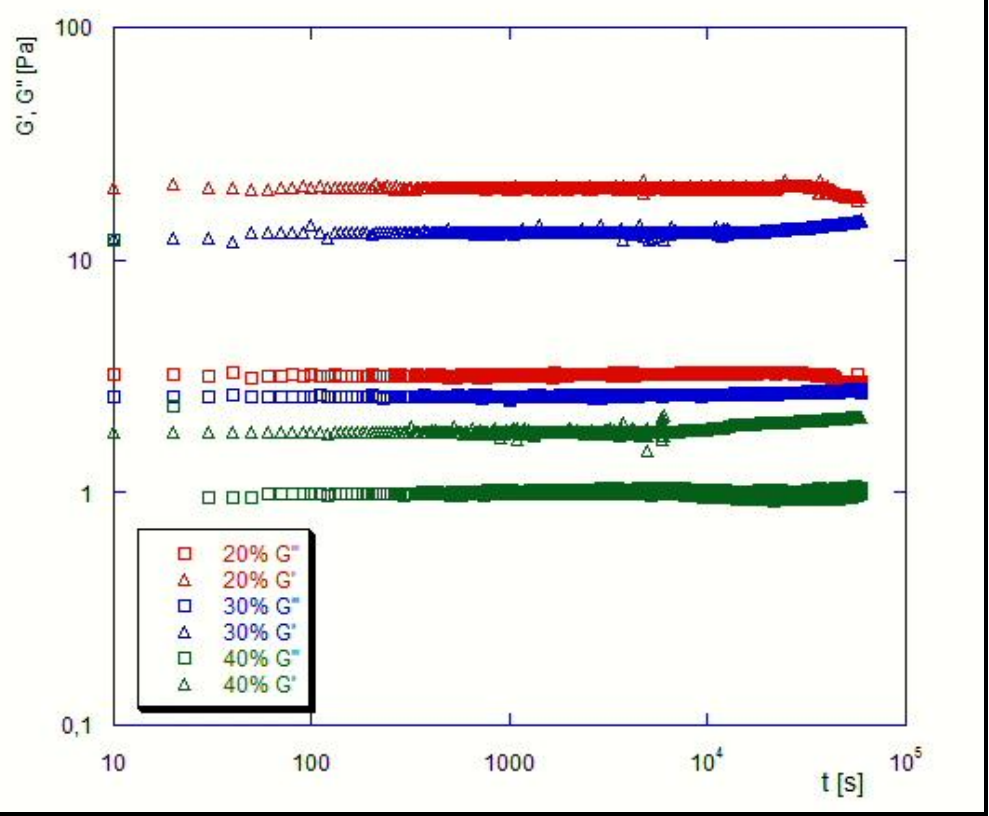

Figura 44: Varredura no tempo Morlina S2 B150 a $20^{\circ} \mathrm{C}$ e $1 \%$ de tensoativos.

O teste de varredura no tempo (Time Sweep) confirmou os resultados do teste de varredura de tensão, além de mostrar que as emulsões tiveram um tempo de estabilidade superior 9000 s, tempo suficiente para executar qualquer teste deste estudo para essas emulsões. 


\subsection{5}

Resultados - Óleo Mineral com $5 \%$ de tensoativos

A seguir serão apresentados os resultados dos testes reológicos das emulsões preparadas com o Óleo Mineral. Para o estudo das emulsões preparadas com esse óleo foi selecionada a geometria de placas ranhuradas (Cross Hatched), como descrito no item 3.3.2 deste estudo. Também, os testes já estão apresentados com a devida correção.

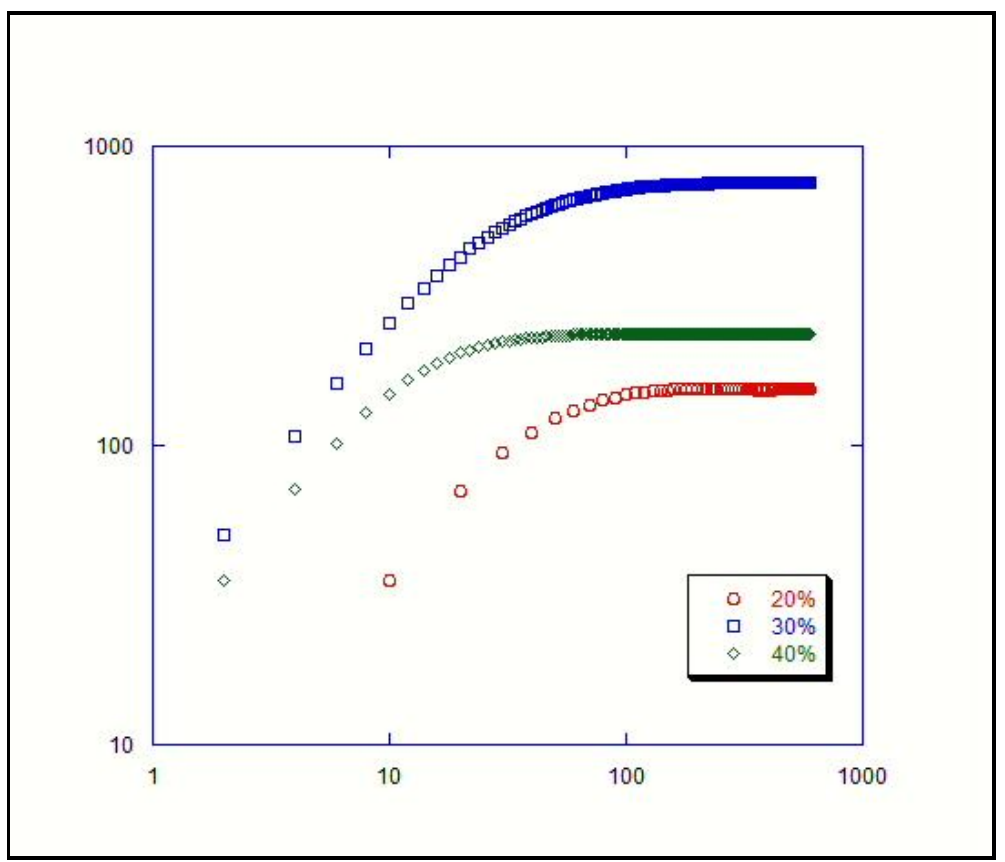

Figura 45: Viscosidade vs. tempo, taxa de deformação constante 0,01 1/s, Óleo Mineral a $20^{\circ} \mathrm{C}$ e $5 \%$ de tensoativos.

Da Fig. 45 pode se conseguir os tempos necessários para se utilizar nas curvas de escoamento. Portanto, foram utilizados os seguintes tempos: 120s para os cortes de água de $20 \%$ e $40 \%$ e 200 s para o corte de água de $30 \%$. 

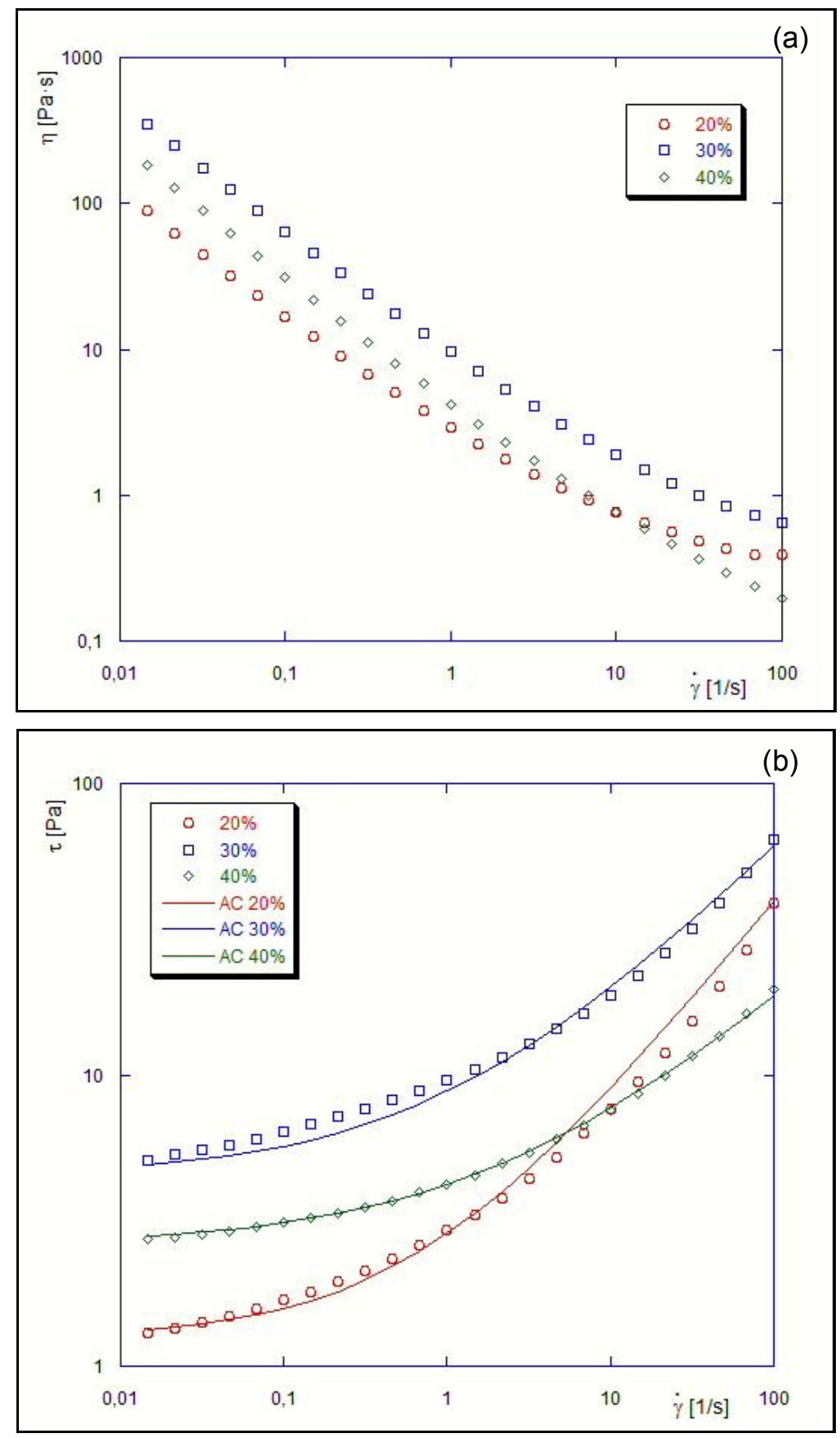

Figura 46: Curvas de escoamento: (a) viscosidade vs. taxa de deformação e (b) tensão de cisalhamento vs. taxa de deformação, Óleo Mineral a $20^{\circ} \mathrm{C}$ e $5 \%$ de tensoativos.

As viscosidades das emulsões variaram de acordo com o corte de água, tendo um aumento na viscosidade entre o corte de água de $20 \%$ para $30 \%$, e uma redução entre o corte de água de $30 \%$ para $40 \%$. 
Para o Óleo Mineral, o modelo de fluido associado aos resultados obtidos foi o modelo de Herschel-Bulkley, para todas as emulsões preparadas. $\mathrm{Na}$ Tabela 13 estão os parâmetros utilizados para obter o ajuste de curva dos cortes de água.

Tabela 13: Índices das emulsões com Óleo Mineral e 5\% de tensoativos.

\begin{tabular}{|c|c|c|c|c|c|}
\hline \multicolumn{5}{|c|}{ Óleo Mineral } \\
\hline Corte de água & Tensão Limite de Escoamento (Pa) & $\mathbf{k}$ & $\mathbf{n}$ & $\mathbf{R}^{\mathbf{2}}$ & Modelo de fluido \\
\hline $20 \%$ & 1,25 & 1,60 & 0,69 & 0,991 & Herschel-Bulkley \\
\hline $30 \%$ & 4,50 & 4,30 & 0,56 & 0,993 & Herschel-Bulkley \\
\hline $40 \%$ & 2,60 & 1,62 & 0,50 & 0,999 & Herschel-Bulkley \\
\hline
\end{tabular}

As emulsões preparadas com $20 \%$ de corte de água apresentaram o maior índice power law. A maior tensão limite de escoamento foi medida com o corte de água de $30 \%$, esta também possui o maior índice de consistência das emulsões estudadas. Outra característica a ser evidenciada é a proximidade no valor balizado para o índice power law entre os cortes de água de 30\% e 40\%. Para este óleo o índice power law também ficou abaixo de 1, caracterizando um comportamento pseudo-plástico para todas as emulsões.

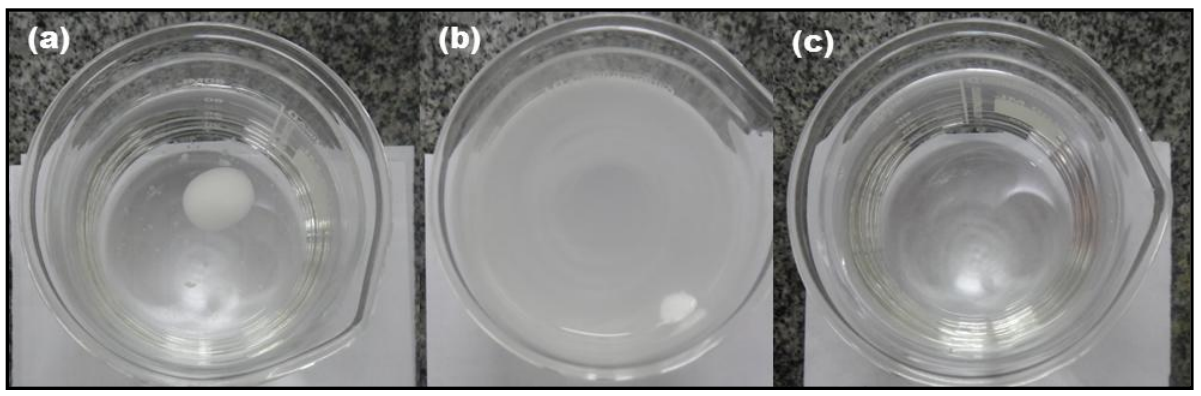

Figura 47: Prova de gota com Óleo Mineral e $5 \%$ de tensoativos, (a) $20 \%$, (b) $30 \%$ e (c) $40 \%$ de corte de água.

Para o Óleo Mineral, algumas conclusões também são bem importantes. As emulsões preparadas com corte de água de $20 \%$ e $5 \%$ de tensoativos não se dissolveram em água. Contudo, todas as demais emulsões dissolveram quando gotejadas na água, indicando uma possível inversão de fase.

Ainda nos testes reológicos se pode constatar que nos resultados das emulsões preparadas com corte de água de $30 \%$ há um aumento no valor da 
viscosidade em relação ao corte de água de $20 \%$, não indicando claramente uma inversão de fase. Já para as emulsões preparadas com $40 \%$ de corte de água há uma queda no valor da viscosidade em comparação com o corte de água de $30 \%$, evidenciando a inversão de fase. Portanto, o teste da prova de gota pôde elucidar os resultados reológicos das curvas de escoamento.

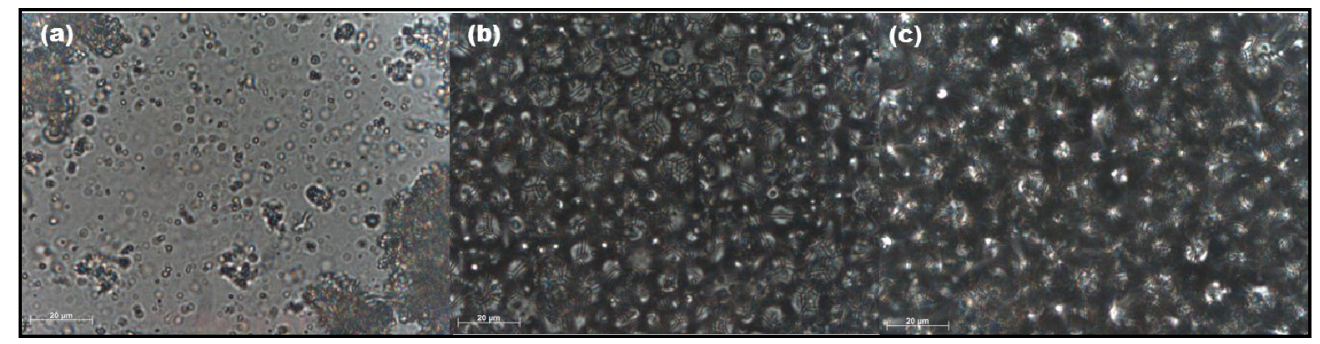

Figura 48: Mircoscopia das emulsões com Óleo Mineral e 5\% de tensoativos: (a) $20 \%$, (b) $30 \%$ e (c) $40 \%$ de corte de água.

Com o auxílio das imagens obtidas pela microscopia, pode-se estimar um tamanho de gota das emulsões nos respectivos cortes de água. Para o corte de água de $20 \%$ as gotas de água não ultrapassaram $6 \mu \mathrm{m}$. Já para os cortes de água de $30 \%$ e $40 \%$, cuja fase contínua é a água, as gotas de óleo apresentaram tamanhos médios estão ente 1 e $4 \mu \mathrm{m}$.

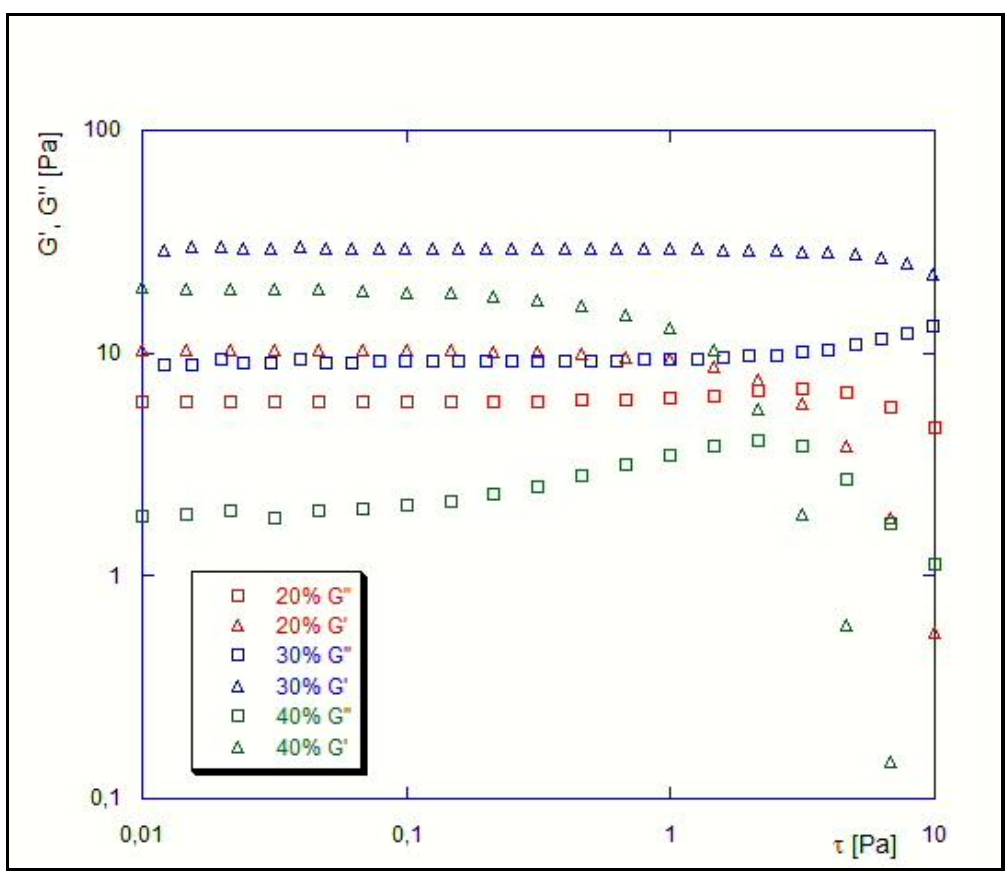

Figura 49: Varredura de tensão Óleo Mineral a $20^{\circ} \mathrm{C}$ e $5 \%$ de tensoativos. 
Um resultado esperado foi obtido nos testes de varredura de tensão (Stress Sweep), em todos os cortes de água estudados, 20\%, 30\% e 40\%. O módulo elástico ou de armazenamento G' medido ficou acima do módulo viscoso ou de perda G" até determinada tensão, ratificando o comportamento da curva de escoamento, onde uma tensão limite de escoamento ficou determinada para cada corte de água.

Como dado de entrada para os testes de varredura no tempo, optou-se pela tensão de 0,2 $\mathrm{Pa}$, para o corte de água de $20 \%$ e $30 \%$, porque além de estar dentro da faixa confiável de torque do reômetro utilizado (Phyica 301), está dentro de uma região abaixo da tensão limite de escoamento. Para o corte de água de $40 \%$ foi utilizada uma tensão de $0,1 \mathrm{~Pa}$. Em todos os testes, a frequência de $1 \mathrm{~Hz}$ foi a empregada.

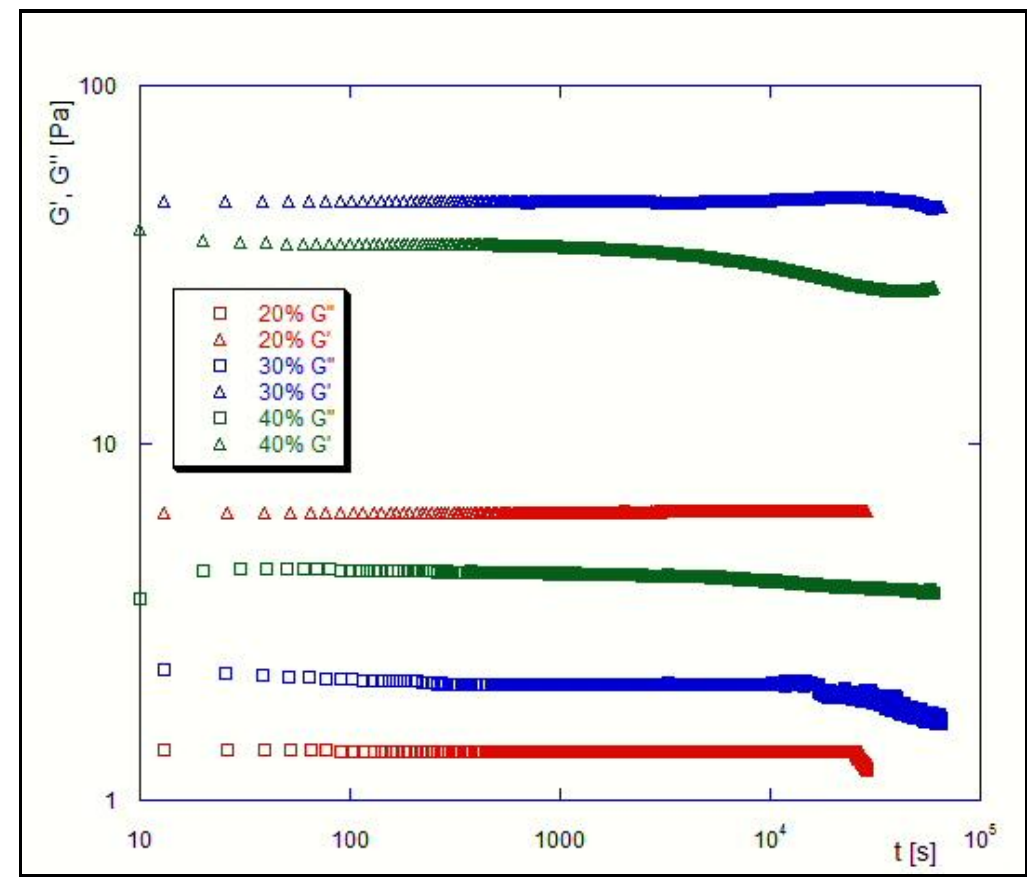

Figura 50: Varredura no tempo Óleo Mineral a $20^{\circ} \mathrm{C}$ e $5 \%$ de tensoativos.

O teste de varredura no tempo (Time Sweep) confirmou os resultados do teste de varredura de tensão. Neste caso a emulsão que apresentou o melhor resultado foi a preparada com $20 \%$ de água, a estabilidade dessa chegou próximo de 7000 s. As emulsões preparadas com $30 \%$ e $40 \%$ de água não apresentaram bons resultados, sendo a primeira com uma estabilidade de 
aproximadamente de 4000 s e a segunda em torno de 2000s. A frequência empregada nos testes foi de $1 \mathrm{~Hz}$.

\subsection{6}

Resultados - Óleo Mineral com $1 \%$ de tensoativos

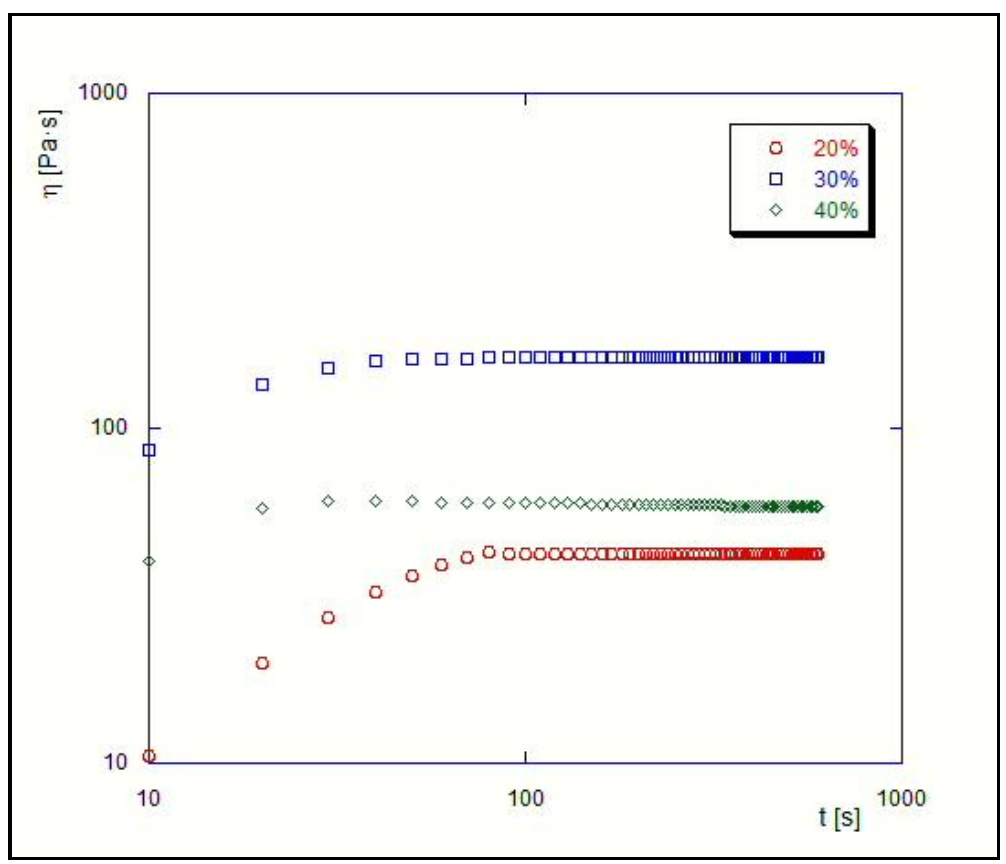

Figura 51: Viscosidade vs. tempo, taxa de deformação constante 0,01 1/s, Óleo Mineral a $20^{\circ} \mathrm{C}$ e $1 \%$ de tensoativos.

Da Fig. 50 pode se obter os tempos necessários para se utilizar nas curvas de escoamento. Assim sendo, foram utilizados os seguintes tempos: 160 s para o corte de água de $20 \%$, 100 s para o corte de água de $30 \%$ e 80 s para o corte de água de $40 \%$. 

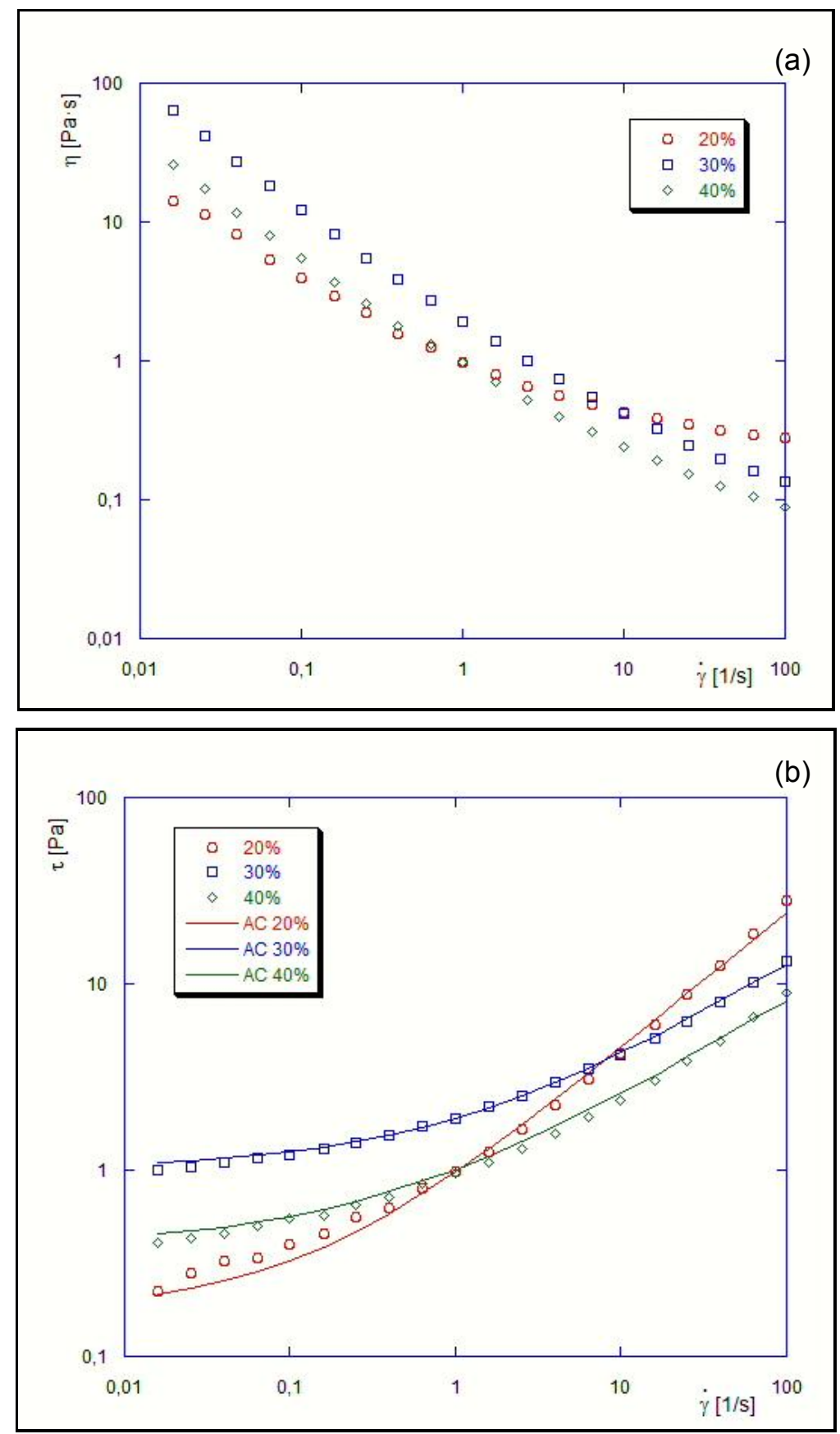

Figura 52: Curvas de escoamento: (a) viscosidade vs. taxa de deformação e (b) tensão de cisalhamento vs. taxa de deformação, Óleo Mineral a $20^{\circ} \mathrm{C}$ e $1 \%$ de tensoativos.

As viscosidades das emulsões variaram de acordo com o corte de água e de acordo com a taxa de deformação a que foram submetidas, como visto nas Figs. 48 e 49. Para taxas de deformação superiores a 50 1/s, a emulsão com $20 \%$ de corte de água apresenta maior viscosidade, e para taxas de deformação inferiores a $0,11 / \mathrm{s}$ o comportamento se assemelha às emulsões com $5 \%$ de 
tensoativos. No intervalo de taxa de deformação entre 0,1 1/s e 50 1/s quem possui a maior viscosidade volta a ser a emulsão preparada com $30 \%$ de água.

Novamente o modelo de fluido utilizado para fazer o ajuste de curva foi o modelo de Herschel-Bulkley para todas as emulsões aprontadas. Apesar da diminuição da concentração de tensoativos, as emulsões não sofreram grandes alterações nos modelos de fluidos utilizados no item anterior (item 4.2.5). $\mathrm{Na}$ Tabela 14 estão os parâmetros utilizados para obter o ajuste de curva dos cortes de água.

Tabela 14: Índices das emulsões com Óleo Mineral e 1\% de tensoativos.

\begin{tabular}{|c|c|c|c|c|c|}
\hline \multicolumn{5}{|c|}{ Óleo Mineral } \\
\hline Corte de água & Tensão Limite de Escoamento (Pa) & $\mathbf{k}$ & $\mathbf{n}$ & $\mathbf{R}^{\mathbf{2}}$ & Modelo de fluido \\
\hline $20 \%$ & 0,18 & 0,80 & 0,74 & 0,995 & Herschel-Bulkley \\
\hline $30 \%$ & 1,01 & 0,90 & 0,56 & 0,999 & Herschel-Bulkley \\
\hline $40 \%$ & 0,39 & 0,62 & 0,55 & 0,995 & Herschel-Bulkley \\
\hline
\end{tabular}

Seguindo a mesma tendência das emulsões preparadas com $5 \%$ de tensoativos, as emulsões preparadas com $20 \%$ de corte de água exibiram o maior índice power law, nas demais emulsões à medida que o corte de água aumentou o índice de consistência diminuiu.

A maior tensão limite de escoamento foi estipulada com o corte de água de $30 \%$, esta também possui o maior índice de consistência das emulsões estudadas. Outra característica a ser destacada é a proximidade no valor calculado para o índice power law entre os cortes de água de $30 \%$ e $40 \%$. Todas as emulsões preparadas nos cortes de água deste estudo apresentaram um comportamento pseudo-plástico, já que o índice power law medido ficou menor que 1.

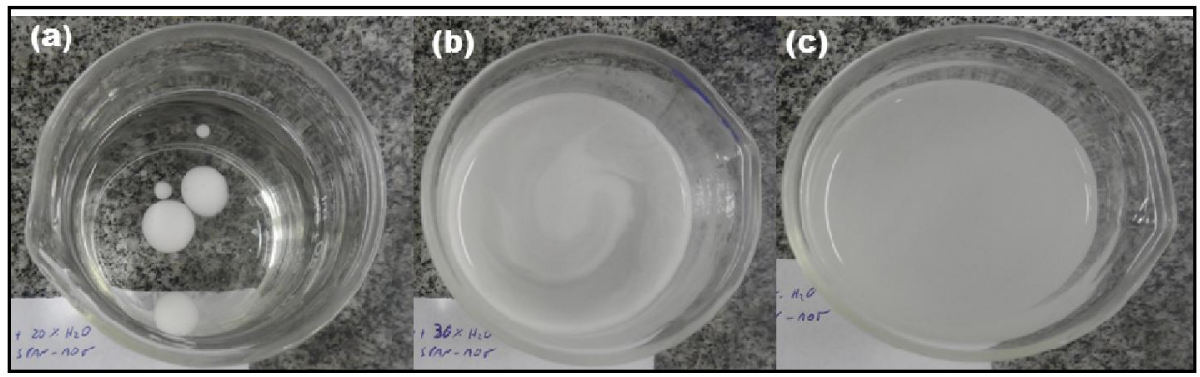

Figura 53: Prova de gota com Óleo Mineral e 5\% de tensoativos, (a) 20\%, (b) $30 \%$ e (c) $40 \%$ de corte de água. 
Assim como as emulsões preparadas com 5\% de tensoativos, dentre as emulsões preparadas com $1 \%$ de tensoativos apenas a emulsão com $20 \%$ de corte de água não inverteu de fase. O valor de viscosidade entre os cortes de água ficaram muito próximos e o comportamento seguiu algumas características da concentração de $5 \%$ de tensoativos.

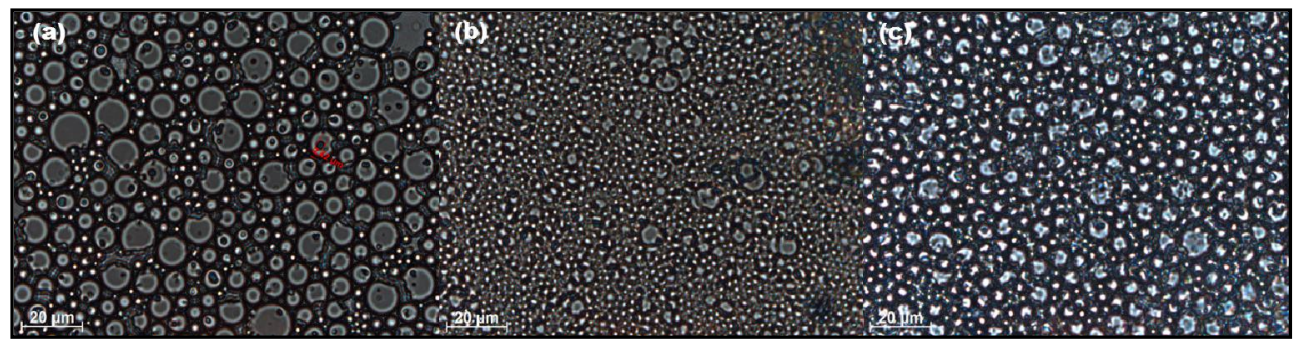

Figura 54: Mircoscopia das emulsões com Óleo Mineral e 1\% de tensoativos: (a) 20\%, (b) $30 \%$ e (c) $40 \%$ de corte de água.

De acordo com as imagens da Fig. 54, as estruturas das emulsões com $20 \%$ de corte de água diferem das estruturas dos cortes de água de $30 \%$ e $40 \%$. De acordo com os resultados da prova de gota, onde as emulsões preparadas com $30 \%$ e $40 \%$ de corte de água inverteram de fase, assim como o tamanho das gotas das fases dispersas.

Um tamanho de gota estimado entre 1 e 4 para as emulsões com $20 \%$ de corte de água, este mesmo tamanho de gotas pode ser estipulado para o óleo que está disperso na água para as emulsões preparadas com $30 \%$ e $40 \%$ de corte de água. 


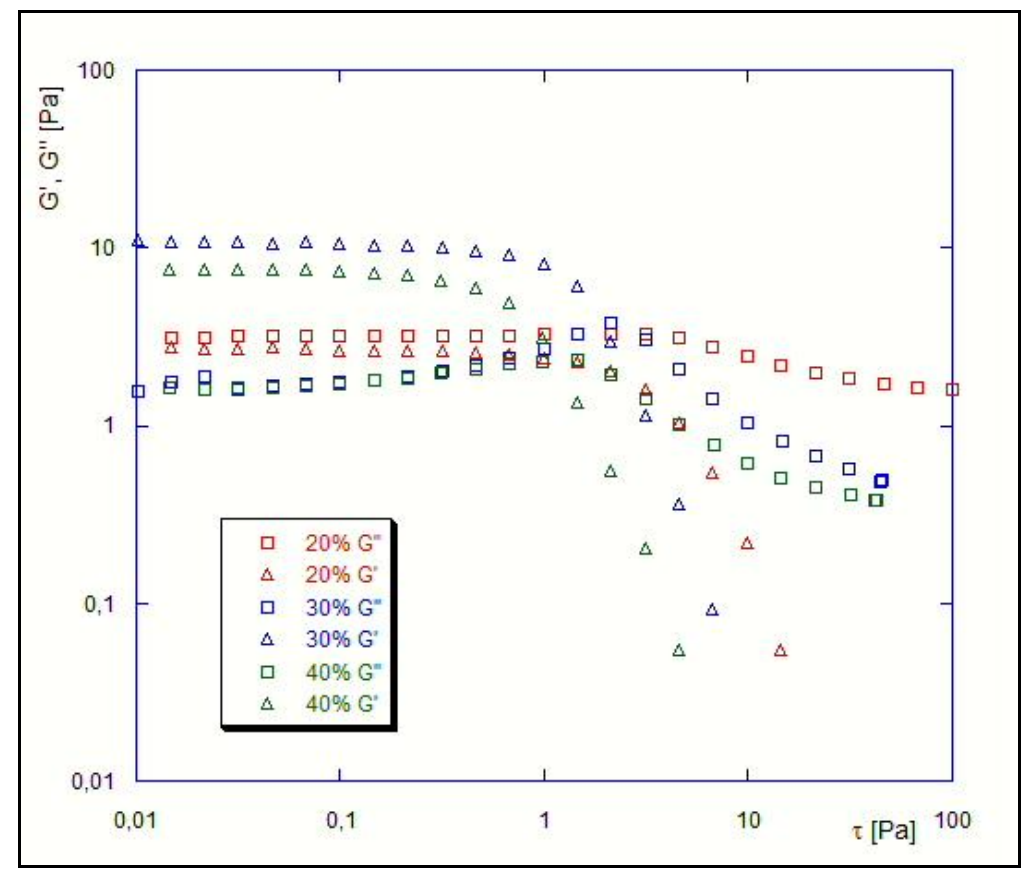

Figura 55: Varredura de tensão Óleo Mineral a $20{ }^{\circ} \mathrm{C}$.

As emulsões apresentaram módulo elástico ou de armazenamento G' e módulo viscoso ou de perda G" dentro da faixa tensões avaliada. Contudo, o teste realizado para o corte de água de $20 \%$ apresentou o módulo viscoso ou de perda G" medido sucessivamente maior que módulo elástico ou de armazenamento G'. Para as outras emulsões, com corte de água de 30\% e 40\%, uma região vicoselástica linear bem definida foi medida. Os dados de entrada de tensão para o teste de varredura no tempo para os cortes de água foram o seguinte: 0,5 Pa para o corte de água de $20 \%$ e 0,2 Pa para os cortes de água de $30 \%$ e $40 \%$, e uma frequência de $1 \mathrm{~Hz}$. Tais valores ficaram baseados numa região de torque acima da sensibilidade do reômetro utilizado (Phyica 501). 


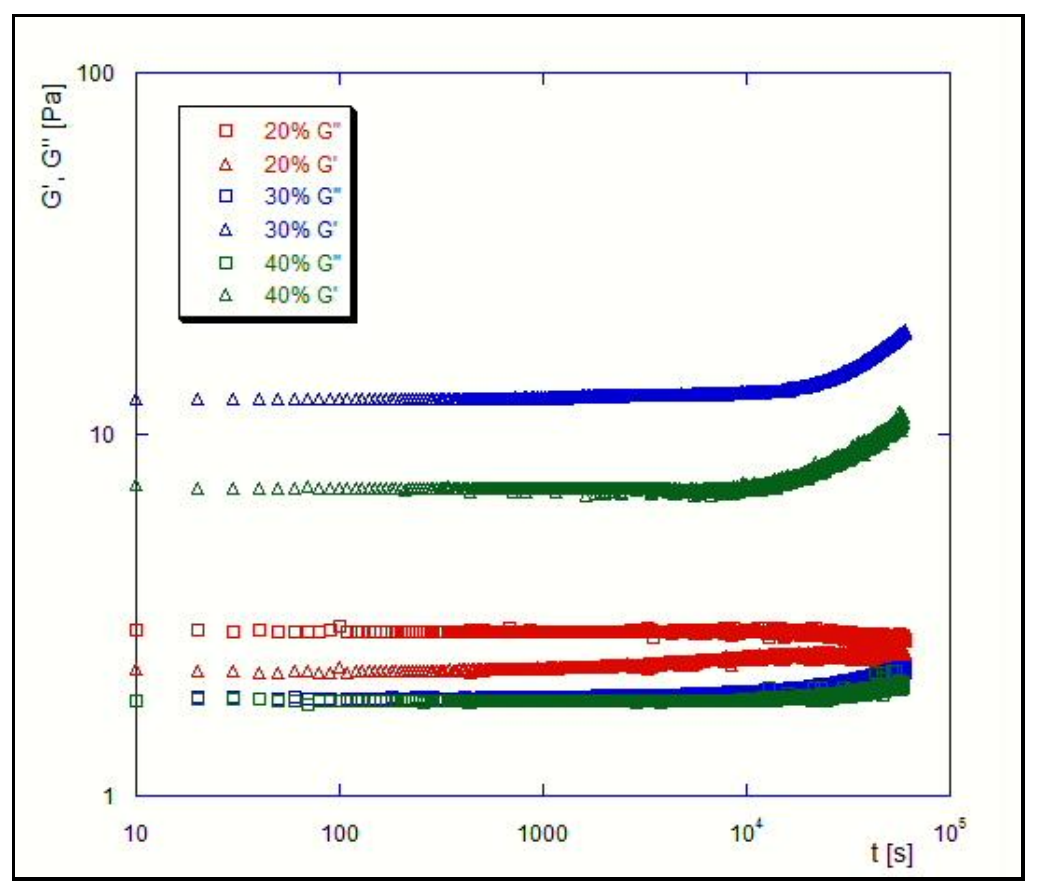

Figura 56: Varredura no tempo Óleo Mineral a $20{ }^{\circ} \mathrm{C}$.

O teste de varredura no tempo (Time Sweep) confirmou os resultados do teste de varredura de tensão, onde os módulos viscosos ou de perda G" dos cortes de água de $30 \%$ e de $40 \%$ são muito próximos, em alguns momentos apresentando o mesmo valor na medição nos dois testes. Também mostra que as emulsões tiveram um tempo de estabilidade superior 6000s para todas as emulsões.

\section{3}

\section{Discussão}

\subsection{1}

\section{Efeito da concentração de tensoativos}

Os testes reológicos foram realizados com duas concentrações de tensoativos, ambas definidas a partir dos resultados do teste de tensão interfacial. Não obstante, a interação entre os tensoativos escolhidos para o 
desenvolvimento deste estudo e os óleos selecionados não acontece da mesma maneira. Fato que pode ter influenciado nos resultados obtidos.

A sequência das figuras será a mesma empregada no item 4.1, por conseguinte, Shell Morlina S2 BL 10, Shell Morlina S2 B 150 e o Óleo Mineral.

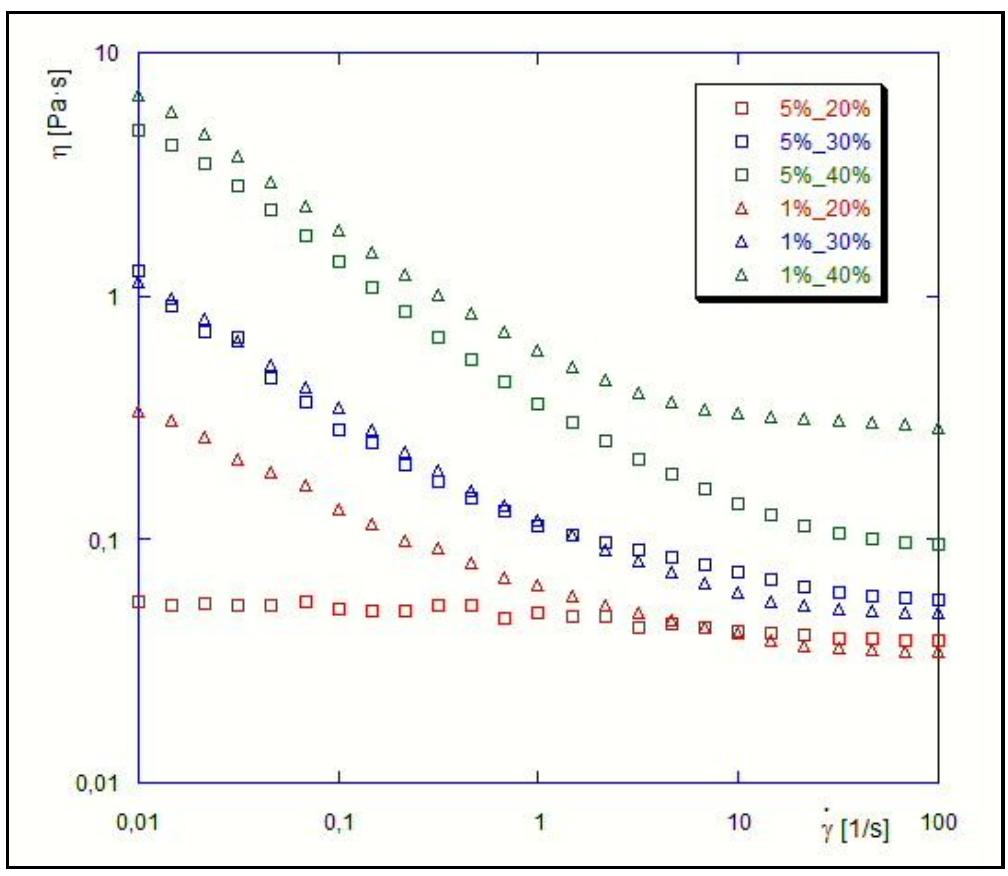

Figura 57: Morlina S2 BL 10 com 5\% e $1 \%$ de tensoativos.

O Morlina S2 BL 10 é o menos viscoso dos óleos deste trabalho e o que menos alterou os resultados dentre as concentrações de $5 \%$ e $1 \%$ de tensoativos, como mostrado na Fig. 61. Para o corte de água de $30 \%$ praticamente não houve alteração. Já para os cortes de água de $20 \%$ e $40 \%$ os comportamentos das emulsões foram bem semelhantes. 


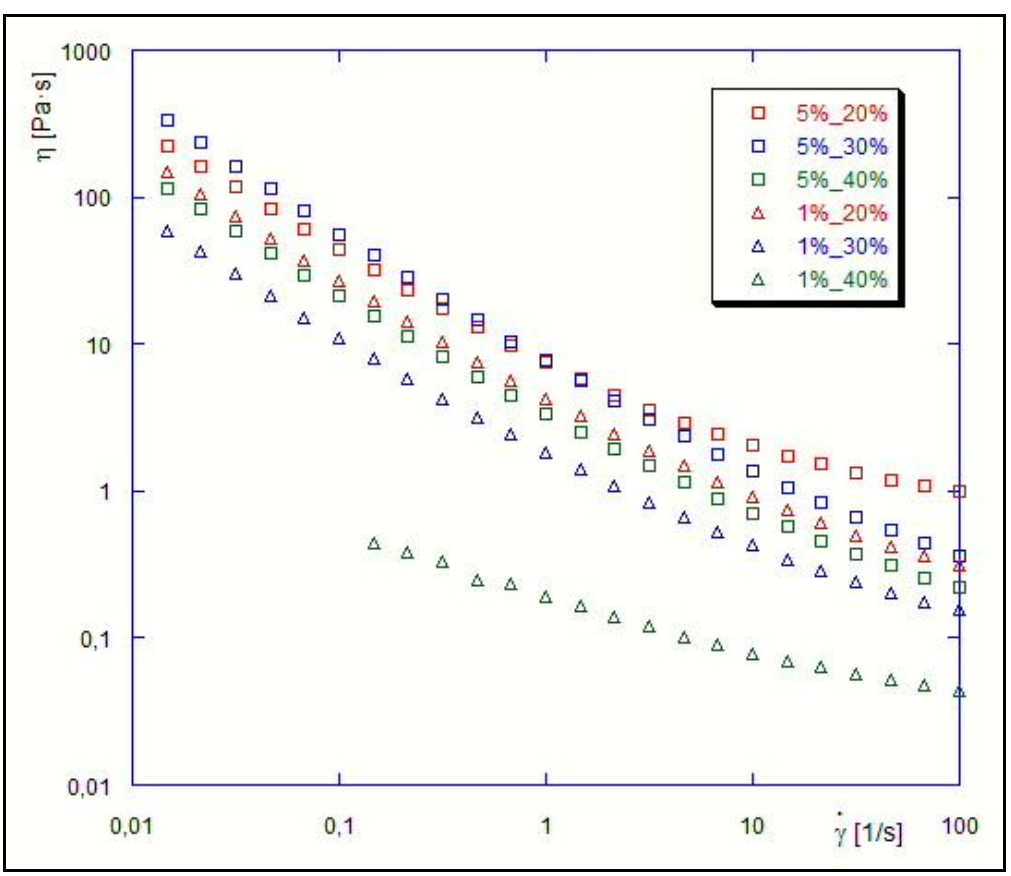

Figura 58: Morlina S2 B 150 com 5\% e 1\% de tensoativos.

O Morlina S2 B 150 é o mais viscoso dos óleos deste estudo e apresentou alterações significativas entre os resultados das concentrações de $5 \%$ e $1 \%$ de tensoativos, como mostrado na Fig. 62. À medida que o corte de água foi aumentando, a variação entre os resultados acompanhou a mesma direção, isto é, aumentou cada vez mais. 


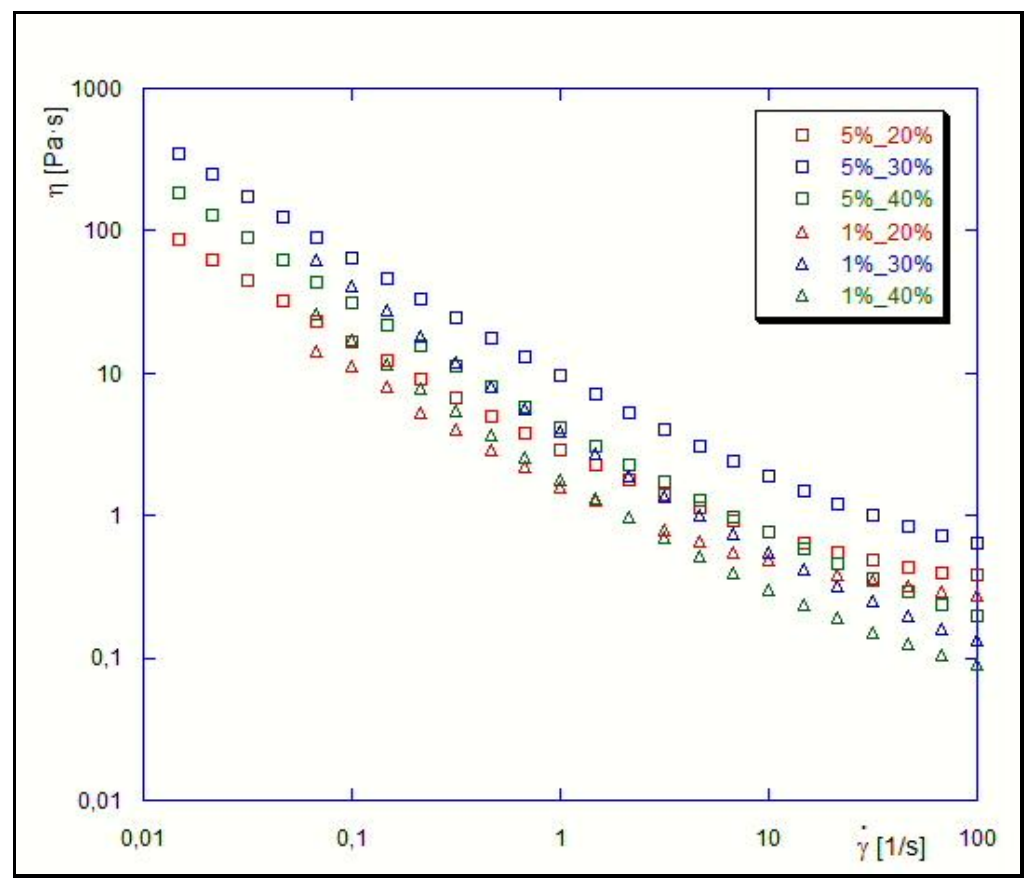

Figura 59: Óleo Mineral com 5\% e 1\% de tensoativos.

Com uma viscosidade intermediária entre o Morlina S2 BL 10 e o Morlina S2 B 150, o Óleo Mineral também apresentou variações expressivas entre as concentrações de $5 \%$ e 1\%. No entanto, diferentemente do Morlina S2 B 150, essa variação permaneceu aproximadamente constante, ou seja, entre as concentrações de $5 \%$ e $1 \%$ e seus respectivos cortes de água, tal variação seguiu um mesmo padrão. 


\section{5. \\ Conclusões e sugestões para trabalhos futuros}

\section{1}

Conclusões

Para concatenar os resultados obtidos foi realizada uma análise qualitativa envolvendo os seguintes parâmetros:

1. Inversão de fase: neste quesito será analisada se houve ou não a inversão de fase, além disso, quanto maior for a quantidade de emulsões que inverteram de fase menor será a pontuação.

2. Estabilidade: a estabilidade referida neste quesito é a macroscópica, ou seja, após o preparo das emulsões quanto tempo depois as mesmas começaram a apresentar separação entre as fases. Quanto mais rápido houver a separação de fase, menor será a nota para o óleo dessas emulsões.

3. Repetitividade: a análise será obtida sobre as variações dos testes reológicos realizados em diversos dias. Será atribuída a menor nota àquele óleo cujas variações ficarem mais discrepantes dentro do intervalo de dias analisados.

4. Viscosidade da emulsão: parâmetro de suma importância na seleção da geometria, além de indicar se o torque dos testes está dentro do intervalo de confiabilidade do reômetro. A menor nota será dada ao óleo que proporcionar a menor faixa de viscosidade.

5. Influência da concentração de tensoativos: depois de feita as medidas de tensão interfacial, a concentração de tensoativos não deveria influenciar de maneira significativa nos resultados dos testes reológicos. Contudo, na prática, isso não ocorreu, a menor nota será atribuída ao óleo que apresentar a maior variação entre os resultados dos testes reológicos nas duas concentrações de tensoativos ( $1 \%$ e $5 \%)$. 
Nesse estudo foram apresentados resultados de três diferentes óleos, Morlina S2 BL 10, Morlina S2 B 150 e Óleo Mineral. Deste modo, na Tabela 15 foram atribuídas notas variando entre 1 e 3 para cada um dos óleos, de acordo com cada parâmetro apresentado anteriormente.

Tabela 15: Análise qualitativa entre os óleos.

\begin{tabular}{|c|c|c|c|c|c|c|}
\hline \multirow{2}{*}{ Óleo } & \multicolumn{5}{|c|}{ Parâmetros } \\
\cline { 2 - 7 } & $\begin{array}{c}\text { Inversão de } \\
\text { fase }\end{array}$ & Estabilidade & Repetitividade & $\begin{array}{c}\text { Viscosidade } \\
\text { da emulsão }\end{array}$ & $\begin{array}{c}\text { Influência da } \\
\text { concentração } \\
\text { de tensoativos }\end{array}$ & Total \\
\hline $\begin{array}{c}\text { Shell Morlina } \\
\text { S2 BL 10 }\end{array}$ & 3 & 3 & 3 & 1 & 3 & 13 \\
\hline $\begin{array}{c}\text { Shell Morlina } \\
\text { S2 B 150 }\end{array}$ & 1 & 1 & 1 & 3 & 1 & 7 \\
\hline Óleo Mineral & 2 & 2 & 2 & 2 & 2 & 10 \\
\hline
\end{tabular}

A partir da Tabela 15 podem-se estabelecer as seguintes conclusões:

1. O Shell Morlina S2 BL 10 é o óleo com menor viscosidade utilizado no preparo das emulsões, favorecendo a formação de tamanho de gotas menores. Proporcionou bons resultados para os testes de varredura no tempo nas duas concentrações de tensoativos (1\% e $5 \%)$. Além disso, apresentou uma excelente repetitividade nos resultados entre as emulsões preparadas em datas diversas. Destacando que a influência das concentrações de tensoativos utilizadas neste estudo não foi significante.

2. Por outro lado, as emulsões preparadas com Shell Morlina S2 BL 10 apresentaram valores de viscosidade bem inferiores que os dos outros óleos. A escolha da geometria para realização dos testes reológicos para as emulsões com Shell Morlina S2 BL 10 não foi simples. Além disso, a geometria de cilindro concêntrico de fenda dupla (Double Gap - DG) é utilizada para fluidos pouco viscosos, podendo trazer problemas de confiabilidade na faixa de torque dos reômetros Physica MCR301 e Physica MCR501. Alguns testes são necessários para validar a utilização de tal geometria.

3. O Shell Morlina S2 B 150 é o óleo com maior viscosidade utilizado no preparo das emulsões. Nos testes reológicos realizados apresentou uma excelente faixa de torque em todas as emulsões 
estudadas. No entanto, devido as suas caraterísticas de utilização em aplicações que exijam máxima proteção contra a corrosão e separação de água, as emulsões preparadas com esse óleo apresentaram acelerada separação entre fases.

4. Novamente para o Shell Morlina S2 B 150, se pode destacar que, com o decréscimo da concentração de tensoativos, as suas emulsões inverteram de fase, segundo a prova de gota realizada. Outro ponto relevante a ser destacado é a grande influência das concentrações de tensoativos utilizadas no estudo, onde este óleo apresentou a maior variação nos resultados dos testes reológicos.

5. O Óleo Mineral apresentou uma boa repetitividade nos resultados entre as emulsões preparadas em datas diversas. As suas emulsões apresentaram uma alta viscosidade e boas faixas de torque. Analisando a parte visual, apresentaram uma boa estabilidade, demorando um pouco mais a passar a existir separação de fases que o Shell Morlina S2 B 150. No quesito inversão de fase, apenas as emulsões preparadas com corte de água de $20 \%$ não inverteram. Houve um pouco de influência nas concentrações de tensoativos utilizadas neste estudo

Como proposta de fluido modelo, ou fluidos modelos a serem utilizados no estudo de formação de hidratos, em que emulsões de água em óleo são necessárias, e também tomando como base a análise qualitativa, as emulsões preparadas com Shell Morlina S2 BL 10 apresentaram bons resultados podendo ser empregadas em quaisquer cortes de água e de tensoativos utilizados neste estudo.

Já para os demais óleos, Shell Morlina S2 B 150 e Óleo Mineral, deve-se tomar certo cuidado, pois algumas de suas emulsões inverteram de fase, conforme a prova de gota. 


\section{2}

\section{Sugestões para trabalhos futuros}

Para trabalhos futuros, apresentam-se as seguintes sugestões:

1. Modificar a maneira de preparar as emulsões, por exemplo, dissolvendo o AOT na fase aquosa e o Span 80 na fase oleosa.

2. Utilizar outros cortes de água $(10 \%, 50 \%, 60 \%$ e $70 \%)$ no preparo das emulsões para conseguir uma variedade maior de dados.

3. Utilizar outros tensoativos, ou outras proporções dos tensoativos empregados neste estudo, buscando sempre uma combinação ótima entre eles, para conseguir emulsões mais estáveis, tanto do ponto de vista reológico quanto em relação à separação de fases.

4. Na indicação de uma possível inversão de fases, usar outros métodos investigativos que apontem tal inversão, como por exemplo, o método da condutividade elétrica.

5. Modificar outros parâmetros durante o preparo das emulsões, tais como: rotação e haste do Ultra - Turrax ${ }^{\circledR}$, tempo de mistura, tamanho do béquer, tempo de exposição e temperatura da fase oleosa no agitador com placa de aquecimento, dentre outros.

6. Adicionar ciclopentano à emulsão e fazer a caracterização reológica. 


\section{6. Referências Bibliográficas}

ANP - Agência Nacional do Petróleo, Gás Natural e Biocombustíveis Relatório: Produção Nacional de Petróleo e Gás Natural - Produção de Petróleo 2003 a 2012. Rio de Janeiro, 2014. Disponível em:< http://anp.gov.br/?pg=67236\&m=\&t1=\&t2=\&t3=\&t4=\&ar=\&ps=\&cachebust=14068 24950510\#Se_o_2>. Acesso em: 31 jul. de 2014.

BAPTISTA, J.M.M. Análise da Formação de Hidratos em Atividades de Perfuração de Campos Petrolíferos. Monografia (Projeto Final), Departamento Acadêmico de Mecânica, Universidade Tecnológica Federal do Paraná. Curitiba. 167p. 2007.

BARNES, H. A. A Handbook of Elementary Rheology. Aberystwyth, University of Wales, Institute of Non-Newtonian Fluid Mechanics. 200p. 2000.

CASTRO, A. G.; COVAS, J. A.; DIOGO, A. C. Reologia e Suas Aplicações Industriais. 1.ed. Ciência e Técnica (Instituto Piaget). Lisboa, Portugal. 462 p. 2001.

CHRISMAN, E. LIMA; V.; MENECHINI, P. Asphaltenes - Problems and Solutions in E\&P of Brazilian Crude Oils. InTech open. Rijeka, Croatia. 25p. 2012

COUTINHO, R. C. C. Estudo da estabilidade de emulsões de água em petróleo. Dissertação de Mestrado, Departamento de Engenharia, COPPE/UFRJ. Rio de Janeiro. 112p. 2005.

CUNHA, R. E. P. Modelagem Matemática da Separação Gravitacional de Emulsões de Petróleo. Dissertação de Mestrado, Departamento de Engenharia Química, Universidade Tiradentes. Aracajú. 148p. 2007. 
DAVY, H. On Some of the Principles, to Inflammable Bodies and on the Chemical Relations of These Combinations of Oxymuriatic Gas and Oxygene. Phil. Trans. R. Soc. Lond. 1811 101, doi: 10.1098/rstl.1811.0001. Disponível em: http://rstl.royalsocietypublishing.org/content/101/1.2.full.pdf+html. Acesso em: 02 mar. de 2014.

FERREIRA, E. E. et al. Reologia de suspensões minerais: uma revisão. Revista da Escola de Minas de Ouro Preto. v.58. Ouro Preto. p. 83-87. 2005.

Folha de Dados Técnica - Shell Morlina S2 BL 10, v1. Disponível em: http://www.lubcenter.com/fichas\%20tecnicas/shell/fispq\%20shell/morlina\%20s2 \%20bl\%2010-21\%203277-7468.pdf. Acesso em: 22 dez. 2013.

Folha de Dados Técnica - Shell Morlina S2 B 150, v2. Disponível em: http://www.lubcenter.com/fichas\%20tecnicas/shell/fispq\%20shell/morlina\%20s2 \%20b\%20150-21\%203277-7468.pdf. Acesso em: 22 dez. 2013.

GRIFFIN, W.C. Classification of Surface-Active Agents by "HLB". Journal of The Society of Cosmetic Chemists. v. 1. p. 311-326. 1949.

HAMMERSCHMIDT, E.G., Formation of Gas Hydrates in Natural Gas Transmission Lines. Ind. Eng. Chem.v. 26. Estados Unidos. p. 851 - 855. 1934.

http://www.sciencedirect.com/science? ob=ArticleListURL\& method=list\& ArticleList|D=90150973\&_st $=5 \&$ searchtype $=a \&$ originPage $=r s \mid t$ list \&_acct $=C 0000$ 37078\&_version=1\&_urlVersion=0\&_userid=686091\&md5=45b0b5d9c609e3d82 cc05696ef664cd1).) - Acesso em: 15 jun. 2014.

KAWATRA, S. K., BAKSHI, A. K. On-line measurement of viscosity and determination of flow types for mineral suspensions. International Journal of Mineral Processing. v. 47. p.275-283. 1996.

KOKAL, S. Crude Oil Emulsion: A State-Of-Art Review. SPE Annual Technical Conference and exhibition. V. 20. Santo Antonio, Texas. p. 5 - 13. 2005. 
MACOSCO, C.W. Rheology: principles, measurements and applications. WILEY-VCH Publishers. New York. 568p. 1994.

MCCLEMENTS, D. J. Food Emulsions: Principles, Practice, and Techniques. CRC Press. Boca Raton, Flórida. 378 p. 1999.

MELO, E. M. Estabilidade de Emulsões de Petróleo em Sistemas Pressurizados. Dissertação de Mestrado, Departamento de Engenharia Química, Universidade Tiradentes. Aracajú. p.7- 15. 2008.

MULLIGAN, C.N. Environmental applications for biosurfactants. Environmental Pollution. v. 133. Oxford. p. 183-198. 2005.

MYERS, D. Surfaces, Interfaces, and Colloids: Principles and Applications. 2.ed. New York. John Wiley \& Sons. 493p. 1999.

PLOU et. al - Enzymatic acylation of di-and trisaccharides with fatty acids: choosing the appropriate enzyme, support and solvent. Journal of Biotechnology. v. 96. p. 55-66. 2002.

SANTOS, O. L. A. Segurança de Poço em Lâminas de Água Ultra profundas. Encontro Nacional de Hidráulica de Perfuração e Completação de Poços de Petróleo e Gás. Domingos Martins. 7p. 2006.

SCHRAMM, L. L.; STASIUKB, E. N.; MARANGONIC, D. G. Surfactants and their applications. Annual Reports Program Chemistry, Section. C: Phys. Chem. v.99. p. 3-48. 2003.

SHAW, D. J. Introdução à Química de Colóides e Superfícies. 1.ed. Edgard Blucher. São Paulo. 185 p. 1975.

SJÖBLOM, J. et al. Our Current Understanding of Water-in Crude Oil Emulsions. Recent Characterization Techniques and High Pressure Performance. Advances in Colloid and Interface Science. p. 299-437. 2003. 
SLOAN, E. D.; KOH, C. A. - Clathrate Hydrates of Natural Gases. 3.ed. Boca Raton, FL. CRC Press. 758p. 2008.

SULLIVAN, A. P.; KILPATRICK, P. K. The Effects of Inorganic Solid Particles on Water and Crude Oil Emulsion Stability. Industrial Engineering Chemical Resource. American Chemical Society. v. 41. North Carolina. p. 3389-3404. 2002. 